\title{
Proceedings of the Third International American Moroccan Agricultural Sciences Conference - AMAS Conference III, December 13-16, 2016, Ouarzazate, Morocco
}

\author{
My Abdelmajid Kassem ${ }^{1 *}$, Alan Walters², Karen Midden², and Khalid Meksem ${ }^{2}$ \\ 1 Plant Genetics, Genomics, and Biotechnology Lab, Dept. of Biological Sciences, Fayetteville State University, \\ Fayetteville, NC 28301, USA; ${ }^{2}$ Dept. of Plant, Soil, and Agricultural Systems, Southern Illinois University, Car- \\ bondale, IL 62901-4415, USA
}

Received: December 16, 2016 / Accepted: February 1, 2017

\begin{abstract}
The International American Moroccan Agricultural Sciences Conference (AMAS Conference; www.amas-conference.org) is an international conference organized by the High Council of Moroccan American Scholars and Academics (HC-MASA; www.hc-masa.org) in collaboration with various universities and research institutes in Morocco. The first edition (AMAS Conference I) was organized on March 18-19, 2013 in Rabat, Morocco; AMAS Conference II was organized on October 18-20, 2014 in Marrakech, Morocco; and AMAS III was organized on December 13-16, 2016 in Ouarzazate, Morocco. The current proceedings summarizes abstracts from 62 oral presentations and 100 posters that were presented during AMAS Conference III.
\end{abstract}

Keywords: AMAS Conference, HC-MASA, Agricultural Sciences.

\section{Date Palm Adaptative Strategies to Desert Conditions}

Alejandro Aragón Raygoza, Juan Caballero, Xiao, Ting Ting, Yanming Deng, Ramona Marasco, Daniele Daffonchio and lkram Blilou".

\section{Abstract}

Date palm cultivars are among the few plants adapted arid

\footnotetext{
*Corresponding author: mkassem@uncfsu.edu
} 
conditions, however, the molecular mechanisms conferring date palm tolerance remain largely unknown. As the root system is an important agronomic trait, having the proper root system architecture in a given environment is critical to allow plants to survive periods of water and nutrient deficit, and compete effectively for resources. Here we provide a detailed analysis of date palm root system architecture from embryogenesis to seedling state. We show that the described gene networks regulating stem cells in the model plants Arabidopsis and rice are also present in date palm; we have mapped their expression domains at the cellular resolution and we are currently studying their function in the model plant Arabidopsis. Using RNAseq technologies, we identified date palm genes differentially expressed in roots and shoots. We also show that date palm uses several adaptive strategies to survive desert conditions, ranging from its mode of germination to traits acquired by different cultivars and to the microbial community colonizing the date palm rhizosphere.

2. Date Palm Root Microbiome: the Ecological Services Involved in Plant Growth, Survival and Tolerance to Abiotic Stresses

Ramona Marasco $^{1 *}$, Maria Mosquiera', Ikram Blilou², and Daniele Daffonchio'

1 BESE, Biological and Environmental Sciences and Engineering Division, King Abdullah University of Science and Technology (KAUST), Saudi Arabia; ${ }^{2}$ Wageningen University, The Netherlands

\section{Abstract}

Date palm (Phoenix dactylifera L.) is an iconic crop plant of desert environments capable to keep ecological dominance under arid conditions and high temperature, but yet very limited knowledge is available on its root microbiome and its contribution to the water and nutritional acquisition by the plant. Under the ongoing climate change, the microbial communities associated with the root system is increasingly recognized as an essential resource for development of a sustainable and environmental friendly modern agriculture. Recent studies demonstrated that the beneficial-microbiome - naturally associated to all the plants - accomplishes essential functions and ecological services complementary to the adaptation features encoded by the host plant, but the undergoing mechanisms remain yet elusive. Our purpose is to reveal the dynamics and functions of endophytic bacteria associated with the date palm root system in relation to promoting root growth and conferring abiotic stress tolerance. To unravel the mechanisms used by endophytic bacteria, we took advantage of the model system Arabidospis thaliana. We found that the selected endophytic strains dramatically influence the root architecture, by increasing the number of lateral roots and by promoting root hair length allowing a larger surface area for resource acquisition. As result, the effects of bacteria on the root system conferred an 'adaptive advantage' to the plants exposed to salt stresses. Using a series of reporter and mutants lines of $A$. thaliana, we show that the observed effect in root architecture is strongly linked to the central signaling pathway of growth regulator auxin. Our data suggest that beneficial root-associated bacteria can increase date palm tolerance to stresses by directly reprogramming the root growth developmental program through the activation of the auxin signaling pathways. We believe that the beneficial effect - observed in both in model and crops plants - will be valuable for improving agriculture production under the continuous changing global environmental conditions.

\section{Optimizing Growth and Tolerance of Date Palm (Phoenix dactylifera L.) to Drought and Fusarium oxysporum f. sp. Albedi- nis by Application of Arbuscular Mycorrhizal Fungi}

Abdelilah Meddich $^{1 *}$, Toshiaki Mitsui ${ }^{2}$, and Marouane Baslam ${ }^{2}$

1 Département de Biologie, Laboratoire Biotechnologie et Physiologie Végétale, Faculté des Sciences Semlalia, Université Cadi Ayyad Marrakech Maroc. ${ }^{2}$ Department of Applied Biological Chemistry, Faculty of Agriculture, Niigata University, Niigata 950-2181, Japan. "Presenting and corresponding author: a.meddich@uca.ma. ${ }^{\dagger}$ Corresponding author: mbaslam@ gs.niigata-u.ac.jp.

\section{Abstract}

Date palm (Phoenix dactylifera L.) is an important agricultural and commercial crop in the North of Africa and Middle Eastern countries of Asia. Date palm trees could be used for generations to come due to its remarkable nutritional, health and economic value in addition to its esthetic and environmental benefits. Every part of the date palm is useful and the importance of the date in human nutrition comes from the acceptable taste and its rich composition of carbohydrates, salts and minerals. During the last decade, date palm plantations were subjected to degradation due to an extensive exploitation and to drastic environmental conditions. Furthermore, fusarium wilts ('Bayoud') are economically important soil-borne diseases that result in significant crop losses and damage to natural ecosystems. Plant-microbe interactions can be either beneficial or detrimental and a fast and accurate assessment of the surrounding organisms is essential for the plant's survival. Arbuscular mycorrhizal fungi (AMF) are a major component of soil biofertility and its use can improve crop resistance to biotic and abiotic stresses. Our results revealed that mycorrhizal infection rates were higher and slightly affected by water stress. The inoculation by the Consortium Aoufous, G. monosporus or Glomus clarum increased biomass production of date palm instead of the attacks by the fungal pathogen F. oxysporum, whatever the water regime. AMF allowed leaf water parameters to be maintained in F. oxysporum-inoculated plants or not under water-limiting conditions. The mortality rate among the date palm trees infected by F. oxysporum was lower in mycorrhizal plants than nonmycorrhizal plants. Results showed that AMF decrease the deleterious effect of $F$. oxysporum on date palm, nevertheless the bioprotection effect against the plant pathogen was dependant on the type of AMF species. It therefore seems that the indigenous $A M$ fungal community 
"Aoufous" take advantage to improve crop resistance to those harsh biotic and abiotic conditions. Keywords: Oasis ecosystem, drought, Fusarium oxysporum fsp. albedinis, mycorrhizal symbioses, date palm, tolerance, bioprotector agents.

\section{SESSION II. ABIOTIC STRESS AND WATER MAN- AGEMENT}

Co-Chair: Alan Walters, Southern Illinois University, USA

\section{Vegetation Fire as Related to Leaf Shrinkage and Water Stress}

\section{Salah Eddine Essaghi* and Mohamed Yessef}

IAV Hassan II, Madinat Al Irfane, BP 6202-Instituts, 10101 Rabat, Morocco.

\section{Abstract}

Leaf shrinkage provides insights into the potential variation of foliar surface area-to-volume ratio (SVR), within the same species, when leaf moisture content is changing in response to water deficit. Since SVR is among the most significant plant flammability features, leaf shrinkage would be a relevant component of fuel hazard assessment through its influence on SVR, enhancing-if it is taken into account-thereby the wildfire prediction accuracy. The purpose of this work is, first, to consider the leaf shrinkage by characterizing the plant species towards the shrinkability of their leaves, taking account the possible site effect, to characterize the behavior of shrinkage as a function of moisture content and finally to perform a classification for some dominant Mediterranean species based on the shrinkage levels. The assessment of the hierarchical relationships between the dimensional shrinkages is also aimed. Leaves and needles of thirteen tree and shrub species were harvested from six different sites in western Rif Mountains. Leaves dimensions and moisture content were measured regularly during a gradual drying at the laboratory. Dimensional shrinkages were calculated at each moisture content level. Dimensional shrinkages behaved similarly whether in leaf or timber and kept the same reporting relationships between each other. Among the species sampled in different sites, site effect is significant only in Pinus canariensis and Pistacia lentiscus. A classification of the plant species was carried out in three separate classes. Generally, shrinkage class of the plant species studied gave an idea on its flammability ranking reported in the literature, implying thus a cause-and-effect relationship between both parameters. Keywords: Dimensional shrinkage, Leaves and needles, Foliar SVR

\section{New Invasive Pest: Integrated Pest Management Strategies of the Prickly Pear Cochineal Dactylopius opuntiae}

Rachid Bouharroud ${ }^{1 *}$, M. El Bouhssini ${ }^{2}$, M. Sbaghi ${ }^{3}$, S. Lhaloui ${ }^{2}, M$. Boujghagh $^{1}$, K. EL Fakhouri ${ }^{2}$, and A. Sabraoui ${ }^{2}$

' Centre Régional de la Recherche Agronomique d'Agadir, INRA,
Morocco ; ${ }^{2}$ International Center for Agricultural Research in the Dry Areas (ICARDA), Rabat, Morocco; 3 Division scientifique INRA, Rabat, Morocco. "Presenting author: bouharroud@yahoo. fr.

\section{Abstract}

In Morocco, the prickly pear cactus Opuntiae ficus-indica grows in arid and semi-arid areas where it plays an essential role in the ecological system, preventing desertification and preserving biodiversity. The fruits are consumed as a food and cladodes as cattle feed. However, O. f. indica is subjected to several attacks by pests and diseases. The prickly pear cochineal Dactylopius opuntiae (Hemiptera: Dactylopiidae) (Cockerell) has been recently reported in Morocco. Our aim is to reduce the rapid spread of this devastating pest through the development of an integrated management strategy based on the study of biology of this species in the environmental conditions of Morocco the use of natural enemies, biopesticides and resistant/tolerant cultivars. The evaluation of 249 cactus ecotypes (INRA-Agadir cactetum) is being explored for possible tolerance/ resistance to this cochineal. The goal of our efforts would be the implementation of a national integrated pest management strategy to control and limit the rapid spread of this cochineal to uninfested productive areas of cactus pear in Morocco.

\section{Using Subsurface Drip Irrigation for Date Palm Water Use Effeciency in Oasis Areas}

Rqia Bourziza*, Ali Hammani, and Ahmed Bouaziz

IAV Hassan II, Madinat Al Irfane. BP 6202-Instituts, 10101 Rabat, Morocco. "Presenting author: rqia.bourziza@gmail.com.

\section{Abstract}

The subsurface drip irrigation (SDI) can be considered as a recent improvement of irrigation water application. The reason given is that it prevents or in most cases considerably reduces losses by direct evaporation, runoff and deep percolation. Due to its high efficiency potential, SDI system was recently introduced in Morocco. This paper deals with its application to the young date palm in the Tafilalet oases (Southeastern of Morocco) where an appropriate design and irrigation management of this system has to be proposed to farmers. A better understanding in local conditions of the infiltration process around a buried source, and its impact on plant growth is necessarily required. This study aims to improve the water use efficiency by testing the performances of SDI system, especially in areas where water is a limited source. To reach this objective, an experimental test has been installed on a farm plot in the region of Erfoud (Errachidia Province, Southeast Morocco) to characterize the respective performances of surface and subsurface drip irrigation on young date palm. The results show an increase in root development and in the number of leaves, as well as a substantial water savings due to lower evaporation losses compared to the classic drip irrigation. The results of this study showed that subsurface 
drip irrigation is an efficient technique, which allows sustainable irrigation in oasis areas. Keywords: Subsurface drip irrigation, evaporation, young date palm, performances, oasis aeas.

\section{Utility of Local Vegetable Crop Populations to Mitigate Yield Responses to Climate Change}

Alan Walters $^{1 *}$, Mimouni Abdelaziz ${ }^{2}$, Rachid Bouharroud ${ }^{2}$, and Ahmed Wifaya ${ }^{2}$

1 Dept. Plant, Soil, and Agricultural Systems, Southern Illinois University, Carbondale, IL USA; ${ }^{2}$ Institut National de la Recherche Agronomique (INRA), Agadir Center, Morocco. "Presenting author: awalters@siu.edu

\section{Abstract}

Future food security challenges must be met in part by developing agricultural technologies to mitigate plant responses to climate change, while at the same time, essential natural resources need to be conserved so that effective food production activities can be sustained for generations. Water is an increasingly limited resource influenced by a changing climate and has a definite influence on the long-term productivity of world agriculture. The utilization of more locally adapted crop germplasm (e.g., landraces) to mitigate the effects of drought due to fluctuating water supplies is a strategy that can be used to cope with these ongoing and future food security challenges. However, new crop variety development is generally non-existent in many developing countries, such as Morocco, with seeds typically sourced from developed countries. This dependence is troubling as it creates a myriad of problems, especially for smaller subsistence farmers. The selection of locally adapted vegetable crop populations that could be readily adapted by smallholder farmers is an important step to increase food security in a changing climate. Although there are limited ongoing efforts to improve crop growth and productivity in developing countries having harsh, dry climates through new variety development, the absence of sustained vegetable breeding programs in these countries will continue to hinder food production, nutritional health and the resulting food security for generations.

\section{Identification and Characterization of Desert Plant Bacte- rial Endophytes Inducing Abiotic Stress Tolerance in Arabi- dopsis thaliana}

Axel de Zelicourt ${ }^{1,2 *}$, Lukas Synek, Hanin Alzubaidy, Rewaa Jalal, Yakun Xie, Eleonora Rolli, Santosh Satbhai, Wolfgang Busch, Rene Geurts, Ton Bisseling, Maged Saad, and Heribert Hirt ${ }^{2}$

1 Institute of Plant Sciences Paris-Saclay (IPS2), CNRS, INRA, Université Paris-Sud, Université d'Evry, Université Paris-Diderot, Université Paris-Saclay, Bâtiment 630, 91405 Orsay, France; ${ }^{2}$ Division of Biological and Environmental Sciences and Engineering, King Abdullah University of Science and Technology KAUST, Thuwal, Saudi Arabia. *Presenting author: axel.de-julien-dezelicourt@ips2.universite-paris-saclay.fr.

\section{Abstract}

Food security is of major importance globally and harvest losses due to abiotic stresses amount to more than $60 \%$ of total productivity, making abiotic stress tolerance the main goal of crop improvement worldwide. The ability of a variety of plants to cope with stress conditions depends on their association with rhizosphere microbes and can potentially help increase food production in a sustainable way. However, so far, neither the microbial diversity nor the mechanisms of their beneficial interaction with plants are sufficiently understood. Our project DARWIN2 1 (http://www.darwin21.net) is to isolate and characterize endophyte microbial strains that can help plants to survive and develop in harsh conditions. From an endophyte bacterial library isolated from desert plant roots of the Jizan region in Saudi Arabia, we have established a screening protocol to select strains that can enhance plant tolerance to salt stress in Arabidopsis thaliana. Using a number of anatomical and physiological parameters, we identified 37 strains, classified as STPRs (Stress Tolerance Promoting Rhizobacteria). For example, SA 187 confers salt, drought and heat stress tolerance in Arabidopsis and enhances yield and biomass of crop plants under desert agriculture conditions. A detailed microscopic analysis revealed that SA 187 colonizes both surface and inner tissues of Arabidopsis roots and shoots. Using biochemical, genetic and transcriptomic approaches, the ethylene pathway was found to be crucial for mediating the abiotic stress tolerance by SA 187 . These results prove that endophytic bacteria can enhance desert agriculture but may also reveal new strategies for breeding crops for enhanced stress tolerance.

\section{SESSION III. DATE PALM II: ECOSYSTEM'S PRES- ENT AND FUTURE, MAJOR DISEASES, AND PRO- DUCTION SYSTEMS}

Co-Chair: Mohamed Baaziz, Professor, Cadi Ayyad University, Marrakech, Morocco

Co-Chair: Ikram Blilou, Professor, Wageningen University \& Research, The Netherlands

\section{4. "Bayoud" Disease in Date Palm: Current Status, Manage- ment, and Perspectives}

\section{Adil Essarioui*}

INRA, Errachidia, Morocco

\section{Abstract}

Date palm (Phoenix dactylifera) is an important food source and commercial perennial crop in the Sahara and North Africa. "Bayoud", a vascular wilt disease, incited by the soilborne fungus Fusarium oxyxporum f. sp. albedinis, has become a serious threat to date production in date palm-growing regions in Morocco and Algeria. Since it first appeared in Morocco in the late 19th century, the disease has spread throughout Morocco and 
into the western half of Algerian Sahara. Attempts to control the disease using systemic fungicides have been unsuccessful. In Morocco, date palm groves possess tremendous genetic variability that is the basis for mass selection and identification of many cultivars that combine resistance and good fruit quality. However, some of the cultivars most highly valued by growers for their quality and productivity are highly susceptible to Bayoud and require intensive management to control the disease. The discovery of soils that are suppressive to the disease and the isolation of many antagonists presents opportunities for the use of these antagonists as biocontrol agents, particularly in combination with soil solarization and fumigation, and soil amendments. Preliminary results indicate that soil solarization and fumigation in combination have the potential to disinfest soils and create an empty niche suitable for rapid colonization by biocontrol agents introduced with soil amendments to protect date palm from the pathogen. Research in this area is still in its infancy and Bayoud disease continues to prevent growers in Morocco from growing the best-but-susceptible cultivars of date palm.

\section{Use of Arbuscular Mycorrhizal Fungi and Bacteria as New Strategy to Control Bayoud Disease in Date Palm}

Fatima Jaiti ${ }^{1 *}$, Abdelhi Dihazi ${ }^{2}$, Reda Meziani ${ }^{3}$, and Khalid Naamani $^{4}$

1 Equipe Protection, Amélioration et écophysiologie végétales, Faculté des Sciences et Techniques Errachidia, Université My Ismail, Meknes, Morocco; ${ }^{2}$ Laboratoire de Biotechnologie, de la Valorisation et de la Protection des Agroressources, Université Cadi Ayyad, Faculté des Sciences et Techniques, Marrakech, Morocco; ${ }^{3}$ Laboratoire National de culture des tissus de palmier dattier, Institut National de la Recherche Agronomique, Errachidia, Morocco; ${ }^{4}$ Equipe de Biotechnologie, Biochimie et Protection des Plantes, Faculté des Sciences Semlalia, Université Cadi Ayyad Marrakech, Morocco. *Presenting author: fatimajaiti@ yahoo.fr.

\section{Abstract}

Fusarium oxysporum f. sp. albedinis (Foa) is a vascular pathogen that causes drastic reduction in cultivation and expansion of date palm in Morocco, leading to a considerable socio-economical impact. The control of Foa is difficult because chemical treatments are not effective and the prophylactic methods are not of interest due to the contamination of several palm plantations and to their non-durable impact. Therefore, planting resistant cultivars constitutes the only efficient and economic method to control this Fusarium wilt "bayoud". A promising approach for minimizing the severity of diseases is based on the induction of systemic resistance using localized pre-treatment with elicitors in order to enhance resistance to pathogen infection. Arbuscular mycorrhizal fungi (AMF) have been shown to protect date palm seedlings against bayoud disease. Treatment with AMF reduced disease severity by $8-77 \%$ depending on the AMF isolate used. In addition, the AMF induce change in activities of two defencerelated enzymes (peroxidases and polyphenoloxidases) and amplifies the accumulation of non-constitutive hydroxycinnamic acid derivatives, such as the sinapic derivative 12 , known to play a crucial role in resistance of date palm to Foa. In the second part of the study, two bacteria, Bacillus amyloliquefaciens strain Agl (Ag) and Burkholderia cepacia strain Cs5 (Cs), were examined for their potential to control this disease. Both bacterial strains inhibited both growth and sporulation of Foa. They released compounds into the culture medium, which resulted into cytological changes in Foa's mycelial structure. One month after inoculation, date palm defense reactions against Foa were different depending on the bacterium used, and B. cepacia led to higher accumulation of constitutive caffeoylshikimic acid isomers while $B$. amyloliquefaciens triggered the induction of new phenolic compounds identified as hydroxycinnamic acid derivatives. Peroxidase activity has also been stimulated significantly and varied with the bacterial strain used and with Foa inoculation. These results highlight the importance of mycorrhizal fungi and selected bacteria as biocontrol agents to combat Bayoud disease and improve date palm culture in infected palm groves. Keywords: Arbuscular mycorrhizal fungi, Bacteria, Bayoud, Biological control, Date palm, Fusarium oxysporum f. sp. albedinis, Bayoud.

\section{Transpiration and Groundwater Uptake of Date Palm (Phoenix dactylifera) in Tafilalet Oasis, Morocco}

\section{Wafae Elkhoumsi, Ali Hammani, and Ahmed Bouaziz}

IAV Hassan II, Madinat Al Irfane. BP 6202-Instituts, 10101 Rabat, Morocco.

\section{Abstract}

Improved water management is one of the main challenges for the sustainability of the oasis ecosystem. Indeed, there is an urgent need to improve our knowledge concerning the water use by plants. The quantity of water transpired by plant is an important factor in investigating irrigation control and plant-water relations. In addition, the contribution of groundwater table to plant transpiration can be very important in these areas. The objectives of this research is to study the transpiration and groundwater uptake of date palm under oasis conditions. An experiment was conducted in farmland located in the Tafilalet oasis. We have been able to calculate transpiration of date palm by using the Granierr's method for irrigated and non-irrigated date palm. The daily average values of transpiration are aboute 0,5 $\mathrm{mm} /$ day to $5 \mathrm{~mm} /$ day dépending on the climatic demand. We have also established the relationship between transpiration and groundwater uptake. Indeed, during the dry season and without irrigation supply, $50 \%$ of date palm transpiration comes from groundwater. This relationship is important for control irrigation and water supply, especially since we found that farmers are using more than twice as much water as is needed to irrigate the date palm. Keywords: Date palm, water use, transpiration, groundwater uptake, Tafilalet oasis. 
7. Effect of Regulated Deficit Irrigation on Date Palm Productivity and Water Use Efficiency cv Majhoul

A. Sabri ${ }^{*}$, A. Bouaziz ${ }^{2}$, A. Hammani ${ }^{2}$, M. Kuper ${ }^{2,3}$, A. Douaik' and M. Badraoui ${ }^{1,2}$

1 Institut National de la Recherche Agronomique, Rabat, Morocco; ${ }^{2}$ Institut Agronomique et Vétérinaire Hassan II, Rabat, Morocco; CIRAD, Montpellier, France. "Presenting author: sabri_ inra2004@yahoo.fr.

\section{Abstract}

Regulated deficit irrigation is one of the ways to save water in regions with limited water resources, while limiting the impact on crop yields. To test the effectiveness of this approach on the productivity of date palm cv Majhoul, an experiment was conducted in Tafilalet (Morocco) for two consecutive years (March 2012-February 2014). The annual cycle of growth and development of this variety was divided into three distinct periods: the first from November to February, the second from March to June and the last from July to October. During these times, seven water regimes were applied under drip irrigation: farmer regime (TO), 100\% (T1), 80\% (T2), 60\% (T3), 80-100-60\% (T4), $150 \%$ (T5) and $60-100-80 \%$ (T6) ETM. The measures focused on the monitoring of meteorological parameters, the water irrigation and the evolution of date yields of Majhoul variety. The results at the end of the second year of this trial show that: i. Water regime has significantly affected the average yields and water use efficiency, ii. Water irrigation needs are, on average, $51 \mathrm{~m}^{3} /$ tree/year, varying between 30 and $76 \mathrm{~m}^{3} /$ tree/ year, and iii. Average date yield and water use efficiency by water regime are $31,61,46,39,43,45$, and $59 \mathrm{~kg}$ of dates/ tree/year and $0.44,1.20,1.13,1.30,1.07,0.59$, and $1.36 \mathrm{~kg}$ of dates $/ \mathrm{m}^{3}$, respectively for treatments $T 0, T 1, T 2, T 3, T 4, T 5$, and T6. Thus, the water regime T6 has improved the water use efficiency and the conservation has allowed $14 \%$ of water irrigation compared to the $\mathrm{Tl}$. The regulated water stress strategy contributes to the rationalization of water and sustainability of oasis. Keywords: Regulated deficit irrigation, date palm, Ma¡houl, water use efficiency.

\section{SESSION IV. STUDENTS ORAL PRESENTATIONS}

Co-Chair: Latifa Lefrere, Ibn Zohr University, Morocco

Co-Chair: Karen Miden, Southern Illinois University

\section{Evaluation of Olive Tree Resistance to Verticillium wilt}

Imane Ben Salah ${ }^{1 *}$, Abderrahman Ouzzine', Mouna Lamaoui', Abdelghani Chakhchar', Ali Mhais', Allal Douira ${ }^{2}$, Abdelmajid Moukhli ${ }^{3}$, Abdelkarim Filali-Maltouf ${ }^{4}$, Ahmed Tadlaoui Ouafi', and Cherkaoui El Modafar ${ }^{1}$

' Laboratoire de Biotechnologie, Valorisation et Protection des Agro-Ressources, Faculté des Sciences et Techniques Guéliz, Université Cadi Ayyad, Marrakech, Morocco; ${ }^{2}$ Laboratoire de Botanique et Protection des Plantes, Faculté des Sciences, Université Ibn Tofail, Kénitra, Morocco; ${ }^{3}$ UR, Amélioration des Plantes, INRA Marrakech, Morocco; ${ }^{4}$ Laboratoire de Microbiologie et Biologie Moléculaire, Faculté des Sciences, Université Mohammed $\vee$ Agdal, Rabat, Morocco. "Presenting author: bensalah. imane7@gmail.com

\section{Abstract}

Verticillium wilt of Olive (VWO) caused by Verticillium dahliae Kleb is currently one of the most devastating diseases affecting olive tree in the world. So far, the use of resistant cultivars is the only effective method to control this vascular disease. The aim of this work was the assessment of symptoms of VWO in 20 olive cultivars from the world collection of olive tree located in Tassaoute (Marrakech, Morocco) and the evaluation of their resistance to Verticillium dahliae (VD) using a simple, fast and nondestructive method (twigs inoculated with a conidial solution). Resistance was evaluated by assessing symptom severity using a $0-4$ rating scale. Cultivars were classified by combining the final mean severity (FMS) of the disease and the percentage of the area under disease progress curves (AUDPCP). Our results showed a high variability of cultivar's resistance. Four groups were obtained; a group of highly susceptible cultivars (Arbequina, Aggezi shan, Doukar, Leccino and Picual), group of susceptible cultivars (Galegavulga, Souidi, Amphisis, Lagoydhera, Moroccan Picholine, Ifiri, Chemlal and Zaity), group of moderately resistant cultivars (Picholine of Languedoc, Jemribouch, Doebli, Hojiblanca and Koroneiki) and a group of resistant cultivars (Chetoui and Wateken). This result was compared with that obtained by the principal component analysis (PCA) taking into account all variables: FMS, AUDPCP, defoliation, leaf rolling, dieback, mortality and disease incidence. The PCA clustered the 20 cultivars into three classes; susceptible, intermediate and resistant class. This analysis confirmed the previous result however, it provided an objective wider grouping of individuals. Therefore, to control the VWO, the four resistant cultivars; Wateken, Chetoui, Picholine of Languedoc and Jemribouch are recommended. Keywords: Olive tree, Verticillium dahliae, resistant cultivars, twigs, world collection of Tassaoute.

This work is carried out under the project ArimNet "Pestolive" supported by the Ministry of Higher Education, Scientific Research 
and Executive Training and the project "Rhizolive" supported by the Hassan II Academy of Science and Technologies.

\section{Ethnobotanical Study of Medicinal Flora in the Southeast Morocco: Case of Ouarzazat "Great Taznakht"}

Younesse El Ouazzani ${ }^{1 *}$, Aziz Hasib', Abdelali Boulli', and Mustapha Bouzaid ${ }^{2}$

1 Environment Laboratory and Valorization of the Agro-Resources of the Faculty of Sciences and Techniques of Beni Mellal, Morocco; ${ }^{2}$ Laboratory of Bioprocesses and Bio-interface of the Faculty of Sciences and Techniques of Beni Mellal, Morocco. *Presenting author: y.elouazzani@yahoo.com.

\section{Abstract}

Medicinal plants represent a treasure for those who have been used to treat human ailments over many centuries and cure their illnesses differently, turning thir backs to the chemical arsenal of current medicine. This study was carried out in the region of Ouarzazat, which is renowned for its botanical biodiversity. We distributed 665 surveys during two months on 46 ethnobotanical fields, these survey sheets were completed by traditional practitioners, herbalists and users of medicinal plants of the community who are living in the town of the "Great Taznakht" as well as in the different Villages and surrounding Douars. The statistical treatment of the results obtained from the questionnaires sheets, has allowed us to target the plant species suspected having a caregiver power against various diseases, methods of preparation and more. Keywords: Ethnobotanical Survey, Medicinal and Aromatic Plant, Traditional Practice, Biodiversity, Pharmacopoeia, Ouarzazat, South East of Morocco.

\section{Postharvest Control of Pathogenic fungi of tomato using two Brown Seaweed Extracts; Cystoseira tamariscifolia and Bi- furcaria bifurcata}

Nadia Bahammou $^{1 *}$, O. Cherifi ${ }^{1 \dagger}, \mathrm{H}$. Bouamama $^{2}$, and K. Cherifi ${ }^{3}$

1 Laboratory of Food, Environment and Health, Biology Department, Faculty of Sciences and Techniques, Cadi Ayyad University, Marrakech, Morocco; ${ }^{2}$ Laboratory of Organic and Macromolecular Chemistry, Biology Department, Faculty of Sciences and Techniques, Cadi Ayyad University, Marrakech, Morocco; ${ }^{3}$ Laboratory of Biotechnology and Valorization of Natural resources, Biology Department, Faculty of Sciences, IBn Zohr University, Agadir, Morocco.

\section{Abstract}

Fungicides are chemical compounds having toxicological properties, used by the farmers to fight against the phytopathogenic fungi. These fungicides neutralize and reduce the activity of fungi but they remain a worrying and frightening source of pollution and toxicity. To search for biological molecules with antifungal potential, this study was done to investigate the antifungal potentiality of the marine algae collected from the Moroccan coast Sid Bouzid El-jadida. Hexane and aqueous extracts of two algae species belonging to Phaeophyceae were screened for their antifungal activity against some tomato pathogenic fungi: Alternaria sp. and Botrytis cinerea. The overall results show that the fractions from hexanic $(91,000 \mathrm{ppm})$ and aqueux extract $(49,600 \mathrm{ppm})$ of Cystoseira tamariscifolia and Bifurcaria bifurcata exhibits remarkable biological activity with a very small amount of $100 \mu \mathrm{l}$. An interesting antifungal effect was observed for the hexanic crude extract of Cystoseira tamariscifolia where the inhibition zones were up to $2 \mathrm{~cm} \pm 0.18$ and $1.32 \pm 0.21 \mathrm{~cm}$ against $B$. cinerea and Alternaria sp., respectively. The Atlantic coast is a source of bioactive compounds with potential applications in controlling undesired microorganisms of crops. This may encourage the use of natural products to promote agroecology in substitution of chemical compounds in food systems, regarding risks of fungicides on human health and the environment. Keywords: Macroalgae extracts, Phaeophyceae, Phytopathogenic fungi, Tomato, Postharvest.

\section{Rock Phosphate and Vesicular-Arbuscular Mycorrhiza Ef- fects on Growth and Mineral Nutrition of Acacia gummifera Wild}

\section{Fatima Zahra Lahdachi", L. Nassiri, J. Ibijbijen, and F. Mokhtari}

University My Ismail, Meknes, Morocco. *Presenting author: fatimazahra.lahdachi@gmail.com.

\section{Abstract}

The influence of arbuscular mycorrhizae (AM) and rock phosphate (RP) was studied on Acacia gummifera, an endemic Moroccan species which is experiencing significant losses. They are also a source of firewood and charcoal and precious air fodder in the dry season. Acacias were inoculated or not by a mixture of two species of arbuscular mycorrhizal fungi (Glomus intrardices and Glomus mossae) to which were added two levels of RP: 0,25 and $0,5 \mathrm{~g} \mathrm{P} / \mathrm{kg}$ of soil. The percentage of mycorrhizal infection varied from $10 \%$ to $25 \%$ when RP applications increased. Acacia seedlings grew poorly without mycorrhizal colonization and without RP applications. However, AM plants with RP applications achieved better results in terms of content of $P$ and $N$ in shoot and root. In contrast, there were not additive effects of inoculation and fertilization on total biomass at any RP applications. However, mycorrhizal acacias took up more $P$ and $\mathrm{N}$ at $0.25 \mathrm{~g} \mathrm{P} \mathrm{kg}^{-1}$ of soil and above. These results suggest that $A M$ are able to absorb $P$ from soil and rock phosphate for a better mineral nutrition of Acacia gummifera. Keywords: Acacia gummifera, rock phosphate, arbuscular mycorrhizae. 


\section{SESSION V. PLANT GENETICS, GENOMICS, BIO- TECHNOLOGY, AND BIOINFORMATICS I}

\author{
Co-Chair: My Abdelmajid Kassem, Fayetteville State University, \\ USA \\ Co-Chair: Lamiae Ghaouti, IAV Hassan II, Morocco
}

\section{Genetic Mapping of QTL for Seed Isoflavone Contents in Several Soybean Recombinant Inbred Line Populations Across Multiple Environments in the USA}

Masum Akond', Shiming Liu', Stella K. Kantartzi ${ }^{2}$, Khalid Mek$\mathrm{sem}^{2}$, Nacer Belalloui ${ }^{3}$, David A. Lightfoot ${ }^{2}$ and My Abdelmaiid Kassem $^{1 *}$

1 Plant Genomics and Biotechnology Laboratory, Department of Biological Sciences, Fayetteville State University, Fayetteville, NC28301-4298, USA; ${ }^{2}$ Department of Plant, Soil and Agricultural Systems, Southern Illinois University, Carbondale, IL 62901 4415, USA; ${ }^{3}$ Crop Genetics Research Unit, U.S. Department of Agriculture, Agricultural Research Service, 141 Experiment Station Road, P.O. Box 345, Stoneville, MS 38776, USA;4 Department of Plant, Soil and Microbial Sciences, Michigan State University, East Lansing, MI 48824-1325, USA. "Presenting author: mkassem@uncfsu.edu.

\section{Abstract}

Soybean is one of the most important crops worldwide for its protein and oil as well as the health beneficial phytoestrogens or isoflavone. Here, we sumarize three years of genetic and QTL mapping of seed isoflavone contents in three recombinant inbred line (RIL) populations across different environments in the USA. Three SNP-based genetic linkage maps based on the 'PI 438489B' By 'Hamilton, 'MD 96-5722' By 'Spencer', and 'Hamilton' By 'Spencer' RIL populations have been constructed and used for QTL mapping of seed isoflavone contents and other agronomic trairs. In the 'PI 438489B' By 'Hamilton' RIL population, we identified 6 QTL for seed isoflavone contents on chromosomes 1, 2, 3, 6, 7, 8, 9, and 12. In the 'MD 96-5722' By 'Spencer' RIL population, we identified 3 QTL for seed isoflavone contents on chromosomes 5, 9, and 14. In the 'Hamilton' By 'Spencer' RIL population, we also identified 3 QTL for seed isoflavone contents but on chromosomes 6 and 18. These newly assembled soybean linkage maps are useful tools to identify and map QTL for important agronomic traits and enhance the identification of the genes involved in these traits. Keywords: Soybean, single nucleotide polymorphism, Quantitative trait loci, isoflavone, daidzein, genistein, glycitein.

\section{The GmSNAP18 is the Peking-type rhgl-a Gene for Resis- tance to Soybean Cyst Nematode}

Shiming Liu', Pramod K. Kandoth ${ }^{2}$, Naoufal Lakhssassi ${ }^{*}$, Jingwen Kang ${ }^{2}$, Vincent Colantonio', Robert Heinz ${ }^{2}$, Greg Yeckel', Zhou Zhou', Sadia Bekal', Johannes Dapprich ${ }^{3}$, Biorn Rotter ${ }^{4}$, Silvia Cianzio ${ }^{5}$, Melissa G. Mitchum ${ }^{2}$, and Khalid Meksem ${ }^{1, \dagger}$
1 Department of Plant, Soil and Agricultural Systems, Southern Illinois University, Carbondale, IL 62901, USA; ${ }^{2}$ Division of Plant Sciences and Bond Life Sciences Center, University of Missouri, Columbia, MO 65211 , USA; ${ }^{3}$ Generation Biotech, Lawrenceville, NJ 08648, USA; ${ }^{4}$ GenXPro-GmbH, Altenhöferallee 3, 60438 Frankfurt am Main, Germany; ${ }^{5}$ Department of Agronomy, lowa State University, Ames, IA 50011, USA. "Presenting author: naoufal.lakhssassi@gmail.com. 'Corresponding author: meksem@siu.edu.

\section{Abstract}

Two types of resistant soybeans [Glycine max (L.) Merr.] sources are widely used against soybean cyst nematode (SCN, Heterodera glycine Ichinohe): The Peking-type soybean resistance requires both the rhg $1-\mathrm{a}$ and Rhg4 alleles, and the PI 88788type soybean resistance requires only the $\mathrm{rhg} 1-\mathrm{b}$ allele for resistance. We identified, by map based cloning, targeted genome sequencing, haplotyping, and genetic complementation, that the Peking-type GmSNAP1 8 alone is the rhg 1 -a gene conferring resistance to SCN at the rhg 1 -a locus. In GmSNAP18, there are nine amino acid differences between resistant (Pekingtype soybean cv. Forrest and PI 88788) and susceptible (Essex) soybeans and five amino acid differences between two resistant soybeans: Forrest and PI 88788. Our findings reveal that Peking-type GmSNAP 18 is most likely performing a different role in SCN resistance than PI 88788-type GmSNAP18. To our best knowledge, this is the first report of a gene that evolved to possibly use two mechanisms to ensure the same function within the same species, in this case, resistance to a pathogen. The knowledge gained from this study can be readily used to improve nematode resistance of soybeans.

\section{Improvement of Saffron (Crocus sativus) by Plant Biotech- nology}

Mohamed Amine Serghini ${ }^{*}$, K. Lagram', M. Ben El Caid', M. Lachheb', L. H. Atyane', L. Salaka', and Y. Karra ${ }^{2}$

${ }^{1}$ Faculté des Sciences, University Ibn Zohr, BP 8106, Agadir, Morocco; 2 INRA, BP 124, Inezgane, Morocco; *Presenting author: maserghini@live.fr.

\section{Abstract}

Saffron describes both the Crocus sativus plant and the spice resulting from its dried stigmas. It is the most expensive spice in the world that is valued in refined culinary art, used in traditional medicine/cosmetic and as dye in textile and woodwork. The commercial part of saffron is the flower style composed of 3 stigmas. 150 to 200 flowers are needed to produce $1 \mathrm{gram}$ of dried spice. Its exclusive vegetative propagation considerably reduces its biodiversity and excludes its improvement by classical hybridization. A lot of scientific work has focused on the morphlogical and physiological traits of saffron in terms of mass and shape of corms, the number of shoots and flowers per corm, the form and the mass of the stigma and the effect of tem- 
perature and irrigation on flowering. In all these characteristics, variability between cultivars is significant. The in vitro cultivation of saffron can allow the rapid multiplication of healthy selected material. At the molecular level, markers such as RFLP, RAPD and microsatellites and sequencing were a tool of choice for finding variability in saffron cultivars and defining their molecular identity. The chemistry of saffron is mainly based on crocin, picrocrocin and safranal metabolites. Its study by chemical techniques such as UV-Vis, HPLC and GC attempt to explain the content of saffron secondary metabolites and to establish a chemical identity able to support the hallmarks of quality and to control the falsification of this spice. Packaging and storage of saffron have also sparked some experiments focused on the content of crocin which defines, most importantly, the product's commercial category (ISO 3632 International Standard). The conference will highlight the most significant scientific results in saffron research and will present a synthesis of research conducted on different axes of saffron in our laboratory. Keywords: Crocus sativus, Saffron, Corm, In Vitro, Molecular Markers.

\section{Evaluation of Safflower (Carthamus tinctorius L.) Acces- sions Using Agro-Morphological and Technological Param- eters}

Karim Houmanat ${ }^{1,2}$, Mohamed El Fechtali' ${ }^{1}$, Hamid Mazouz ${ }^{2}$, and Abdelghani Nabloussi $^{1 *}$

${ }^{1}$ INRA, Research Unit of Plant Breeding and Plant Genetic Resources Conservation, CRRA of Meknes, Po. Box 578, Meknes, Morocco; ${ }^{2}$ University Moulay Ismail, Laboratory of Biotechnology and Molecular Biology, Faculty of Sciences, Meknès, Morocco. "Presenting author: abdelghani.nabloussi@gmail.com.

\section{Abstract}

Safflower (Carthamus tinctorius L.) is a minor hardy crop well adapted to semi-arid conditions. In Morocco, it can be cultivated as an alternative for barley based monocropping system in the southern region of the country. Recently, a breeding program has been launched in order to develop varieties adapted to local environmental conditions and with high agronomic and technological performances. In 2013-2014, a total of 60 accessions from different origins of the world were evaluated in the INRA-experimental station located at Douyet $(10 \mathrm{~km}$ from Fez city) for morphological, agronomic and technological traits. They were conducted using a complete-randomized-blocks design (CRBD) with two replicates. Results indicated large variability among these accessions for spinelessness level (SL), plant height $(\mathrm{PH})$, earliness, branching, leaf rust resistance (RR), thousand seed weight (TSW), seed yield per plant (SYP) and seed oil content (SOC). Generally, genotypes with high seed yield per plant were also characterized by high TSW, early flowering and were dwarf and spiny. Average TSW was $15.50 \mathrm{~g}$, with a high variation from 22 to $63 \mathrm{~g}$. Seed oil content ranged from 20 to $42.1 \%$, with an average of $28.20 \%$. Average seed yield per hectare is about $2.1 \mathrm{t}$, and the highest yield observed was 7.9 t. The accessions studied were grouped into five pools on the basis of desired traits: seed yield per plant, seed oil content, spineless, earliness and resistance to leaf rust. However, the nature and composition of these groups must be confirmed in other environments. These groups will be considered as genetic pools and selected genotypes from each pool will be used as elite parents in our safflower hybridization program. Keywords: Morocco, semi-arid, genetic pools, hybridization.

\section{SESSION VI. ANIMAL SCIENCES}

\author{
Chair: Mohamed Bouslikhane, Professor, IAV, Morocco \\ Co-Chair: Ahmed Elamrani, University Mohamed I, Morocco
}

\section{Lipid and Fatty Acid Composition of Longissumus dorsi muscle of Béni-Guil Sheep Fed on Different Dryland Forages in Eastern Morocco}

Kamal Belhaj', Farid Mansouri', Abdessamad Ben-Moumen', Marianne Sindic ${ }^{2}$, Marie-Laure Fauconnier ${ }^{3}$, Mohamed Boukharta $^{4}$, Hana Serghini-Caid ${ }^{1}$, and Ahmed Elamrani ${ }^{1 *}$

1 Laboratoire de Biologie des Plantes et des Micro-organismes, Faculté des Sciences, Université Mohamed ler, Oujda; Morocco; ${ }^{2}$ Laboratoire Qualité et Sécurité des Produits Alimentaires, Gembloux Agro-Bio Tech, Université de Liège; Belgium; ${ }^{3}$ Laboratoire de Chimie générale et Organique, Gembloux Agro BioTech, Université de Liége; Belgium; ${ }^{4}$ Institut Supérieur Industriel agronomique, Huy, Belgium. "Presenting author:

\section{Abstract}

Sheep meat of the Beni Guil breed is a famous meat in eastern Morocco. This sheep breed was integrated into the national program of agricultural development due to the nutritional and sensory properties of its meat widely consumed in eastern Morocco However, this good reputation is still only limited to the assessments of tasting panels. Thus the objective of this study is to assess from a scientific point of view the nutritional quality of this meat via biochemical analyses, examining major and minor muscle composition of the meat of this breed and specifically fatty acid (FA) composition of the longissumus dorsi muscle In this first study, 10 longissumus dorsi muscle samples were selected and cut with the help of the agents of the National Association of Sheep and Goats (ANOC*). The results showed that $100 \mathrm{~g}$ of fresh meat material contains $25.72 \%$ of dry matter, including $5.13 \%$ of Fat, $19.42 \%$ of protein and $0.93 \%$ of mineral matter. Qualitative and quantitative analyses of fatty acids of 10 samples allowed the identification of 27 components. Palmitic, Oleic and stearic esters were the main fatty acid methyl esters (FAMEs) identified. Saturated fatty acids represented about $41.13 \%$ of FAs, with the majority being palmitic acid $(20.69 \%)$ and stearic acid $(16 \%)$ The unsaturated fatty acids were principally represented by oleic acid $(36.06 \%)$ and linolenic acid $(9.64 \%)$. The average content of total fatty acids in meat samples analyzed is 24.98 grams per 100 grams of fat. Many reports in the literature have shown that the $n-6$ and n-3 polyunsaturated FA are important contributors to the savor and flavor of ruminant meat and that this composition is mainly 
correlated with feeding systems used in eastern Morocco. Keywords: Beni Guil, Sheep, longissumus dorsi muscle, Fatty Acid. *ANOC: Association National des Ovins et Caprins, translated as National Association of Sheep and goats.

\section{Can Livestock Contribute to the Ecological Intensification of the Agriculture in the Oasis: A Case Study from the Drâa Valley?}

\section{T. Sraïri ${ }^{*}$, S. Mansour ${ }^{1}$, V. Alary ${ }^{2}$, and M. Benidir ${ }^{3}$}

${ }^{1}$ Hassan II Agronomy and Veterinary Medicine Institute, P.O. Box 6202, Rabat, Morocco;

2 International Center of Agricultural Research for Development (CIRAD), Montpellier, France; ${ }^{3}$ Regional Office of Agricultural Development, Ouarzazate, Morocco. *Presenting author: mt.srairi@iav.ac.ma.

\section{Abstract}

Recent developments in the global agriculture have been characterized by the emergence of the concept of ecological intensification, as a means to decrease the use of inputs and their impacts on the environment, while increasing and/or stabilizing crops and livestock yields. In the meantime, research studies have emphasized the ability of crops integration with livestock farming systems to adapt themselves to numerous stresses (economic, climate, etc.) in comparison to specialized systems with only crops or livestock. In the oasis, such integration has been traditionally achieved, as it has allowed for centuries the resilience of the cropping activities, in an environment characterized by numerous constraints, particularly frequent water shortages. However, this resilience has nowadays become challenged by increased stresses, above all climate change and its consequences and also social changes, with growing demands of the local population for better livelihoods. Therefore, in this study, the focus was on the ability of livestock to contribute to the ecological intensification of the farming systems adopted in the oasis. A sample of twelve (12) farms located in the oasis of the Drâa valley was selected and it was representing four types of livestock systems (i.e. 3 farms per system). A follow-up of farms was adopted to characterize inputs uses, water volumes and their origins (rainfall, surface irrigation and groundwater) and incomes from crops. The same methods were used for livestock production. In addition, work needs for crops and livestock were also measured, by determining the contribution of off-farm work uses. The results showed the importance of crop/ livestock association in all the systems, in order to implement a sustainable farming activity. The intensification of livestock systems (retrieved in farms with prominent off-farm feed uses, i.e. D'man breed flocks and dairy cattle) showed the best incomes from crops, and that was mostly remarkable for date palms, which benefitted from the surplus irrigation of the underlying alfalfa, as well as manure from the herds. In the contexts where agriculture intensification was not feasible (due to water, land or capital scarcity), livestock remained the main source of incomes, adding value to vast pastoral areas (as in the area of M'hamid
EL Ghizlane) and to crop by-products (mainly date wastes). Altogether, the results imply the need of further research devoted to the performances of the farming systems in the oasis, and the use efficiency of scarce inputs, such as water, land and work. Keywords: Climate change, Crop-livestock integration, Ecological intensification, Incomes, Morocco, Oasis.

\section{Reproduction Performances of the Female D'man Sheep}

\section{Lahsen Derqaoui*}

Department of Medicine, Surgery and Reproduction, I.A.V. Hassan II, P.O. box 6202, Rabat-Institutes, 10101 , Rabat, Morocco. *Presenting author: I.derqaoui@iav.ac.ma.

\section{Abstract}

The D'man is the local sheep breed of the pre-Saharan regions of southern Morocco. It is located mainly in the oases of the Draa (Ouarzazat, Zagora, Tata, Guelmime), Ziz (Errachidia Arfoud) and Dades valleys. Its total population was estimated to some 200000 head. It is raised in very small size herds (one ram and 3 to 4 ewes, in average) and kept indoors throughout the year. The diet is based on alfalfa and date wastes. The D'man breed is known for its exceptional reproductive traits, namely precocious puberty, high prolificacy and fertility rates, non seasonality and short postpartum anestrous. Puberty is commonly defined as the phase of life from which an individual acquires the ability to reproduce. In the female, it corresponds to the age at which it becomes able to ovulate, to manifest signs of heat, to mate and to carry out a gestation. In their native areas, D'man lambs reach puberty at an average age of 5 months (150 days). However, lambing was observed at eight months of age, corresponding to fertile mating at 3 months of age. In ewes born and raised outside the native area, the first estrus occurs at 212 to 229 days of age. The effect of birth season on age at puberty is controversial. Moreover, this parameter is genetically transmitted to the crosses between the D'man and seasonal breeds Sardi and Timahdite. At puberty, the average live weight of the D'man ewe lamb ranges from 18 to $24.5 \mathrm{~kg}$ (about $50 \%$ of mature weight). The precocity of this breed and its crosses allows the lengthening of their reproductive career. Lambing occurs all year around in the D'man sheep, which is in favor of the absence of seasonal anestrous in this breed. Experimental studies showed that ewes exhibit continuous sexual activity throughout the year. However, ewes show a period of decreased sexual activity from mid-March to mid-May during their first breeding season. Practically, this trait offers the possibility to use the D'man ewe according to a desired breeding program. In the D'man ewe, the duration of the estrous cycle is 1 7.5 days on average (14 to 21 days), with cycles of 17 and 1 8 days representing $60 \%$ of the cycles. The duration of estrous behavior (heat) varies from 12 to 72 hours with an average of 39 hours in aged females, with $50 \%$ of females in heat for 48 hours at least. In the young ewe lambs, estrus is relatively shorter and lasts 33 hours only. The lengthening of the estrus behavior increases the possibilities of mating and improves the fertility of 
the breed. Postpartum anestrous is the stage of sexual inactivity after lambing. In the D'man ewe, resumption of estrous and ovarian activities during the postpartum period is precocious. Indeed, ovarian and estrous activities resume lactating ewes within 45 days after lambing. The shortening of the post-partum anestrous period makes allowed accelerated lambing program. The D'man sheep is known for its multiovulatory ability. Thus, average ovulation rates range from 2.50 to 3.63 ( 1 to 8 ) with a higher incidence of double ovulations (32.9\%). The average ovulation rate increases with age and then decreases slightly towards the end of the breeding career of the female, i.e. minimal (2.16) in ewes less than two years old maximal (3.63) at 4 to 5 years. The average litter size ranged from 1.90 to 2.27 , according to the breeding system. In addition, the incidence of twining was highest $(47.1 \%)$. Likewise, the litter size followed similar pattern as the ovulation rate. Given the reproduction performances of the D'man sheep, namely age at puberty, ovulation rate, fertility and prolificacy are genetically transmitted to the breed's offspring and its crosses with satisfactory heritability rates, the use of this breed is desirable in intensive lamb production systems.

\section{Epidemiological and clinico-pathological features of ede- ma syndrome in camel dromedaries in Southern areas of Mo- rocco}

Boutkhoum Khadija', Mohammed Bouslikhane', Jaouad Berrada', and Faouzi Kichou'

1 Département de Pathologie et Santé Publique Vétérinaires, Institut Agronomique et Vétérinaire Hassan II, BP 10101, Rabat, Maroc. *Presenting author: ?. †Corresponding author: f.kichou@ iav.ac.ma

\section{Abstract}

This work is a contribution to studying the edema syndrome in camel dromedaries in Southern areas of Morocco. The aim of the work was to determine the epidemiological and clinico-pathological characteristics of this syndrome and make plausible suspicion relative to the causes implicated. To do so, clinical and epidemiological investigations were carried out in 46 herds of dromedaries in the areas of Laayoune-Boujdour, Guelmim, EsSmara, Oued Ed-Dahab-Lagouira. Clinical examinations were performed exclusively on animals suffering from edematous syndrome. Additional investigations including hematological (hematocrit) and biochemical (ALT and AST, urea, creatinin, total protein and albumin) examinations were performed on blood samples harvested from sick and healthy animals. The results of this work showed a prevalence of $26 \%$ of affected flocks by the edema syndrome, an estimated overall individual prevalence of $0.5 \%$ and an average individual prevalence of $2.6 \%$. The affected animals showed a chronic generalized passive edema localized mainly in the neck, flank and hindquarters areas. Biochemical tests revealed hypoproteinemia in sick animals as shown by a significant decrease in total plasma proteins and albumins. Post-mortem examinations carried out on a single case showed generalized edema (severe subcutaneous edema and serous fluid in body cavities), generalized serous atrophy of fat, congested liver of nutmeg appearance, flabby heart and bilateral atrophy and dilation of heart ventricles. The most prominent microscopic lesions were centro-lobular passive congestion and important hemosiderin pigmentation in the liver consistent with the diagnosis of right heart failure. A lympho-plasmocytic enteritis and peri-bronchiolar and interstitial fibrosis of bandlike areas in pulmonary parenchyma were also noted. Based on the above findings, the causes of edema syndrome could be trypanosomiasis, haemonchosis, mycotoxicosis, malabsorption syndrome, proteino-energitic malnutrition and/or liver failure. Keywords: Edema, Dromedary, Epidemiology, Biochemistry, Hematology, Histopathology, South of Morocco.

\section{Risk Factors, Clinical, and Lesion Characteristics of Case- ous Lymphadenitis or Abscess Disease in Sheep in Eastern Morocco}

Faouzi Kichou ${ }^{1 *}$, Ahmed Mechaal', Mohammed Bouslikhane', Ahlam Kadiri' ${ }^{1}$ Khalil Zro², and Jaouad Berrada'

1 Département de Pathologie et Santé Publique Vétérinaires, Institut Agronomique et Vétérinaire Hassan II, BP 10101, Rabat, Morocco; ${ }^{2}$ Biopharma, Agdal Rabat Morocco.

*Presenting author: f.kichou@iav.ac.ma.

\section{Abstract}

The aims of this study were to determine the prevalence and risk factors of caseous lymphadenitis in sheep in the Orien $\neg$ tal region in Morocco, and to determine its clinical and lesion characteristics. Surveys were conducted in different provinces of the region. They focused on 6376 animals in 107 farms. In addition, search for lesions, and lymph node and abscess collection for histopathological examination were performed in five slaughterhouses of the region. The results showed that almost $100 \%$ of the farms (106 out of 107) were affected by caseous lymphadenitis. The overall individual prevalence of the disease was $24 \%$, and the average prevalence in farms and slaughterhouses were 28 and $16 \%$, respectively. Besides the poor hygiene and high density of sheep in houses, use of traumatic equipment (metal feeders, drinkers and fences) seemed to be the main factor that lead to the spread of abscesses between animals of a same herd. Superficial abscesses, open or not, surrounded by enlarged lymph nodes were present in all affected animals. The location of the lesions varied but about $79 \%$ of them were located in the head or the neck. Histopathological examination of lymph nodes revealed two types: active abscesses (87\%), and lesions of diffuse and severe necrosis and suppuration of the lymphoid tissues (13\%). In the lungs, abscesses were well defined and circumscribed. Keywords: Sheep, caseous lymphadenitis, abscess, risk factor, histopathology, epidemiology, Morocco. 
VII. Session VII - Plant Genetics, Genomics, Biotechnology, and Bioinformatics II

\author{
Co-Chair: Lamiae Ghaouti, Professor, IAV Morocco \\ Co-Chair: Ahmed Bouaziz, Professor, IAV Morocco
}

5. How Large is the Genetic Diversity in Argan (Argania spinosa (L.) Skeels)? What Opportunities Present the Use of the Molecular Tools?

Mohamed Louay Metougui ${ }^{1 *}$, Mimoun Mokhtari ${ }^{2}$, and Ouafae Benlahbib $^{1}$

' Department of Plant Production, Protection and Biotechnology, Hassan II Institute of Agronomy and Veterinary medicine, Rabat, Morocco; ${ }^{2}$ Department of Horticulture, Hassan II Institute of Agronomy and Veterinary medicine, Horticultural Complex of Agadir, Morocco.

\section{Abstract}

Argan tree (Argania spinosa (L.) Skeels) is a multipurpose species of great social and economic interest in Morocco. The Natural stands are more and more threatened by anthropomorphic pressures and environmental changes which are slowing the natural regeneration of the species. Thus, characterization and diversity studies are essential to determine where genetic resources conservation efforts should be focused. In this study, the agro-morphological diversity of argan trees was investigated over three years in the in situ preserved population of Admine, a protected area in southwestern Morocco. A total number of 122 trees out of 1200 were characterized using 30 quantitative traits. Significant differences between genotypes and between years were seen for all traits. Correlation analysis between traits showed that vigor traits (leaves and shoots sizes) were positively correlated with fruit traits. Cluster analysis using Euclidian distances was used to establish the relationships among the argan germplasm and grouped the genotypes into five relatively homogenous clusters. The yield's genotype $\times$ year interaction analysis indicated that the genotype factor contributed more to the yield's variance than the year. But the genotype $x$ year interaction explained more than $65 \%$ of the total variation, revealing specific response of each genotype to each environment and the complexity of this trait. Notwithstanding the importance of argan as an emerging alternative oilseed species, and the difficulty of generating reliable data for the selection of stable, plus-trees, and understanding the genetic background of this species from phenotypic data. Only a few molecular investigations have been reported in Argania and even fewer molecular tools, which are needed for advanced genomic studies and modern plant breeding, have been developed. Genomic analysis tools, such as sequence-based molecular markers (e.g., SSRs and SNPs), genetic linkage maps, and expressed sequence tagged (EST) collections have yet to be developed for Argania spinosa. Development of these molecular resources for argan will have a direct application to argan conservation and potential improvement (i.e. breeding and selection) of the species.

\section{Genetic Diversity of Vicia faba L. Landraces in Morocco: A Reservoir for the Enhancement of the Competitive Ability to Weed Stress}

Lamiae Ghaouti ${ }^{*}$, N. Aqtbouz', L. Belqadi', and W. Link ${ }^{2}$

1 Département de Production, Protection et Biotechnologies Végétales, Institut Agronomique et Vétérinaire Hassan II, Rabat, Morroco; ${ }^{2}$ Department of Crop Sciences, Georg-August Universität, Göttingen, Germany.

\section{Abstract}

Faba bean (Vicia faba L.), the major legume crop in Morocco with an acreage over 190.000 ha, is cultivated mainly as a break crop in cereal based cropping systems. It is an ancient crop in Morocco with a large extent of genetic diversity, mainly grown in rain-fed and marginal areas with high level of agrobiodiversity. Over $90 \%$ of the farmers are cropping local landraces based on traditional farming practices with very low inputs. Weeds compete with crop plants for light, nutrients, soil moisture and space. Above critical population thresholds, weeds can significantly reduce crop yield and quality. The yield loss attributed to weed stress in faba bean can amount 60 to $70 \%$. Mechanical weeding is very rarely used especially for large cropped areas and chemical weeding is mainly used only in case of broomrape infestations. The high level of genetic diversity of the Moroccan faba bean landraces constitutes one of the few options available to the farmers to cope with weed stress. Indeed, a very valuable option for weed control is the use of genotypes with high competitive ability toward weeds. High grain yield, despite significant weed pressure, is an attribute of competitive crop genotypes. However no study has been carried out so far on the competitiveness of the Moroccan landraces toward weed stress. The identification of local populations with high competitive ability is a relevant approach responding to farmer's need and providing useful germplasm sources for breeders. The objective of the study is (1) to assess the genetic diversity of a collection of Moroccan faba bean populations and (2) to evaluate their competitive ability to weed stress. A set of 60 Moroccan local populations collected from Taounate province, and 2 checks (Aguadulce et Defez) which are commonly used cultivars, were (1) analyzed molecularly through Amplified Fragment Length Polymorphism (AFLP) markers based on four selective primer combinations to assess their genetic diversity and (2) tested under field conditions in four Environments to assess their competitive ability toward weeds. The trials were laid out as a split-plot design with two treatments (with and without weeds). The white mustard (Sinapis alba), a species related to wild mustard (Sinapis arvensis) which is a common weed of faba bean, was used as a model weed. AFLP analysis revealed a large diversity within the local populations $(82 \%)$ compared to the diversity between the local populations ( $18 \%$ ). Both levels of variation were significant. The analysis of variance showed that the differences between genotypes and treatments as well as their interactions were significant to highly significant for maturity, grain yield and grain yield components. Two indexes relative 
to yield loss (YL) and mean productivity (MP), were calculated based on grain yield to identify populations that combine both high competitive ability and high productivity. The populations were significantly different for both indexes. YL ranged from $8 \%$ to $81 \%$ with an average of $67 \%$, whereas MP ranged from $11 \mathrm{dt} / \mathrm{ha}$ to $31 \mathrm{dt} / \mathrm{ha}$ with an average of $19 \mathrm{dt} / \mathrm{ha}$. Aguadulce exhibited a MP of $21 \mathrm{dt} / \mathrm{ha}$ and a YL of $59 \%$, whereas Defez was less performing with a MP of $12 \mathrm{dt} / \mathrm{ha}$ and a $\mathrm{YL}$ of $69 \%$. A range of populations have proven to perform better regarding the indexes than the check cultivars. Two local populations exhibited a compromise with a low YL and a high MP. These local populations showing a high competitive ability are of interest for the farming systems where weeding practices are rarely or never applied. Keywords: Faba bean, Genetic diversity, Weed stress, Competitive ability.

\section{Sustainable Use of Halophytes for the Rehabilitation of Marginal Dry Areas in Morocco}

\section{Salma Daoud $^{1 *}$ and M. C. Harrouni ${ }^{2}$}

1 Faculty of Sciences, Ibn Zohr University, Agadir, Morocco; ${ }^{2}$ Hassan II Institute of Agronomy and Veterinary Medicine, Agadir, Morocco

\section{Abstract}

Salinity in the soil and water is a common feature in arid lands of Morocco. Moreover, population increase in these areas increases the pressure on fresh water resources which results in less supply for home use. These areas are still inhabited by people who are attached to their land and to their traditions. We present a survey of agriculture in some salt affected areas (coastal and inland) in Morocco focusing on adaptation to the constraints and opportunities of saline environments, as well as the potential for survival in the future. Some considerations for the identification and the evaluation of the capacity of these marginalised areas to cope with drought and salinity problems based on the capitalization of the local know knowledge and young human resources via appropriate valuing and training. This presentation also demonstrates the potential for the utilization of local and acclimated halophytic species by using a biosaline agriculture approach with the proposition of solutions for the restoration of biodiversity and productivity in salt affected areas in Morocco. Keywords: Morocco, arid lands, drought, salinity, local know-how, halophytes, traditional uses, young human resources, management, biodiversity, productivity.

\section{Biological Control of Bacteria Onion Diseases Using a Bac- terium, Pantoea agglomerans 2066-7}

El Hassan Achbani ${ }^{1 *}$, S. Sadik ${ }^{1,2}$, A. Bebouazza', and H. Mazouz ${ }^{2}$ ' La boratoire de Bactériologie Végétale et de Lutte Biologique, URPP, CRRA de Méknès (INRA), Morocco; ${ }^{2}$ Faculté des Sciences de Méknès, Morocco. *Presenting author: achbani105@gmail. com.

\section{Abstract}

Epiphytic microorganisms isolated from olive knots, apple fruits and trees, quince, compost and water from different areas were screened for antagonistic activity against Pseudomonas marginalis, Pseudomonas viridiflava, Xanthomonas retroflexus and Pantoea ananatis, bacteria recently reported on onion in Morocco. From 82 microorganisms tested for antagonistic properties against bacteria onion diseases, the strain Pantoea agglomerans 2066-7 was selected. This bacterium was very effective against Pseudomonas marginalis, Pseudomonas viridiflava, Xanthomonas retroflexus and Pantoea ananatis. Complete control at $106 \mathrm{CFU}$. ml- 1 was obtained on wounded onions bulbs inoculated with 105 CFU.ml-1 of Pseudomonas marginalis and Pseudomonas viridiflava. At 107 CFU.ml-1 Pantoea aggolomerans reduced Xanthomonas retroflexus and Pantoea ananatis decay by more than 90\%. Keywords: Onion, Pseudomonas marginalis, Pseudomonas viridiflava, Pantoae ananatis, Xanthomonas retroflexus, Biocontrol and Morocco.

\section{SESSION VIII. FOOD, HEALTH, AND NUTRI- TION}

Co-Chair: Jack Turman, Professor, Indiana State University, USA

Co-Chair: Karen Midden, Prof., Southern Illinois University, USA

\section{The Important Role of Nutrition in Early Brain and Behav- ior Development}

\section{Jack Turman Jr.}

Dept. of Applied Medicine and Rehabilitation, College of Health and Human Services Indiana State University, USA. "Presenting author: jackturman2@hotmail.com.

\section{Abstract}

The first 1000 days of life (from conception to the end of the second year of life) is a period of highly orchestrated brain development. The neural circuits that emerge during this period serve as the foundation for life long motor, cognitive, social, and emotional behaviors. Brain development during this period is dependent upon adequate nutrition, gene expression patterns, environmental conditions and early life experiences. The first objective of this presentation is to provide a brief overview of basic research studies that elucidate the role that macro and micronutrients play in the cellular processes that underlie brain development. The second objective to is to differentiate severe acute malnutrition, chronic undernutrition, iron deficiency and iodine deficiency, as all of these conditions serve as serious risk factors for altered brain development that results in poor motor, cognitive and emotional development. The third and final objective is to provide examples of strategies used to address these nutritional deficiencies. Interestingly, it is now observed that intervention strategies are often not replicated in other regions/ cultures different from their origin. Developing an innovative interdisciplinary framework to address these deficiencies in dif- 
ferent world regions is a global health priority. This presentation aims to stimulate creative discussions between neuroscientists, nutritionists, maternal and child health clinicians and agricultural scientists to design strategies that will successfully address nutritional deficiencies that continue to influence development of some Moroccan children.

\section{Closing the Nutritional Gap in Moroccan Maternal and Child Health through Home Gardening}

Karen Midden*, Professor, Associate Dean, Landscape Architect

College of Agricultural Sciences, Southern Illinois University, Carbondale, Illinois, USA.

\section{Abstract}

Gardens play a powerful role in the wellbeing of an individual and communities, if the opportunities are understood and utilized. Adults and children gain mental and physical benefits being outdoors, connecting with nature, gardening as well as including nutrient rich produce in their diets from their gardens (Louv, Kuo, Taylor, Mandel, Cobb, Simson and Straus). The powerful aspect of home gardening for urban or rural people is that the fresh healthy produce they grow can help close serious nutritional gaps leading to malnourishment or undernourishment. It is possible to address health issues generated from lack of specific nutrients by producing and consuming nutrient rich fruits and vegetables in home gardens. The World Bank data of 2008, emphasized that attention and changes are needed in Morocco to move towards the status of a developed nation and to provide greater health opportunities for children. The data found that $15 \%$ of infants in Morocco are born with a low birth weight, about $10 \%$ are wasted, $43 \%$ of those aged 15 and above are overweight or obese and $16 \%$ of children under the age of 5 are overweight (World Bank). UNICEF data for Morocco dating $2009-2013$ reported $15 \%$ of infants are born with low birth rates, $15 \%$ are stunted, $2 \%$ are wasted, $3 \%$ are underweight, $11 \%$ are overweight and there is an infant mortality rate of $18 \%$. The World Bank states that there is food insecurity that accompanies the malnourishment resulting in a majority of these problems. Vitamin A, folic acid and iron are 'fore-runner's in the deficiencies (World Bank). All three of these micronutrients are available in common fruits and vegetables that can be easily grown in an economical fashion in a home garden. However, it may be a challenge for the average small farmer or homeowner to have access to seeds that offer the highest value. This problem demands collaborate action to move a nation forward for improved health efforts. The demands include scientists who understand the physical and mental nutrient requirements for a healthy body. It requires scientists in agriculture, through inquiry and research, to provide plant seeds that will fulfill these nutrient needs. To disseminate this information and product, educators at various levels are necessary to be the link from the scientist to the public. The possibility of utilizing home gardening to empower the general public in Morocco, especially women and children, to close the nutritional gap is feasible and realistic with the efforts of scientists and educators.

\section{Seasonal Variations of Metallothioneins and Trace Metals in Edible Cockle Cerastoderma edule (L., 1758) in Two Lagoon Ecosystems (Khnifiss and Oualidia)}

Lefrere Latifa $^{1 *}$, Z. Idardare ${ }^{1}, \mathrm{H}$ Bergayou', C. Mouneyrac-Balocco $^{2}$, and A. Moukrim

' Laboratoire des "Systèmes Aquatiques : Milieu Marin et Continental ", Faculté des Sciences, Université Ibn Zohr, Agadir, Morocco; ${ }^{2}$ Equipe : "Mer Molécules Santé ", EA 2160 - Université de Nantes; Faculté des Sciences / MMS-UCO, Angers, France.

\section{Abstract}

The aim of this study is to evaluate the seasonal variation of metallothioneins (MTLP) and some trace metals in the edible cockle Cerastoderma edule (Mollusca, Bivalvia, Linnaeus, 1758) in two Moroccan lagoons, Oualidia (north) and Khnifiss (south). Our work also takes into account the correlations between MTLP and metals as well as the influence of some biotic and abiotic parameters on the metal contamination. The samples are taken on a monthly basis, at low tide, from April to January. Thirty individuals are taken for quantifying the amount MTLP, while fifty individuals are used to calculate the condition index and quantify trace metals in the whole individual. Significant high values of metallothioneins levels are observed in bivalves of Oualidia versus those of Khnifiss. For metals, the contents of $\mathrm{Cu}$ and $\mathrm{Zn}$ are also higher in bivalves of Oualidia.; the highest levels of $\mathrm{Cd}$ were recorded in molluscs of Khnifiss. Significant relationship exist between MTLP and metals (positive slope). For Cd, the MTLP has a high correlation with the metal insoluble fraction; while in the case of $\mathrm{Zn}$ and $\mathrm{Cu}$, the correlation with the MTLP is mainly linked to the metal in soluble fraction. The relationship between the biological (Condition index, MTLP) and physico-chemical parameters (Temperature, Salinity, $\mathrm{pH}, \mathrm{Cd}, \mathrm{Zn}, \mathrm{Cu}$ ) were performed by PCA. Two metals, $\mathrm{Cu}$ and $\mathrm{Zn}$, are significantly and negatively correlated with salinity, while they are significantly and positively correlated to MTLP levels. These two metals are also strongly positively correlated with each other. Furthermore, the $\mathrm{Cd}$ levels are significantly and positively correlated with the weight (Condition Index). MTLP, Cu and Zn are negatively correlated with weight in C. edule. Keywords: Bivalves, Cerastoderma edule, Metallothioneins, Moroccan Coasts, Metals, Lagoons. 


\section{SESSION IX. OLIVE TREE WORKSHOP}

Co-Chair: Ikram Blilou, Professor, Wageningen University \& Research, The Netherlands

Co-Chair: Ahmed Elamrani, University Mohamed I, Morocco

1. De Novo Sequencing Brings Insight into the Biology and Evolution of the Olive Tree Genome

Turgay Unver', Mine Turktas², Gabriel Dorado3, Pilar Hernan$\mathrm{dez}^{4}$, David A Lightfoot ${ }^{6}$, Pavan Kasarla ${ }^{5}$, Oussama Badad ${ }^{6,7}$, and Hassan Ghazal. International Olive Genome Consortium.

${ }^{1}$ Cankiri Karatekin University, Cankiri, Turkey; ${ }^{2}$ Cankiri Karatekin University, Cankiri, Turkey; ${ }^{3}$ Campus de Excelencia Internacional Agroalimentario (ceiA3), Universidad de Córdoba, Cordoba, Spain; ${ }^{4}$ Instituto de Agricultura Sostenible, Cordoba, Spain; ${ }^{5}$ Department of Plant, Soil and Agricultural Systems, Southern Illinois University, Carbondale, IL 62901, USA; ${ }^{6}$ Department of Plant, Soil and Agricultural Systems, Southern Illinois University, Carbondale, IL 62901, USA; ${ }^{7}$ Laboratory of Plant physiology, University Mohamed The Fifth , Rabat, Morocco; ${ }^{8}$ Laboratory of Biotechnology and Genetics, Faculty of Sciences, Mohamed First University, Oujda, Morocco. *Presenting author: oussama.badad@gmail.com.

\section{Abstract}

The olive tree (Olea europaea L.) is an economically-important fruit and oiltree. The olive tree is a diploid $(2 n=2 x=46)$, predominantly allogamous, and largely vegetatively propagated species. The genome was sequenced and assembled with $246 \mathrm{X}$ coverage. SOAPdenovo suite was used to assemble reads, which resulted in a draft genome of 1.48 Gbp with scaffold N50 of $228 \mathrm{kbp}$. A total of 42,843 scaffolds (>1 kbp) were assembled (1.14 Gbp). Using a newly-constructed genetic map, 50\% of the sequences were anchored onto 23 linkage groups, (572 Mbp). About $50 \%$ of the genome was composed of repetitive DNA. Transposable elements and interspersed repeats occupied $50 \%$ of the genome. Protein-encoding gene models were constructed. A total of 50,684 protein-encoding gene models were predicted, of which 31,245 were anchored. Heterozygosity was estimated to be about $1.3 \%$. A phylogenetic tree was constructed where the olive-tree clustered with oil-crop sesame (S. indicum L.). Genes involved in oil biosynthesis, fruit ripening, secondary metabolite synthesis and alternate fruit bearing were annotated. Small RNAs and transcription factor genes were annotated. The annotated genes were further analyzed to build a protein-protein interaction network map. The olive tree reference genome is available at the Olive genome browser (http:// h3abionet.fso.ump.ma/cgi-bin/gb2/gbrowse/olea_europea/), and will serve as a crucial source for the study of the olive genome, and fruit tree genomics. More effective olive tree breeding programs will be enabled.

\section{Integrated and Sustainable Management of the Olive Tree in the Gharb Region of Morocco}

\section{Nour Eddine Essafi*}

Regional Directorate of Agriculture, Kenitra, Ministry of Agriculture and Fisheries, Morocco

*Presenting author: essafi_n@yahoo.fr.

\section{Abstract}

In the Gharb region, the olive grove occupies about 30,000 ha, of which almost all ( $88 \%$ ) is located in the north area of Sidi Kacem province. The olive grove of Gharb is dominated by the variety "Picholine Marocaine" (92\%) mainly characterized by its adaptability to various soil and climatic conditions and olive qualities with dual purpose. The new strategy of the Green Morocco Plan (GMP) has given considerable importance to small farmers (Pillar II), which aims to upgrade agriculture solidarity, the fight against poverty and improve the standard of livelihoods. Approximately 250 beneficiaries working upon 350 ha are concerned by the Integration Project of Climate Change in the implementation of the Green Morocco Plan (PICCPMV) funded by the World Bank and the Global Environment. This project aims mainly the conversion of the perimeter with the lowyielding cereal, located in remote and marginal areas, which will be replaced by an orchard of olive tree. New agricultural technologies for adaptation to climate change enhance the resilience of the olive grove in respect of climate change. Furthermore, integrated management, variety, supplemental irrigation and inputs are considered priority and sustainable technologies that are considered as part of the Pillar II. These technologies have a positive environmental impact, resulting in a reduction of the effects of erosion, mitigating the effects of climate change and improving water efficiency by supplemental irrigation. Keywords: Climate change, Supplemental Irrigation, Olive tree, PICCPMV, Pillar II.

\section{Some Results of Morphological Characterization an Ag- ronomic Evaluation of the Main Olive Tree Varieties Investi- gated in Various Regions of Morocco}

\section{Oumkaltoum Krimi Benchegroun* and Lahcen Hssaini}

INRA Meknes, Morocco. "Presenting author: oumkaltoumkrimi@ yahoo.fr.

\section{Abstract}

In Morocco, the olive cultivation is vested with great socio-economic importance. Today, the area devoted to olive cultivation has gone beyond 1000000 ha, thus representing more than half of the national arboreal area. Furthermore, the Contract Program for the Development of the Olive cultivation section which was established by the Ministry of Agriculture and the Green Morocco Plan, in its 2015 edition, has fixed as one of its major objectives the extension of olive cultivation to an area 
of 1.220.000 ha by the year 2020. On the national scale, the olive cultivation is mostly carried out in a traditional mode. In such conditions, the average harvest per hectare, between $1 \mathrm{~T} /$ ha and $1.5 \mathrm{~T} /$ ha are neatly inferior to the real potential production. The realization of higher levels of production and exportation fixed by the Contract Program mentioned earlier calls for and necessitates a modernization of olive cultivation. In Spain, since 1986, the intensification of the production factors based on the use of performing and adapted varieties, the application of high densities, the drop by drop irrigation and the mechanization of the harvest which allows a substantial improvement, has made it possible to triple the quantity of the production between 1986 and 2003. In 2012, Spain has contributed, on its own, to $62 \%$ of the overall quantity of olive oil produced by the European Union. In Morocco, in terms of the research work which is being conducted by INRA on olive tree in various fields of experimentation, some national and international varieties of the latter have yielded higher levels of production which swing between 10T/ha and 17T/ha. Similarly, other specifications of agronomic interest have been spotted in some samples under investigation. The present communication aims to review some morphological characterization and evaluation results of agronomic performances of some national and international varieties of olive tree which have been studied in various experimentation fields and areas, the ultimate goal being to evaluate the degree of adaptation of these genetic resources to local pedo-climatic conditions. Keywords: Olive tree, varieties, pedo-climatic, performances, adaptation.

\section{Quality and Chemical Profiles of Monovarietal Olive Oils in Eastern Morocco}

Ahmed Elamrani ${ }^{1 *}$, Farid Mansouri', Marianne Sindic ${ }^{2}$, MarieLaure Fauconnier ${ }^{3}$, and Hana Serghini-Caid'

' Laboratoire de Biologie des Plantes et des Micro-Organismes, Faculté des Sciences, Université Mohamed ler Oujda; Morocco; ${ }^{2}$ Laboratoire Qualité et Sécurité des Produits Alimentaires, Gembloux Agro-Bio Tech, Université de Liège; Belgium; ${ }^{3}$ Laboratoire de Chimie générale et Organique, Gembloux Agro Bio-Tech, Université de Liége; Belgium. *Presenting author: ahmed.elamrani@gmail.com.

\section{Abstract}

Olive oil becomes the object of a considerable amount of research. There are numerous data on chemical-physical characteristics and olive oils quality, of various origins from different world's production areas, particularly Mediterranean countries. Paradoxically, very few data, on olive oil produced in the eastern Morocco. In this region, olive oil production is considered as an ancient activity, where old olive groves can still be observed, but recently monovarietal groves seem to be increasing and the olive cultivation is being improved by renewing old trees, reducing the association with other crops, selecting the olive varieties suited to local agro-climates and planting new single variety orchards. The extension of olive grove surface areas and improve- ment of olive oil quality (according to the great *Morocco's green plan) and this is leading to an increase in the prevalence of monovarietal olive oils. Thus, the monovarietal oils produced from the 'Arbequina', 'Arbosana' and 'Koroneiki' varieties, which have recently been introduced under intensive cultivation in the eastern Morocco, underwent physico-chemical characterization to determine quality criteria, natural antioxidant content, fatty acid composition and triacylglycerol profile. The Rancimat test was performed to assess the oxidative stability of these monovarietal oils and their blends to determine the storage stability and the best shelf life of the blends. Keywords: MonovarietalOlive oil, Arbequina, Arbosana, Koroneiki, Fatty acid, Triacylglycerol, Quality.

* The Olive Oil agro-industry is one of the most concerned sector by *Morocco's Green Plan (2010 - 2020) designed to promote the development of the entire agricultural and territorial potential and aims to meet new challenges facing Morocco's competitiveness and opening of markets. Thanks to "Maroc-Belgique cooperation" for supporting financially this applied research.

\section{SESSION X. AROMATIC, MEDICINAL, AND ECO- NOMIC PLANTS}

Chair: Alan Walters, Prof., Southern Illinois University, USA

\section{Determination of Fat and Sugar Contents in Carob Pulp from Wild and Domesticated Moroccan Trees}

Rababe Essoufi ${ }^{1}$, José Manuel Igartuburu², Zineb Neijar El Ansari $^{1 *}$, Brahim El Bouzdoudi ${ }^{1}$, Francisco Antonio Macias Dominguez ${ }^{2}$, José María Gonzalez Molinillo², and Ahmed Lamarti ${ }^{1}$

1 Laboratory of Plant Biotechnology, Department of Biology, Faculty of Sciences, Abdelmalek Essaadi University, M'hannech II, B.P.2121, Tetouan, Morocco; ${ }^{2}$ Cádiz Allelopathy Group (IN$\mathrm{BIO}$, ceiA3), Departamento de Química Orgánica, Facultad de Ciencias, Universidad de Cádiz, c/ República Saharaui, s/n, 11510 -Puerto Real, Cádiz, Spain. *Corresponding and presenting author: zinebnejiarelansari@hotmail.com.

\section{Abstract}

Ceratonia siliqua L. (carob tree) is a fruit and fodder tree which has potential to enhance soil conservation and rural development. This typical essence of Mediterranean flora has many socio-economic, ecological and industrial interests. In order to valorize the Moroccan carob, we have carried out a fat and sugar composition study on carob pods (pulp) of 12 wild trees and 8 domesticated ones from 15 different localities in Morocco. Fat content, identification and quantification of fatty acids on dry pods powder were determined after methylation by Gas Chromatography (GC), and Sugar content was studied through ion chromatography. Results show that fat content of carob pods from wild trees varies from $0.053 \%$ to $0.727 \%$, while it varies from $0.079 \%$ to $0.347 \%$ for domesticated ones. Analysis of fatty acids methyl esters by Gas Chromatography allowed identifying and quantifying 10 fatty acids on dry pod powder. Oleic 
acid (C18: $1 n-9 c)$ is the most abundant in all powder samples from wild and domesticated trees, except one wild tree whose most abundant fatty acid is palmitic acid (C16: 0$)$. The three most abundant fatty acids are oleic acid (C18: 1n9c), linoleic acid (C18: $2 \mathrm{nbc}$ ) and palmitic acid (C16:0). The most abundant saturated fatty acids are palmitic acid (from $8.57 \mathrm{mg} / 100 \mathrm{~g}$ of dry matter to $154.05 \mathrm{mg} / 100 \mathrm{~g}$ of dry matter) and stearic acid (C18: 0) (from $1.83 \mathrm{mg} / 100 \mathrm{~g}$ of dry matter to 38.52 $\mathrm{mg} / 100 \mathrm{~g}$ of dry matter. Oleic acid is the main unsaturated fatty acid in all the samples (from $8.6745 \mathrm{mg} / 100 \mathrm{~g}$ of dry matter to $291.56 \mathrm{mg} / 100 \mathrm{~g}$ of dry matter), followed by linoleic acid (from $1.36 \mathrm{mg} / 100 \mathrm{~g}$ of dry matter to $95.07 \mathrm{mg} / 100 \mathrm{~g}$ of dry matter). Results obtained for sugar composition show that carob pulp contains up to $40 \%$ of sugars, which are sucrose, glucose and fructose, identified and quantified by ion chromatography. Sucrose (non-reducing sugar) is the dominant sugar in the carob pulp, with content varying from 192.10 to $351.60 \mathrm{~g} /$ $\mathrm{kg}$ of dry matter for wild trees and from 159.16 to $312.67 \mathrm{~g} /$ $\mathrm{kg}$ of dry matter for domesticated ones, followed by reducing sugars: glucose and fructose. Glucose content varies from 3.92 to $81.34 \mathrm{~g} / \mathrm{kg}$ of dry matter for wild trees and from 3.57 to $36.03 \mathrm{~g} / \mathrm{kg}$ of dry matter for domesticated ones. Fructose content varies from 12.48 to $92.55 \mathrm{~g} / \mathrm{kg}$ of dry matter for wild trees and from 22.95 to $60.13 \mathrm{~g} / \mathrm{kg}$ of dry matter for domesticated ones. Keywords: Ceratonia siliqua L., Pod Powder, Gas Chromatography, Ion Chromatography, Fat, Fatty Acid, Sugar, Sucrose, Glucose, Fructose.

\section{In Vivo Wound Healing Potential and Identification of Bio- active Compounds from Pistacia lentiscus Leaves By HPLC- PDA-ESI-MS Detection}

Halima Saiah ${ }^{1,4^{*}}$, Rachida Allem ${ }^{1}$, Meriem Mokhtar ${ }^{2}$, Wassila Sa$\mathrm{iah}^{3}$, Fatima Zohra El Kebir ${ }^{4}$

1 Faculty of SNV, Department of Biology, University of Hassiba Ben Bouali, Chlef, Algeria; ${ }^{2}$ Laboratory of Beneficial Microorganisms, Functional Food and Health, Faculty of Natural Sciences and Life, University of Abdelhamid Ibn Badis, Mostaganem, Algeria; ${ }^{3}$ Department of biological sciences and physiology, Laboratory of bioenergetics and intermediary metabolism, University of Sciences and technology Houari Boumediene, Algiers, Algeria; ${ }^{4}$ Department of Biology, Faculty of Life and Natural Sciences, University of Oran I Ahmed Benbella, Oran, Algeria. *Presenting author: halimasaiahbio@yahoo.com.

\section{Abstract}

The present study was carried out to explore the in vivo wound healing potential of Algerian Pistacia lentiscus and to identify the active compounds that may be responsible for its action. Polyphenols were extracted with $80 \%$ methanol. A $10 \%$ ointment was made from methanol extract of $P$. lentiscus. Studies were performed on excision wound model using the test ointment. The healing potential was assessed by measuring wound contraction rate and hydroxyproline content. In addition, histological evaluations of full thickness wounds on the 16 th post wounding day were performed. HPLC-PAD-ESI-MS analyses were used for identification and confirmation of bioactive compounds. The test ointment-treated groups healed significantly faster, which was indicated by improved contraction rate $(93.45 \pm 3.08) \%$ in comparison to control group (73.12 $\pm 3.51 \%)$. Moreover, biochemical analyses revealed a significant increase in hydroxyproline contents of the ointment-treated wounds in comparison to control group. The results obtained from the histological evaluation indicated that ointment treatment of wounds promotes the process of wound healing by influencing fibroblasts proliferation, collagen synthesis and deposition and enhancing the rate of reepithelialisation. The HPLC-PDA-ESI-MS studies revealed the presence of Catechin as a major compound. This study had demonstrated that the methanol extract promoted the acceleration of the healing process when compared to the control group. This might be due to the combined effect of the constituents present in the extract. Keywords: Pistacia lentiscus, Polyphenols, Wound healing, HPLC-PDA-ESI-MS.

\section{Biological Activities of Thymus leptobotrys and Thymus satu- reioides, two Moroccan Aromatic and Medicinal Plants}

Abdellah El Hamdaoui ${ }^{1,2^{*}}$, Asmaa Bouglad ${ }^{1,2}$, Fouad Msanda', Abdellah Ait Ben Aoumar ${ }^{2}$, Hassan Boubaker ${ }^{2}$, Yassine El Maati ${ }^{1}$, Abdelkhaleq El Moslih 1,2,3, Fouad Achemchem ${ }^{3}$, El Hassan Boudy$\mathrm{ach}^{2}$, and Abdelhamid El Mousadik'

' Laboratoire de Biotechnologies et Valorisation des Ressources Naturelles, Faculté des Sciences, Agadir, Morocco; ${ }^{2}$ Laboratoire de Biotechnologies Microbiennes et Protection des Végétaux, Faculté des Sciences, Agadir, Morocco; ${ }^{3}$ Laboratoire des Sciences de l'Ingénieur et le Management de l'Energie, EST, Agadir, Morocco. *Presenting author: hmd_abdl@hotmail.com.

\section{Abstract}

In the last decades, the essential oils and various extracts of plants have been of great interest as they have been the sources of natural products. The antimicrobial activities of essential oils and plant extracts constitute the basis of many applications, including food preservation, pharmaceuticals, alternative medicine and natural therapies. The Moroccan flora has more than 7000 species and subspecies among which approximately 800 are aromatic and medicinal plants. These plants are a potential source of natural bioactive molecules and can contribute to the economic development of rural populations. Essential oils of Thymus species are classified among the most powerful substances due to their strong antimicrobial activity, particularly against pathogenic microorganisms resistant to antibiotics. Thus, the aim of this study was to evaluate the antioxidant, insecticidal and antibacterial activities of essential oils of two Moroccan aromatic herbs, Thymus leptobotrys and Thymus satureioides. The DPPH radical scavenging ability and Power reducing assay were used to evaluate the antioxidant activity of essential oils. While, the agar disc diffusion assay and broth macro-dilution method were employed for the determination of antibacterial activity against six bacteria, namely Listeria innocua (CECT 4030), Lis- 
teria monocytogenes (CECT 4032), Staphylococcus aureus (CECT 976), Bacillus subtilis (DSM 6633), Proteus vulgaris (CECT 484) and Pseudomonas aeruginosa (CECT 118). The results showed that Thymus leptobotrys oil was found the most active one as antioxidant product with an IC50 value of $0.148 \mathrm{mg} / \mathrm{ml}$ for DPPH assay and $0.023 \mathrm{mg} / \mathrm{ml}$ for Power reducing assay. Concerning antibacterial activities, results showed that both oils inhibited growth of all the tested bacteria with minimal inhibition concentration (MIC) and minimal bactericide concentration (MBC) lower than $2 \mathrm{mg} / \mathrm{ml}$. Both oils showed a moderate insecticidal activity against Tribolium castaneum. Keywords: Essential oil, aromatic and medicinal plants, biological activity, antioxidant activity, insecticidal activity, antibacterial activity.

\section{SESSION XI. US-MOROCCO RESEARCH AND HIGHER EDUCATION COLLABORATION}

\section{Co-Chair: Khalid Meksem, Southern Illinois University, USA \\ Co-Chair: James Miller, MACECE, Morocco}

\section{Undergraduate and Graduate Studies in the US}

\section{My Abdelmaiid Kassem*}

Plant Genetics, Genomics, and Biotechnology Lab, Dept. of Biological Sciences, Fayetteville State University, NC, USA. *Presenting author: mkassem@uncfsu.edu.

\section{Abstract}

In this presentation, I will discuss undergraduate and graduate studies in the US and opportunities for Moroccan students to attend US institutions of higher education including community colleges, four-year colleges, and universities. Emphasis will be on the graduate school and the cost of attending as an international student including tuition, room and board, and additional expenses will be discussed with detailed examples from several US institutions. Opportunities for scholarships, work study, and other financial aid opportunities will also be discussed.

\section{The Graduate School Opportunities at Southern Illinois University, United States}

Karen Midden", Professor, Associate Dean, Landscape Architect

College of Agricultural Sciences, Southern Illinois University, Carbondale, Illinois, USA

\section{Abstract}

Southern Illinois University (SIU) Graduate School has a commitment to enhance advanced education through high quality instruction, experience and research for students. SIU is ranked by the Carnegie Foundation as being in the top 5\% of all higher education research institutions in the United States, a ranking that must be earned and maintained through quality research and grantsmanship. The Graduate School offers master's de- grees in over sixty programs and the doctoral degree in over thirty programs. Graduate students are fortunate to study and research under the leadership of graduate faculty as they pursue advanced study leading to outstanding careers. There are ten colleges with programs and numerous departments within the colleges, one of which is The College of Agricultural Sciences. This college houses four departments with many disciplines within each department and they work collaboratively with outside departments. This presentation will provide general information about SIU, the Graduate School, requirements and opportunities to apply, study and research at SIU. An overview of the colleges will be provided with more specific focus on the faculty, areas of study and highlights of past graduates of the College of Agricultural Sciences Graduate Program.

\section{My Life Experiences in the USA}

\section{Oussama Badad $^{*}$}

Laboratory of Biotechnology and Genetics, Faculty of Sciences, Mohamed First University, Oujda, Morocco. "Presenting author: oussama.badad@gmail.com.

\section{Abstract}

Far beyond the scientific exchange, the Fulbright experience is a cultural crossroad between the United States of America and the Kingdom of Morocco. The Moroccan students are not only research fellows they are also young ambassadors of the Moroccan history and culture. The Fulbright social experience was about discovering and melting into a new culture with all its components: the people, the food the music, and all the traditions. Travelling north, south east and west to more the 20 states in 12 months while still doing great research, visiting the most significant places in the history of the US: capitols, white house(s), Museums, battle fields, cemeteries and music studios. This experience revealed some sides of my personality that I have never seen before brought joy and tears but made me the person I am today.

\section{The Moroccan American Commission for Educational \& Cultural Exchange (MACECE) Mission}

James Miller

MACECE, Rabat, Morocco

\section{Abstract}

Not provided.

\section{Fifty Years of IAV in Morocco}

Mohamed Bouklikhane

IAV Hassan II, Rabat, Morocco 
Abstract

Not provided.

6. Networking and Opportunuities

Khalid Meksem

Southern Illinois University, USA

Abstract

Not provided. 
POSTER PRESENTATIONS ABSTRACTS

WEDNESDAY \& THURSDAY

DECEMBER 14 \& 15, 2016

Poster \# 001. Isolation and Identification of Entomopathogenic Fungi of the Mediterranean Fruit Fly (Ceratitis capitata)

Ayoub Hallouti ${ }^{1}$, Hicham Karim ${ }^{1}$, Abdelaziz Zahidi ${ }^{2}$, Abdelhamid El Mousadik ${ }^{2}$, Abdellah Ait Ben Aoumar', and Hassan Boubaker $^{1}$

' Laboratory of Microbial Biotechnologies and Plant Protection, Department of biologie, Ibn Zohr University, Faculty of Sciences, PO Box 8106, Agadir, Morocco ; ${ }^{2}$ Laboratory of Biotechnology and Valorisation of Natural Resources, Department of biologie, Ibn Zohr University, Faculty of Science, PO Box 8106, Agadir, Morocco. ${ }^{*}$ Corresponding author: Department of biologie, Ibn Zohr University, Faculty of Sciences, Agadir, Morocco. "Presenting author: hallouti.ayoub@gmail.com.

\section{Abstract}

This work forms part of biological control against crop pests and has the objectives of search, isolation and identification of entomopathogenic fungi and the assessment of their pathogenic power against the Mediterranean fruit fly (Ceratitis capitata). Search, isolation and estimation of the abundance of entomopathogenic fungi were carried out on soil samples of Argania spinosa forests and citrus orchards. To trap the insect pathogenic soil fungi, we adopted the technique of using larvae of the fruit fly (Ceratitis capitata) as baits. The resulting fungal isolates are identified, based on macroscopic and microscopic criteria. After trapping, isolation and identification of fungal strains, a pathogenicity tests were used to select several fungal strains that have significant pathogenic powers against the Mediterranean fruit fly. The degree of virulence was estimated based on the ability of the fungus to induce the disease and / or death in the insect and also by calculating the lethal time 50 (LT50). The results obtained demonstrated clearly the sensitivity of medfly of the different treatments tested and particularly to strains of Aspergillus niger and Epicoccum sp that have shown high mortality rates (more than $84 \%$ ) and strains of Fusarium sp, Trichoderma harzianum of Scedosporium sp. and Ulocladium sp with more than $70 \%$ of mortality. Furthermore these strains showed short LT50 (less than 83 hours). All these results confirm firstly the presence of insect pathogenic fungi of the fruit fly Ceratitis capitata in the argan and citrus orchards soil, and prove at secondly the potential of insect pathogenic fungi in the fight against this pest. Keywords: Biological control, Ceratitis capitata, entomopathogenic fungi, citrus, Argania spinosa.
Poster \#002. Lipid Peroxidation of Argania spinosa Selected Lines Tolerant to Salt and Water Stress

Mouna Lamaoui', Imane Ben Salah ${ }^{1}$, Raja Benlaouane', Abdelghani Chakhchar', Abderrahim Ferradous ${ }^{3}$, Said Wahbi ${ }^{2}$, Abdelhamid El Mousadik ${ }^{4}$, Saâd Ibnsouda Koraichi ${ }^{5}$, Abdelkarim Filali-Maltouf', and Cherkaoui El Modafar ${ }^{1}$

' Laboratoire de Biotechnologie Valorisation et Protection des Agroressources, Faculté des Sciences et Techniques Guéliz, Université Cadi Ayyad, 40000 Marrakech, Morocco; ${ }^{2}$ Laboratoire de Physiologie Végétale, Faculté des Sciences Semlalia, Université Cadi Ayyad, 40000 Marrakech, Morocco; ${ }^{3}$ Centre Régional de la Recherche Forestière Marrakech. BP 12360 Ain Itti Ennakhil, Marrakech, Morocco; ${ }^{4}$ Laboratoire de Biotechnologie et Valorisation des Ressources Naturelles. Faculté des Sciences, Université Ibn Zohr. Agadir, Morocco; 5 Laboratoire de Biotechnologie Microbienne. Faculté des Sciences et Techniques. Université Sidi Mohamed Ben Abdellah. Fès, Morocco; 6 Laboratoire de Microbiologie et Biologie Moléculaire. Faculté des Sciences. Université Mohammed V Agdal. Rabat, Morocco. *Presenting author: mounalamaovi@gmail.com.

\section{Abstract}

Lipids play an important role as the structural constituent of most of the cellular membranes. It is well known that free radicalinduced peroxidation of lipid membrane is a sign of stress induced damage at cellular level. Therefore, the level of malondialdehyde (MDA), produced during peroxidation of membrane lipids, is often used as an indicator of oxidative damage. Argania spinosa (L.) callus tolerant to water and salt stress were selected. The effect of the procedure of selection followed on the levels of hydrogen peroxide $\left(\mathrm{H}_{2} \mathrm{O} 2\right)$ and the degrees of the oxidative damage to the membrane lipids were examined. Analysis indicated that selected calli for both salt and water stresses maintained high levels of $\mathrm{H} 2 \mathrm{O} 2$ compared to the nonselected calli while the differences in the content of malondialdehyde (MDA) was insignificant. Which indicates the lower level of oxidative damage caused after the selection procedure and the mobility of antioxidant system activity in order to limit cellular damages. Keywords: Argania spinosa, Callogenesis, salt stress, water stress, hydrogen peroxide, malondialdehyde, lipid peroxidation. This work is supported by the Hassan II Academy of Science and Technology and the Ministry of Higher Education and Scientific Research (Morocco).

\section{Poster \#003. Anti-Stress Molecules in Plants}

$\underline{\text { Saadia Karbou }}^{1,2,3^{*}}$, Y. El Bahloul ${ }^{2}$, B. Benaji ${ }^{3}$, M. Bouksaim ${ }^{2}$, and M. Taoudi Benchekroun'

1 FSAC, Université Hassan II, Casablanca, Morocco; 2 INRA, CRRA, Rabat, Morocco; ${ }^{3}$ ENSET, Rabat, Morocco. "Presenting author: skarbou@gmail.com. 


\section{Abstract}

For the adaptation to climate change, it is now essential to find new sources for food security mostly with the rapid growth of the world population. In the extreme conditions for life on earth, certain vegetal species presents a great capacity for survival in the arid climate and the Sahara. This property attracts the curiosities of the scientific world to study the biological mechanisms involved in this survival power. Our work will try the identify and analyze the biological molecules involved in one of the metabolic pathways of one of these species, argan which plays an essential role both in the adaptation and the product yield of this plant species. This research will help in defining the molecules involved in stress resistance in arid climates. Keywords: Antistress molecule, biological mechanisms, Resistance, Adaptation.

\section{Poster \#004. Pheophytinization of Chlorophyll in Argan Tree Under Drought Stress}

Abdelghani Chakhchar', Mouna Lamaoui', Imane Ben Salah'", Salama Aissam', Abderrahim Ferradous ${ }^{3}$, Said Wahbi ${ }^{2}$, Abdelhamid El Mousadik ${ }^{4}$, Saâd Ibnsouda Koraichi ${ }^{5}$, Abdelkarim Filali-Maltouf ${ }^{6}$, and Cherkaoui El Modafar ${ }^{1}$

' Laboratoire de Biotechnologie Valorisation et Protection des Agroressources, Faculté des Sciences et Techniques Guéliz, Université Cadi Ayad, 40000 Marrakech, Morocco; ${ }^{2}$ Laboratoire de Physiologie Végétale, Faculté des Sciences Semlalia, Université Cadi Ayyad, 40000 Marrakech, Morocco; ${ }^{3}$ Centre Régional de la Recherche Forestière Marrakech. BP 12360 Ain IttiEnnakhil, Marrakech, Morocco; ${ }^{4}$ Laboratoire de Biotechnologie et Valorisation des Ressources Naturelles. Faculté des Sciences, Université Ibn Zohr. Agadir, Morocco; ${ }^{5}$ Laboratoire de Biotechnologie Microbienne. Faculté des Sciences et Techniques. Université Sidi Mohamed Ben Abdellah. Fès, Morocco; ${ }^{6}$ Laboratoire de Microbiologie et Biologie Moléculaire. Faculté des Sciences. Université Mohammed V Agdal. Rabat, Morocco. "Presenting author: bensalah.imane7@gmail.com. 'Corresponding author: chakhchar.ckr@gmail.com.

\section{Abstract}

The objective of this study was undertaken to characterize the pigment composition and to quantify the degradation of chlorophyll in the Argan tree under drought conditions. Two-year old plants taken from contrasting ecotypes were exposed to three different irrigation regimes during two months. The concentration of anthocyanin and pheophytin increased significantly in all ecotypes under drought stress $(\mathrm{P}<0.001)$. However, the $\mathrm{Chl} \mathrm{a/b}$ ratio has decreased as the drought stress increased. In fact, our results showed high increase in percentage of pheophytinised chlorophyll suggesting that drought stress destabilize the chloroplastic pigment-protein complexes, rendering the chlorophyll susceptible to pheophytinization. The drought stress probably caused membrane disorganization in Argan tree and enhanced membrane permeability, which led to a kind of cascade reaction resulting in a lower $\mathrm{pH}$ and promoting pheophytinization.
Intra-specific differences were observed in pigment composition among Argan tree ecotypes studied. According to Three-way ANOVA analysis, a significant ecotype $x$ watering regime $x$ time interaction was recorded for the anthocyanin and pheophytin contents $(P<0.05)$. Keywords: Argan tree, drought stress, pheophytin, anthocyanin.

*** This work is supported by the Hassan II Academy of Science and Technology and the Ministry of Higher Education and Scientific Research (Morocco).

Poster \#005. Evaluating the eating behavior of Type 1 Diabetic patients receiving Functional Insulin Therapy in the Endocrinology Department of ERRAZI Hospital - UH Med VI Marrakesh

Asma Oouzaka ${ }^{1 *}$, Nawal El Ansari', Nabil Layachi², and Ghizlane El Mghari Tabib3

1 Head of the Endocrinology Department, UH Med VI, Marrakech, Morocco; ${ }^{2}$ UH IBN SINA, Rabat, Morocco; ${ }^{3}$ Endocrinology Department - UH Med VI, Marrakech, Morocco.

\section{Abstract}

Functional Insulin Therapy (FIT) is a therapeutic educational method that helps ameliorate the glycemic control; it frees TID patients from treatment constraints and improves their life quality. This study aims at evaluating the eating behavior of T1D patients receiving FIT, changes in metabolic parameters, and the frequency of hypoglycemia. This is an observational study conducted in the Endocrinology Department of the University Hospital Med VI in Marrakech. It covered 20 TID patients receiving FIT $160 \%$ women/ $40 \%$ men; $75 \%$ between 19 and 37 years old; $60 \%$ of all the cases have had TID for or less than 5 years / $40 \%$ for more than 5 years; $\mathrm{HbAlc}$ initial average : $9( \pm 2.05 \%)$. Concerning metabolic data: the frequency of hypoglycemia has decreased; $67 \%$ among the cases who had one session per month. A considerable modification is also noticed in the $\mathrm{HbAlc} ; 3$ months after FIT, HbAlc Average: 8.24 ( $\pm 1.47 \%$ ) and 6 months after FIT, HbAlc Average: 7.47 ( $\pm 0.8 \%$ ). Concerning nutritional evaluation, $1 / 2$ of the participants of the current study have BMI $>25 \mathrm{~kg} / \mathrm{m}^{2}$ vs BMI Average: $24 \mathrm{~kg} / \mathrm{m}^{2}$. Current weight average: $69( \pm 9 \mathrm{~kg})$ vs ideal weight average 61.4 $( \pm 6.61 \mathrm{~kg}$ ). Total Energy Intake Average 2830 ( $\pm 80.35 \mathrm{kcal} /$ day) vs Energetic Needs Average: 2550 ( $\pm 394.03 \mathrm{kcal} /$ day). Concerning life quality, $100 \%$ of T1D patients receiving FIT are pleased to have participated in the FIT as they have adapted their diet to fit their lifestyle. It is noticed that life quality of T1D patients receiving FIT has improved. Thanks to this method, TID patients could consume food said to be "forbidden" for them earlier without any deterioration at the level of the glycemic control. In the end, TID patients have truly become actors in their own health. 
Poster \#006. Chemical Tests for Available Soil Phosphorus

Nora Chaouqi $^{1,2^{*}}$, M. El Gharous ${ }^{2}$, Z. Naceri ${ }^{3}$, and M. Bouzziri ${ }^{1}$

1 Laboratory of Applied Chemistry and Environment, Faculty of Sciences and Techniques, University Hassan 1st, Settat, Moroc$\mathrm{CO}^{2}{ }^{2}$ INRA, Regional Center for Agricultural Research, Settat, Morocco; ${ }^{3}$ Phosphorus-Morocco, Safi-Direction. Quality Control Department, Safl, Morocco. *Presenting author: nora.chaouqi@ gmail.com.

\section{Abstract}

The research goal was to develop a simplified method for estimating the available phosphorus for routine analysis. This study compared the measured Soil-P using the ICP-NaHCO3 with the simplified extraction method (SM-P). The correlation $(r=0.99)$ and the regression(using xlstat-pro) were employed for comparing the data of available phosphorus content in soil samples for a variety of Moroccan soil types, with contrasted physicochemical characteristics: Ali Moumen, Oued Qibane, Ouled Said, Settat, Dower Lhfaya, and Had Ghoualem (are located using ArcGIS 10.1 and fertiMap). SM-P is most suited for soils with $\mathrm{pH}>=$ 7 and $\mathrm{CaCO} 3$ content above $5 \%$. In this experiment, several parameters are modified, the fineness, the type and degree of mechanical agitation, the color development solution $(2.5 \%$ (NH4)6Mo7O24.4H2O, in 5 mol.l- 1 H2SO4), $1 \%(w / v)$ ascorbic acid solution), and the adaptation of the reading at $860 \mathrm{~nm}$. The accuracy of $\mathrm{P}$ analysis was insured, and the high correla-

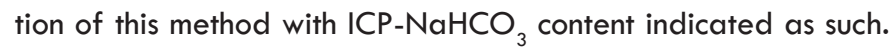
The results of this experiment showed that SM-P can be the best method for predicting the available phosphorus, simple, quick, and easy to execute. Keywords: Fertilizer Phosphate, Extraction Methods, Available Phosphorus, Moroccan Soils

Poster \#007. Micropropagation of Thymus broussonetii Boiss., Threatened Medicianl and Aromatic Plant in Morocco

Zineb Neijar El Ansari, Brahim El Bouzdoudi", Rajae Benkaddour, Ibtissam Boussaoudi, and Ahmed Lamarti

Laboratory of Plant Biotechnology, Department of Biology, Faculty of Sciences, Abdelmalek Essaadi University, M'hannech II, B.P.21 21, Tetouan, Morocco. * Corresponding and presenting author: bchiri2008@gmail.com.

\section{Abstract}

Within the Labiate family, there are about 220 genera, and the genus Thymus is one of the eight most important genera with regard to the number of species included, although this number varies depending on the taxonomical point of view. In Morocco, 15 species of this genus have been identified. These are rare, endemic and endangered species. Indeed, people used intensively and exploited haphazardly thyme populations. Moreover, the interests of the pharmaceutical and food industries focus on specific chemotypes especially thymol. In such a situ- ation, cultivated thyme represent an indispensable alternative, via the selection of endangered species and the implementation of culture techniques under modified environmental conditions (ex vitro culture) or controlled conditions in laboratories (in vitro culture). In vitro vegetative multiplication is a good method for reproduction of genotypes and selected chemotypes of certain species. Plants cultivated in vitro can be used for many purposes and then collection from their natural shelters could be avoided, also, model systems to study the production and accumulation of metabolites with a great interest could be developed. The present study reports an efficient protocol for in vitro clonal propagation of Thymus broussonetii Boiss., threatened medicinal and aromatic plant in Morocco. Initially, seeds collected from wild plants were used for in vitro culture establishment on Gautheret basal salts medium without plant growth regulators. Then, aseptic and living explants were transferred to Shah and Dalal medium for culture multiplication. Afterwards, we have selected one stable clone (the longest one) and we have evaluated the effect of six macronutrients. After that, seven cytokinins in different concentrations have been evaluated. Moreover, the effect of three polyamines has been investigated. Thereby, seeds germination started from the fourth day with a survival rate of 24-28\%. Furthermore, Margara medium has been proved the most favorable for plantlets growing. Higher number of buds (24.083 \pm 1.401$)$ was obtained on Maragara medium supplemented with $0.93 \mu \mathrm{M}$ of DPU, it also ensures good shoot multiplication with an average number of $1.833 \pm 0.177$ and good root development with an average number of $8.208 \pm 0.942$ and a length of $1.254 \pm 0.085 \mathrm{~cm}$. Also, $5 \mu \mathrm{M}$ of Spermine gives higher number of buds (26.833 \pm 1.789$)$, a good shoot multiplication (1.958 \pm 0.153 ) and a good root development (an average number of $8.917 \pm 0.782$ and a length of $1.821 \pm 0.120$ $\mathrm{cm})$. Plantlets with well developed roots were successfully acclimatized to ex vitro conditions and an in vitro propagation was again established from the acclimatized and well grown plants. The in vitro culture system successfully established for Thymus broussonetii Boiss. offers a viable tool for mass micropropagation and conservation of this very threatened species. Keywords: Medicinal and Aromatic Plants, Thymus broussonetii, Micropropagation, Cytokinins, Polyamines.

\section{Poster \#008. Artificial Regeneration of Cork Oak: Difference of Root System}

$\underline{B t i s s a m e ~ B o u t h e r ~}^{1,2^{*}}$, Y. Abbas ${ }^{3}$, M. El Ouajdi ${ }^{2}$, and M. Arahou'

1 Faculty of science of Rabat, university Mohamed V, Rabat, Morocco; ${ }^{2}$ Forest Research Centre Rabat, Morocco; ${ }^{3}$ Faculty of science of Beni-Mellal, Morocco. *Presenting author: bouther. btissame@gmail.com.

\section{Abstract}

Nature is a source of life and survival condition but the man who lived in communion with nature has become a danger for it. He recognizes its value since the rift which was created between him and his environment by the industrialization and the 
multiple aggressions. Since the beginning of the 20th century, the regeneration of cork oak has always been a problematic in the forest of Maâmora. Despite of all efforts to the preservation and conservation of the forest, ecosystems were constantly degraded over time. Several tests of regeneration have been initiated in recent decades by acorn or by plant. Although less studied than the aerial parts, the root system of the cork oak has been the work of the Forest Research Centre (FRC Rabat). If successful plantation is based first and foremost on the choice of species and genetic origins adapted to the plot to restore the quality of introduced plants also influences the recovery of plantations, in this context, our study is based on the production of plants of Cork oak from different origins and to compare between them which is the most adapted and resistant for the climate change. Also, we wanted to study the root system and see the differences between the origins of Cork oak. Keywords: Cork oak, root system, climate change, ecosystem, Maâmora, artificial regeneration.

Poster \#009. Synthesis and Characterization of Acrylonitrile and Polyacrylic Acid Membranes for the Water Treatment Equipment

\section{Ely Cheikh Mahmoud*}

Laboratory of Water and Environment, Dept. of Chemistry, Faculty of Sciences, Chouaib Doukkali University, El-Jadida, Morocco. *Presenting author: cheikhatti@gmail.com.

\section{Abstract}

Today, water sources are overused and poorly protected in many parts of the world. Demography and human activity provide increase in water demand while misuse of water resources can also alter availability of clean water. Membrane processes are increasingly used in environmental protection including the production of drinking water and medical applications. Here we present a simple and effective method for the manufacture of ion exchange ultrafiltration membranes for removal of water pollutants. For synthesis of membranes, poly acrylonitrile (AN69) and poly acid acrylic (PAA) were dissociated separately in the solvent $\mathrm{N}, \mathrm{N}$-diméthylformamid (DMF), and mixed in a known portion. After the two polymers are blended, poured films are then placed on a glass plate and brought to defined temperature and duration. The FTIR spectrum of the membrane AN69 / PAA shows a band at $1683 \mathrm{~cm}^{-1}$ that can be assigned to the vibration of the $\mathrm{CO}$ group indicating the presence of PAA and a peak very end to $2239 \mathrm{~cm}^{-1}$. This shows the presence function $\mathrm{CN}$ in structure of AN69, the spectrum also rose moderately broadband in $1174 \mathrm{~cm}^{-1}$ which correspond to the groups asymmetrical sulfonate SO3Na. Later we will study the morphology of the membranes using SEM and OM.
Poster \#010. Production of Saffron Corms (Crocus sativus L., Iridaceae) by In Vitro Culture

Rajae Benkaddour ${ }^{*}$, Amal Rahmouni', Mounira Lage ${ }^{2}$, and Ahmed Lamart ${ }^{1}$

1 Laboratory of Plant Biotechnology, Department of Biology, Faculty of Sciences, Abdelmalek Essaadi University, M'hannech II, B.P.2121, Tetouan, Morocco; ${ }^{2}$ Department of Plant Breeding and Laboratory of Physiology (INRA), BP. 415, Avenue la Victoire, Rabat, Morocco. "Presenting author: Benkaddourrajae27@gmail.com.

\section{Abstract}

Our purpose is to produce on a large scale of viable Saffron microcorms to meet the needs farmers. We tested a cytokinin (kinetin) in three concentrations $(6,9$ and $12 \mathrm{mg} / \mathrm{I})$ and an auxin (2 4dichlorophenoxyacetic acid, $24-\mathrm{D}$ ) at $0.1 \mathrm{mg} / \mathrm{I}$ on the direct production of microcorms within slices after 6 months of culture. In the darkness, explants react to $100 \%$, but to the light, this percentage decreases in $52 \%$ (for $6 \mathrm{mg} / \mathrm{l}$ of Kinetin) and in $92 \%$ (for $12 \mathrm{mg} / \mathrm{l}$ of Kinetin). The number of microcorms formed by explant is not influenced by the dose of the Kinetin; it is one for explant cultivated in the light and of two for those placed in the darkness. The diameter of microcorm is maximal in the darkness $(14.6 \pm 1.21 \mathrm{~mm})$ in the presence of $12 \mathrm{mg} / \mathrm{l}$ of $\mathrm{Ki}$ netin. However, it is minimal in the light $(6.9 \pm 0.4 \mathrm{~mm})$. The combination of two other plant regulators, 2,4-D in $0.1 \mathrm{mg} / \mathrm{l}$ and BA with various concentrations $(6,9$, and $12 \mathrm{mg} / \mathrm{I})$ does not lead formation of microcorm in the light $(0 \%)$. But, the explants placed in the darkness are $100 \%$ reactive and form a single microcorm of diameter between $2.8 \pm 0.71 \mathrm{~mm}$ (BA in $6 \mathrm{mg} / \mathrm{l}$ ) and $3.8 \pm 1.03 \mathrm{~mm}$ (BA in $12 \mathrm{mg} / \mathrm{l})$. Lastly, microcorms were grown in a hydroponic room (photoperiod 16 hours light / 8 hours darkness; $25^{\circ} \mathrm{C}$ ), and after 5 weeks, $100 \%$ of microcorms germinated. Keywords: Saffron, Crocus sativus L., corm production, tissu culture.

Poster \#01 1. In Vitro Inhibitory Effect of Fungicides Against Colletotrichum acutatum, the Causing Agent of Strawberry Anthracnose

Rababe Es-Soufi", Mohamed L'bachir El Kbiach, and Ahmed Lamarti

Laboratory of Plant Biotechnology, Department of Biology, Faculty of Sciences, Abdelmalek Essaadi University, M'hannech II, B.P.21 21, Tetouan, Morocco.

\section{Abstract}

Anthracnose is one of the most important strawberry (Fragaria $x$ ananassa Duch.) diseases and can be a limiting factor for cultivation, because of its devastating nature, the sensitivity of cultivars and little available control. Since 2012, three fungicides Basultra, Thiramchim and Thiramic (based on Thiram) were 
approved for agricultural use by ONSSA (Database, approval of chemical inputs). To prevent this disease, farmers in Loukous area use a product based on copper (Bordeaux Caffaro) as a plant protector. The aim of this study is to determine the impact of these fungicides on the different stages of the development of Colletotrichum acutatum. C. acutatum has been collected from strawberries attacked with anthracnose and purified in laboratory of plant biotechnology in the faculty of sciences of Tetouan. The study of the inhibitory effect of the fungicides cited above against Colletotrichum acutatum has shown that the Thiram has a big effectiveness on germination and moderately effective on mycelial growth and sporulation. Copper has shown effectiveness on germination as variable activity in other life stages. Keywords: Strawberry antracnose, Fungicides, Thiram, Colletotrichum acutatum, Inhibitory effect.

Poster \#012. Determination of Total Polyphenols and Gallic Acid Content in Carob Pulp

lbtissam Boussaoudi", Brahim El Bouzdoudi, and Ahmed Lamarti

Laboratory of Plant Biotechnology, Department of Biology, Faculty of Sciences, Abdelmalek Essaadi University, M'hannech II, B.P. 2121 , Tetouan, Morocco. *Presenting author: ibtissam.boussaoudi@gmail.com.

\section{Abstract}

Extraction effeciency of total polyphenols (TP) of carob pods (Ceratonia siliqua L., Leguminosae family) was examinated by performing extractions with various solvent systems, in order to evaluate and optimize the conditions for the recovery of polyphenols. Maximum quantities of polyphenolic components were found in $80 \%$ acetone extracts. By contrast, water was inefficient in extracting polyphanols. Total polyphenol compounds were identified with a yield of $11.19 \mathrm{~g} / \mathrm{kg}$ (dry weight) as evaluated by measuring total polyphenol content using the Folin-Ciocalteu method. The profile was dominated by gallic acid $(45.01 \%$ of polyphenols by dry weight). Carob leaves and the diffrent parts of fruits were also analyzed for their total polyphenols and gallic acid content using HPLC. It was presumed that the leaves contain high values of phenolic compounds and gallic acid (45.26 $\mathrm{g} / \mathrm{kg}$ and $17.012 \mathrm{~g} / \mathrm{kg}$, respectively. Tegument contained appreciable amounts of polyphenols and gallic acid $(26.30 \mathrm{~g} / \mathrm{kg}$ and $2.512 \mathrm{~g} / \mathrm{kg}$ of gallic acid), while only traces were detected in germ (germ meal) and endosperm $(1.33 \mathrm{~g} / \mathrm{kg}$ and $0.80 \mathrm{~g} /$ $\mathrm{kg}$ TP ; $0.997 \mathrm{~g} / \mathrm{kg}$ and $0.715 \mathrm{~g} / \mathrm{kg}$ of gallic acid respectively). It should be noted that there are some additional phenolic compounds present whose structures still need to be determined. Keywords: Carob tree, Ceratnoia siliqua L., Leguminosae, Extraction, Polyphenols, Gallic

Acid, HPLC.
Poster \#013. Use of Feces Micro-Histological Analysis to Study Atlas Deer Diet (Cervus elaphus barbarous) in Tazekka National Park (Province of Taza, Morocco)

\author{
Brahim Ismaili* and Mohammed Diouri
}

Moulay Ismail University, Meknes, Morocco

\section{Abstract}

Atlas deer is a flagship species in Morocco. It was reintroduced in Tazekka National Park in 1994 to rehabilitate the natural state in the regions of Middle Atlas and Rif. Very little research has been made on this species and its diet in Morocco. Therefore, a diet study was recommended by the National Strategy for ungulates in order to get useful data for the feasibility of a subsequent release. In this context, we aimed at studying the diet of Atlas deer and its seasonal variation. Feces were collected, during the years 2013 and 2014, in Bab Klati 520-ha reserve located in the west of the aforementioned park. The collection was performed in the existing four types of environments: that of Quercus faginea, that of Quercus suber, scrublands and clearings. Fecal samples were micro-histologically analyzed based on a reference epidermis catalog of all existing plants in the reserve. Poaceae species, the main representatives of the herbaceous category, were consumed at $28 \%, 37 \%$ and $43 \%$ of the diet in autumn, winter and spring, respectively. In summer, their consumption did not exceed $2 \%$; because of their limited availability and the vegetation drying out. Pteridium aqualinium was consumed especially in summer (6\%). Shrubs were represented by three main species: Ulex boivinii and Cytisus triflorus (Paplionaceae) and Lavandula steochas (Lamiaceae). Consumption of $U$. boivinii was high in autumn $(41 \%)$ and spring $(31 \%)$ and low in winter (16\%) and summer $(6 \%)$. As for C. triflorus, the consumption was maximal in winter $(30 \%)$, average in autumn $(19 \%)$ and spring $(18 \%)$ and lowest in summer $(2 \%)$. L. steochas was consumed mainly in autumn ( $8 \%$ ). During the summer, trees were the main component of the diet and were represented by the oak species Q. faginea (61\%), Q. rotandifolia (13\%) and Q. suber (5\%). Keywords: Tazekka National Park, Diet, Atlas deer, micro-histology, feces, Morocco.

\section{Poster \#014. Induction of Secondary Somatic Embryogenesis of Moroccan Cork Oak (Quercus suber L.)}

Safaâ Rahmouni", Brahim El Bouzdoudi, Mohamed L'bachir El Kbiach, and Ahmed Lamarti

Laboratory of Plant Biotechnology, Department of Biology, Faculty of Sciences, Abdelmalek Essaadi University, M'hannech II, B.P.2121, Tetouan, Morocco. "Presenting author: safaarahmouni@hotmail.fr.

\section{Abstract}

Cork oak (Quercus suber L., Fagaceae) is one of the most important species of the Mediterranean basin due to its ecologi- 
cal and socio-economical interests. Nevertheless, the increasing demand for cork and the low natural regeneration provides for a rapid loss of cork oak forests. Vegetative propagation of trees by somatic embryogenesis contributes to the regeneration of forests and their development. This technique allows the formation of a high number of somatic embryos (large scale multiplication). Our study consists in testing the somatic embryogenesis technique on Moroccan cork oak (Quercus suber L.). We have induced primary somatic embryogenesis from leaves obtained from epicormic shoots forced to sprout from segments of branches of Quercus suber L. Branches from Quercus suber L. trees were sterilized and cultured in specific conditions. After 7 days of culture, branches began to emit epicormic shoots. Secondary, leaves obtained from epicormic shoots were used for induction of somatic embryogenesis. After series of transfers in culture media on various nutritive mediums with or without plant growth regulators (ANA and BA), primary somatic embryos were obtained. These embryos were multiplied by secondary somatic embryogenesis by a number of factors. Keywords: Cork oak, Quercus suber L., Fagaceae, secondary somatic embryogenesis.

\section{Poster \#015. The Impact of Organic and Biological Amende- ments on Date Palm Seedlings Salt Stress Tolerance}

Mohamed Ait El Mokhtar*, Said Wahbi, Raja Benlaouane, and Abdelilah Meddich ${ }^{\dagger}$

Laboratory of Biotechnology and Plant Physiology, Faculty of Sciences, University Cadi Ayyad, Marrakech, Morocco. "Presenting author: mohamed.aitelmokhtar@gmail.com. ${ }^{\dagger}$ Corresponding author: a.meddich@uca.ma.

\section{Abstract}

The date palm has suffered from the devastating effects of multiple constraints including salt stress. In this study we will evaluate the impact of two amendments, namely compost and mycorrhizal fungi (AMF) on tolerance of the date palm seedlings under salt stress. Six treatments were applied: compost, AMF and compost + AMF with $(14 \mathrm{~g} / \mathrm{I}$ of $\mathrm{NaCl})$ and without $(0 \mathrm{~g} / \mathrm{I}$ of $\mathrm{NaCl})$ salt stress. After 8 months of mycorrhization ( 5 months from the application of salt stress), AMF and compost seems to have a positive effect on tolerance of the date palm subjected to salt stress compared to control. As a matter of fact, the two amendments, separate or combined, enhance growth and water parameters of the date palm with a high efficiency of the combination of the two amendments. In the absence of salt stress, the growth parameters (aerial elongation, leaf area, shoot and root dry matter) were improved by compost $54 \%$, by AMF $77 \%$ and by compost + AMF 100\% compared to control. The water parameters (stomatal conductance, content water and water potential) were improved by compost $95 \%$, by AMF $168 \%$ and by compost + AMF $224 \%$. Under salt stress, the growth parameters were enhanced by compost $57 \%$, by AMF $100 \%$ and by compost + AMF $117 \%$ compared to control. The water parameters were enhanced by compost $140 \%$, by AMF $202 \%$ and by compost + AMF $230 \%$. Keywords: Date palm, compost, mycorrhizal fungi, salt stress.

Poster \#016. Effect of Salt and Water Stress on Morphological Parameters, Physiological and Agronomic of four Medicinal Plants

Mohammed Chetouani", I. Mzabri, A. Aamar, A. Boukroute, N. Kouddane, and A. Berrichi

Laboratoire de Biologie des Plantes et des Microorganismes, Faculté des Sciences, Université Mohamed Premier, B.P. 717, Oujda 60.000, Morocco. "Presenting author : chetouanimohammed@gmail.com

\section{Abstract}

Salinity is a common factor in the environmental stress seriously affecting crop production in different regions of the world. Morocco, which is known by the scarcity of rainfall in semi-arid and arid regions accentuate the salinization of irrigated areas and make them unsuitable for crops. Under these conditions, changes in mophophysiological and biochemical characteristics (leaf water potential, chlorophyll fluorescence, relative water content and sugar proline content) are effective parameters sensing plant response vis-à-vis the stress, and also realize the water status of the plant and its ability to incorporate water, especially under stress conditions. As part of this approach and to explore the effect of salt stress on the behavior of the plant, we are interested in four medicinal and aromatic plants, namely Salvia officinalis, Cytrus cymbopogon, Lavandula dentata and Rosmarinus officinalis have various agronomic and socio-economic interests in the eastern region. $\mathrm{NaCl}$ concentrations were used in order to assess salt stress and essential oil and its chemical composition. The preliminary results show that these plants are resistant to salt stress for lower doses of $100 \mathrm{mM}(0.086 \mathrm{mM}) \mathrm{NaCl}$ beyond this value the plants wither.

Poster \#017. Effect of Environmental Conditions on Morphological Characteristics of Saffron (Crocus sativus L.) Moroccan Cultivars

Salaka Latifa ${ }^{*}$, M Ben El Caid, K Lagram, M Lachheb, LH Atyane, A El Mousadik, M Fallah, and MA Serghini

Laboratory of Biotechnology and Valorization of Natural Resources, Ibn Zohr University, Sciences Faculty, Agadir, 80000, Morocco. *Presenting author: latifasalaka@gmail.com.

\section{Abstract}

Saffron is the most expensive spice in the world. In Morocco, saffron cultivation is localized in the Taliouine-Tazanakht region. The depth knowledge of Moroccan saffron cultivars and the selection of those with good performances constitute a solid base for the development of this sector and the conservation of this plant. This study aims to evaluate the morphological diversity of Taliouine's saffron cultivars in two sites and to select those with 
the best quality. To reach this objective, corms of saffron from four provenances (Sidi Hssaine, Agadir Melloul, Zagmouzen and Askaoven) were planted in two different sites (Taliouine and Faculty of Science, Agadir (FSA) and were followed for four years. The measured morphological parameters are the number, weight and length of different plant organs, namely, corms, leaves, flowers and stigmas. The multiple analyses highlighted significant differences between saffron provenances for different parameters. The number of flowers produced depends significantly on the corms provenance; it can be five times more important. The length, fresh and dry weight of their stigmas can show a difference 6 times higher. This agro-morphological characterization has revealed the existence of significant morphological variability within the Moroccan saffron. This variability exists despite of the mode of vegetative propagation of the species. During the 4 years of study, the rate of corm proliferation and stigma production now better understood. Keywords: Saffron, Crocus sativus L., morphological characterization, cultivars.

Poster \#018. Improved Micropropagation Method for in vitro Cormlet Production through Indirect Organogenesis of Moroccan Saffron (Crocus sativus L.)

Lagram Khalid", M. Ben El Caid, L.H. Atyane, L. Slaka, M. Lachhab, R. El Boulani, A. El Mousadik, and M.A. Seghrini

Laboratory of Biotechnology and Valorization of Natural Resources, Sciences Faculty, Ibn Zohr University, Agadir, Morocco. *Corresponding and presenting author: lagram.khalid@gmail. com.

\section{Abstract}

Saffron is the most expensive spice in the world. This spice, also called 'red gold', consists of the dried stigmas of Crocus sativus L. It is a male-sterile and triploid plant $(2 n=3 x=24)$ which belongs to Irridaceae family. It spreads vegetatively thought the formation of daughters' corms. Saffron is popular for its color, taste and aroma property due to its essential metabolites that are respectively crocin, picrocrocin and safranal. The auto-triploid nature of saffron creates problems for sexual reproduction and renders improvement by breeding practically impossible. Application of biotechnology, especially tissue culture, can improve the quality and quantity of the saffron product, by the large production of healthy selected saffron corms. In this work, an in vitro regeneration protocol was optimized through indirect organogenesis for the efficient multiplication of selected Moroccan saffron cultivars. The calluses had been initiated after one month on MS medium supplemented with $3 \%$ sucrose, $100 \mathrm{mg} / \mathrm{L}$ ascorbic acid and different combinations of PGRs. As result, we noted that the combination of $1 \mathrm{mg} / \mathrm{L}$ BAP and $1 \mathrm{mg} / \mathrm{L}$ NAA was efficient for callus initiation from the rectangular sections of upper part of corms tissue. Additionally, for shoots formation from calluses, maximum rates were founded in the combination of $2 \mathrm{mg} / \mathrm{I}$ TDZ with $0.5 \mathrm{mg} / \mathrm{I} \mathrm{NAA}$. Shoots obtained previously from callus, were then transferred to the corms and roots induc- tion medium. As a result, we observed the formation of adventitious corms and roots in $1 / 2$ MS medium under the obscurity. Keywords: Corms, In vitro, Organogenesis, Crocus sativus, Callus, propagation, tissue culture.

\section{Poster \#019. Molecular Identification of Moroccan Saffron (Crocus sativus L.) with Microsatellite Markers}

Mohamed Lachheb* ${ }^{*}$ M. Ben El Caid, L. Salaka, K. Lagram, A. El Mousadik, and M.A. Serghini

Laboratory of Biotechnology and Valorization of Natural resources (LBVRN), Faculty of Sciences, Agadir, Morocco. "Presenting author: lachheb.mohamed91@gmail.com

\section{Abstract}

Crocus sativus L. is a male sterile plant. Its flower produces stigmas that when dried, form the most expensive spice in the world commonly known as 'Red Gold'. The saffron name is usually used to refer both to the spice and the plant itself. In Morocco, saffron is primarily cultivated in the area of Taliouine/Taznakht. The improvement of the Moroccan saffron imposes it's morphological, biochemical and molecular characterization. The present study consists of an investigation and an evaluation of the genetic variability of Moroccan saffron by molecular markers. It aims to develop its molecular identity and to get a database allowing better management, selection, exploitation and protection of natural heritage. Samples were collected from four different selected areas (provenances) in the region of Taliouine/Taznakht: Sidi Hssaine, Agadir Melloul, Taznakht and Askaoven. Genomic DNA, was extracted from $40 \mathrm{mg}$ of leaves, using CTAB method and it has used as the matrix for PCR amplification. The microsatellite markers were selected for the identification and analysis of the genetic variability of cultivars of the Moroccan saffron, taking in account their large polymorphism, their specificity, their codominance and their reproducibility and stability. Three hundred and fifty nine (359) EST sequences of genomic DNA of the saffron were collected from the National center for Biotechnology Information (CNIB). The SSRIT software has allowed the identification of 12 EST-SSR (SSRe) and 10 SSR from the genomic DNA (SSRg). The specific primers for each SSR region were determined by the software Primer 3 version 4.0.0. In addition, 12 pairs of primers developed by Nemati et al. (2012) among the Iranian saffron and three pairs of specific primers of Iris ensata, were also selected for the molecular characterization of the Moroccan Saffron. Preliminary results show that Moroccan saffron is genetically different compared to the Iranian saffron and the provenance of Sidi Hssaine is not only agromorphologically but also genetically different compared to the other provenances. This data is invaluable for the improvement of the productivity of Moroccan saffron via SSR markers assisted selection. Keywords: Microsatellite, saffron (Crocus sativus), molecular markers, genetic diversity. 
Poster \#020. Evaluation and Comparison of Standards of Quality of the Plants of the Thuja Tetraclinis articulata Vahl Masters Products in three Moroccan Forest Nurseries

Amal El Khaddari, ${ }^{12 *}$, Mohamed Ouajdi ${ }^{1}$, Saloua El Antry', Jamila Dahmani ${ }^{2}$, Zine El Abidine ${ }^{3}$, and Abbas Younes ${ }^{1}$

1 Centre Nationale de la Recherche Forestières Rue Omar lbn AL Khattab BP 763,10050 Rabat-Agdal, Morocco; ${ }^{2}$ Laboratoire de Botanique, Biotechnologie et Protection des plantes Université Ibn Tofail Faculté des sciences BP. 133 Kenitra, Morocco; 3 Ecole Nationale Forestière des Ingénieures. BP. 51 1, Tabriquet, Salé, Morocco; 4 Université Sultan Moulay Slimane, Faculté Poly disciplinaire de Béni Mellal, Département de Biologie-Géologie, Mghila B.P. 592, Béni Mellal, Morocco. *Presenting author: elkhaddaribiologiste@gmail.com.

\section{Abstract}

The Thuja (Tetraclinis articulata Vahl Masters) is an endemic species of Morocco; it occupies the fourth most important place after the Aleppo pine, the green oak, and the cork oak. It presents a great ecological interest which contributes to the socio-economic development of the country. However, it is threatened as a result of multiple factors related to climate change and human activities. In this regard to preserve this species, the Office of the High Commissioner to the Waters and Forests has undertaken a few strategic measures by installing a large number of forest nurseries in Morocco in order to rectify the faults recorded in relation to the natural regeneration of this species. However, the results on the grounds of reforestation remain unsatisfactory and often, it assigns this failure to the poor quality of the plants produced in nurseries. There is interest in producing quality plants in order to optimize their rate of regeneration once put in the soil. In this context, three different Moroccan nurseries (Sidi Yahia, Bni souhane and Droua) were the subject of this study by comparing the quality attributes of plants products. For each nursery, 21 plants were sampled. The morphological characters were assessed through measures of height, root collar diameter and biomass. The results obtained from the different settings have found that the production of seedlings of red cedar differs from one nursery to another. Also, the nursery of Sidi Yahia is the one that produces the highest quality compared to other nurseries. But this result does not justify that this nursery is the most effective in terms of plant production. It was found that the plants products are not balanced, which reflects failures at the level of the technical measures adopted during their cultuvation (watering, fertilization...). It would be essential to review production methods of red cedar seedlings in the nursery to propose other more effective standards that can be used to better assess and enhance this production. Keywords: Thuja (Tetraclinis araticulata), Comparison," growth, height, diameter, nursery
Poster \#021. Biofilm Formation of Lactic Acid Bacteria on Stainless Steel Surfaces

Mariem Zanzan ${ }^{*}$, F. Achemchem ${ }^{1}$, F. Hamadi ${ }^{2}$, H. Latrache ${ }^{3}$, L. Amzil $^{2}$, A. Elmoslih' ${ }^{2}$, and R. Mimouni ${ }^{2}$

1 Laboratoire de sciences de l'ingenieur et managment de l'energie, Ecole national de sciences appliquées, Agadir, Morocco; ${ }^{2}$ Laboratoire de Biotechnologie et Valorisation des Ressources Naturelles, Faculté des Sciences, Université Ibn Zohr, Agadir, Morocco; ${ }^{3}$ Laboratoire de Bioprocédés et Biointerfaces, Faculté des Sciences et Techniques, Université Sultan Moulay Slimane, Béni-Mellal. *Presenting author : mariem.zanzan@ gmail.com.

\section{Abstract}

The biofilm formation of pathogenic bacteria creates major problems in food industry such as food contamination and materials deterioration. In the literature we found some successful examples of using nonpathogenic bacteria Generally Recognized as Safe (GRAS) to ensure food safety and to protect against biofilms formed by undesirable spoilage and/or pathogenic bacteria. The aims of this work were, to evaluate the ability of thirteen lactic acid bacteria to form biofilm on abiotic surfaces (Stainless steel 316 and Stainless steel 304), and to determine the physicochemical properties of substratum and bacterial surfaces using contact angle measurements. The results obtained show that all lactic acid bacteria have higher ability to form biofilm on two substratum. Keywords: Lactic acid bacteria, Biofilm, Stainless steel, physicochemical properties.

Poster \#022. Potential Antagonism of Some Trichoderma Strains Isolated from Moroccan Soil Against three Phytopathogenic Fungi of Great Economic Importance (Fusarium oxysporum, Verticillium dahlia, and Rhizoctonia solani)

Wafaa Mokhtari ${ }^{*}$, N. Chtaina ${ }^{1}$, E. Halmschlager ${ }^{2}$, H. Volgmayr ${ }^{3}$, C. Stauffer ${ }^{2}$, and W. Jaklitsch ${ }^{3}$

'Institute of Agronomy and Veterinary Sciences, Environment and Pesticides Laboratory, Production, Protection and Biotechnology Department, Rabat, Morocco; ${ }^{2}$ University of Natural Resources and Life Science, Institute of Forest Entomology, Forest Pathology and Forest Protection (IFFF), Hasenauerstrasse 38, 1190 Vienna, Austria; ${ }^{3}$ University of Vienna, Department of Systematic and Evolutionary Botany, Faculty Centre ofBiodiversity, Rennweg 14, 1030 Vienna, Austria.

\section{Abstract}

In this study, 17 Trichoderma strains were isolated from different soils (crop fields and Argan forests) in Morocco. Purified singlespore cultures were identified to species-level using molecular methods and tested for their potential antagonism against three phytopathogenic fungi of great importance in Morocco (Fusarium oxyxporum, Verticillium dahlia and Rhizoctonia solani). After 
DNA extraction translation elongation factor (tef 1 ) was amplified in extracts of 17 strains, sequenced and compared with their ex-types. As a result, three species were identified among the strains, which clustered in two different subclades of Trichoderma. The species, T. afroharzianum and T. Guizhouense, belong to the Harzianum clade, while T. Longibrachiatum belongs to the Longibrachiatum clade. Investigation of potential antagonistic effects of these strains against the soil-borne phytopathogens Fusarium oxysporum, Rhizoctonia solani and Verticilium dahliae was conducted in a dual culture plate assay. All Trichoderma isolates showed effective antagonistic performance by decreasing Ra: radial of pathogens' mycelium confronting Trichoderma isolates. Trichoderma afroharzianum showed significant differences when comparing control radii Rc with the radii confronting antagonist $\mathrm{Ra}(\mathrm{P}<0.05)$. The highest Percentage Inhibition of Radial Growth (PIRG, $80.64 \%$ ) was obtained for isolate T2.1 against Fusarium. In comparison, T9i12 which is a reesei species shows a high radial inhibition of pathogens' mycelium. Keywords: Trichoderma spp., Fusarium oxysporum, Verticillium dahliae, Rhizoctoniasolani, antagonistic fungi.

Poster \#023. Nitrogen, Phosphorus and Potassium Exports Assessment in Wheat and Validation Model 'Nutrient Expert' for the Recommendation of Fertilizers in Rain fed and Irrigated Condition in Morocco

Hanaa Bellasri $^{1 *}, M$. Elgharouss $^{2}$, A. Ibnlfassi ${ }^{1}$, and H. Boulal ${ }^{2}$

' Laboratory of Environmental Sciences and Development, Faculty of Science and Techniques, University Hassan 1 , Casablanca Road , Km3.5 , BP577, 26000, Settat, Morocco; ${ }^{2}$ International Plant Nutrition institute (IPNI). *Presenting author: hanaa.bellasri@gmail.com. *Presenting author:

\section{Abstract}

Wheat is the second most important cereal in Morocco after barley. It is grown primarily under rainfed conditions. In Morocco, grain production varies from less than 10 to more than 70 quintals / ha and this wide range occurs due to prevailing climatic conditions and cultivation techniques. Fertilization contributes to over $50 \%$ improvement to wheat production. Also, surveys of farmers in four regions of Morocco namely Abda, Chaovia, Tadla and Sais showed that the quantities of fertilizers applied to wheat is generally weak and unbalanced which affects the quantity and quality yields. Fertilization is an important step in the production of wheat and must be best used to improve land productivity and water use efficiency, and to lower the damage to soil and groundwater. Thus, in response to the increased cost of fertilizer and the awareness of the risks of environmental degradation, the fertilizer must be adapted and adjusted better to the soil characteristics and culture. Farmers must adopt the concept ' $4 \mathrm{~B}$ ' which is based on providing the right fertilizer at the right dose at the right time and place. The main objectives of our research are using the best fertilization practices for wheat in rainfed and irrigated areas of Morocco under the concept ' $4 \mathrm{~B}$ '. This study assesses nitrogen, phosphorus and potassium, and validation of the recommendation model fertilizers 'Nutrients Expert' at the farmer field locations in four regions of Morocco: Abda, Chaouia, Saïs and Tadla. Field trials were conducted using seven treatments, contribution of NPK, contribution of PK (-N), contribution of NK (-P), contribution of $\mathrm{NP}(-\mathrm{K})$, recommendations based on the soil analysis, recommendations based on the model "Nutrient Expert " and the practice of the farmer. Keywords: Fertilization, wheat, Nutrient Expert.

\section{Poster \#024. Identification of Mineral Content of 8 Khalts and Varieties of Date Palm in South of Morocco}

Abderrahim Alahyane $^{1 *}$, Jamal Ayour', Ahmed Ait oubahou', and Mohamed Benichou'

' Food Sciences Laboratory; Faculty of Science Semlalia; Cadi Ayyad University Marrakech, Morocco; ${ }^{2}$ Horticultural Laboratory; Agricultural and Veterinary Institute Hassan II Complex Horticulture Agadir, Morocco. "Presenting authro: ab.alahyane@ gmail.com.

\section{Abstract}

The date palm (Phoenix dactylifera $\mathrm{L}$ ) is one of the oldest fruit species in Morocco with high ecological significance and socioeconomic impact. Dates, are sources of minerals that could constitute a significant raw material for food. Many studies have focused on the nutrition and agro-industrial characterization of Moroccan dates from the known varieties of date palm (Phoenix dactylifera) while those dedicated to the characterization of unknown clones called khalts remain far fewer. The objective of our work was to determine the mineral composition by ICP of eight cultivars "khalts and varieties" of southern Morocco. Our study included a comparison of these fruits in minerals content. The pulp of the eight fruits studied was more rich in minerals (calcium, magnesium, potassium, iron, manganese) than some widely consumed fruits. The content of some trace elements (zinc, copper) has not exceeded the toxic threshold, indicating that the consumption of these fruits would not be detrimental to public health. The results of the analyzes are very promising and deserve further investigation in order to select clones with great nutritional and health interest and may also be valued at the agro-industrial level. Keywords: Date palm; fruit quality; minerals; valuation.

\section{Poster \#025. Performance of a Solar Pumping System}

\section{Harkani Assia $^{1 *}$, A. El Aissaoui ${ }^{2}$, and H. Fihri Fassi ${ }^{1}$}

1 Laboratory of Engineering, Industrial Management and Innovation FST Settat, Morocco; ${ }^{2}$ Laboratory of agricultural machinery, INRA Settat, Morocco. "Presenting author: a.harkani@uhp. ac.ma. 


\section{Abstract}

In the last few years, photovoltaic energy sector has consistently grown in several countries, due to its economic and environmental benefits. Nowadays, economic and social development in Morocco is based on improving water resources management and promoting efficient irrigation technologies as a part of a global and integrated policy development. This study aims to evaluate the performance of a solar pumping system using maximum power tracking technology (MPPT) according to variability of the daily solar radiation and its impact on the pump response. The evaluation of MPPT behavior showed that its efficiency kept low $(80 \%)$ according to deficiency of its algorithm to improve the outputs of the photovoltaic panel (Pu-max $=300 \mathrm{~W}$ ) and the DC diaphragm pump SHURFLO $(P=60 \mathrm{~W})$. Keywords: photovoltaic energy, MPPT, solar irradiation, DC pump, effeciency.

\section{Poster \#026. Monitoring and Microbiological Bioremediation of Pesticides in Soils of Fez-Meknes Region of Morocco}

Mohamed Maldani", F. Aliyat, O. Zennouhi, L. Nassiri, and J. Ibi¡bijen

Environment \& Soil Microbiology Unit, Faculty of Sciences, Moulay Ismail University B.P. 11201 Zitoune, Meknes, Morocco. *Presenting author: Maldani.mohamed@hotmail.com.

\section{Abstract}

For decades, the majority of modern crop protection practices were based on the use of chemicals for the plant protection. The excessive use of chemicals was considered indispensable for the success of agricultural development which has the aim to increase food production. Despite their importance, the misuse of chemicals can cause direct and indirect threats for humans, animals and for the entire environmental system. These risks are related to the chemicals that are toxic and can have a negative impact on the environment. The soil is oftentimes the portion of the environmental ecosystem that is the most threatened by chemical contamination. Soils are very low renewable resource, and although contamination can be fast; however, it recives time to regenerate. This contamination or pollution directly influences (runoff or leaching by seepage) water (groundwater or surface: rivers, lakes, ground water, etc). Once these two essential components of the environmental ecosystem are contaminated by chemical inputs, the rest of the components will also be affected. Man is affected either directly by consuming contaminated products or indirectly through intermediate channels. According to WHO the increase of the diseases rate (such as colorectal cancer, leukemia, allergies, Parkinson, etc.) can be caused by environmental pollution mainly by chemical inputs. The Meknes region is one of the largest agricultural areas in Morocco which explain the excessive use of chemicals. In this context, and with the aim to participate to the sustainable development of agricultural practices, we have to find a new alternative based on the study of bacterial strains able to degrade the active molecules of the chemical products. These bacterial strains will present an important biotechnological application for the bioremediation of the contaminated soils. Keywords: Soil; Chemicals; Pollution; Bacteria; Bioremediation.

\section{Poster \#027. Evaluation of Seed Production of Interspecific Wild and Cultivated Crosses of Beets}

Siham Oumous ${ }^{1,3^{*}}$, Ilham Rahmouni ${ }^{1}$, Ghizlane Tobi', Hikmat Tahiri $^{3}$, Yasmina El Bahloul ${ }^{1 \dagger}$

1 National Institute of Agronomic Research (INRA), Genetic Resources and Plant Breeding Unit, CRRA-Rabat, BP 6570, 10101 Rabat Instituts, Morocco; ${ }^{2}$ Laboratory Eco valuation, CRRA-Rabat, BP 6570, 10101 Rabat Instituts, Morocco; ${ }^{3}$ Mohamed V University, Faculty of Sciences Rabat, Morocco. *Presenting author: . ${ }^{\dagger}$ Corresponding author: yasmina.elbahloul@inra.org.ma.

\section{Abstract}

The genetic structure of species is the primary way to improve sugar beet genetic potential. These plant genetic resources are an important genetic reservoir used to supply sugar beet germplasm via inter-specific crosses through the transfer of genes of interest. Selected offspring genotypes have a remarkable interest from a food perspective, for biotic and abiotic stress tolerance. Thirteen crosses have been realized in the experimental field of Merchouch a favorable site for vernalization required for the sugar beet seed production. Results showed successful crosses between wild and cultivated beets with a yield per plant ranging from 50 to $80 \mathrm{~g}$. Evaluation based on morphological and genetic traits showed a difference in inherited characters between the crosses according to the parent genotypes. Hybrids issued from the selected crosses are being evaluated for ploidy and biotic stress résistance. Keywords: Interspecific crosses, genetic structuration, beet populations, sugar beet, wild beet.

Poster \#028. The Use of Citrus aurantium Peel Powder to Fight Against Callosobruchus maculatus (Coleoptera, Bruchinae)

Lalla Fatima Douiri ${ }^{*}$, Nada lafkih', Yasmine Ghouati ${ }^{2}$, Hayat Bouhareb ${ }^{1}$, Chakir Meryem ${ }^{3}$, Mohieddine Moumni ${ }^{1}$

1 Department of Biology Sciences Faculty, Moulay Ismail University, P.B 11201 , Meknès, Morocco; ${ }^{2}$ Food Technology and Biochemistry Unit, National School of Agriculture, Meknès, Morocco; 3 Department of Biology Sciences Faculty, Ibn Tofail University, Kenitra, Morocco. *Presenting author: fatimadoviri@yahoo.fr.

\section{Abstract}

Aromatic and medicinal plants are used not only as a source of medical care but also to fight against many pests including Callosobruchus maculatus, pest of legume seeds. During the storage process, most vegetables' seeds are affected by several pests such as Callosobruchus maculatus. This study focuses on the insec- 
ticidal activity of Citrus aurantium powders against C. macualtus feeding on Cicer arietinum seeds. A Laboratory experiment was carried out under controlled conditions $\left(27^{\circ} \mathrm{C}, 70 \pm 5 \%\right.$ relative humidity and 12 hours of light). The results obtained for the studied parameters indicate that powders extrated from the orange peel have an insecticidal activity against weevils. After (1 to 5) days exposure the lowest LC50 and LC99 range respectively from 74.59 to 2.19 and 257.24 to $16,52 \mathrm{mg} / 50$ graines for females and 42.06 to $0,99 \mathrm{mg} / 50$ graines and from 89,79 to $15.74 \mathrm{mg} / 50$ graines for males. In fact, En effet, longevity obtained with the control is 9,1 to 7,73 days, for males 5 to 3,7 days and for females de 6 à 4,7 days. The Citrus powders exert negative effects on all the parameters of the weevil, and can be used against C. maculatus. In addition, they are derived from botanical products, biodegradable, renewable source, economic and have low environmental impact which is often undetectable. Keywords: Citrus aurantium, Cicer Arietinum, powders, Callosobruchus maculatus.

Poster \#029. Lipid and Fatty Acid Composition of Longissumus dorsi Muscle of Béni-Guil Sheep Fed on Different Dryland Forages in Eastern Morocco

Kamal Belhai ${ }^{*}$, Farid Mansouri', Abdessamad Ben moumen', Marianne Sindic ${ }^{2}$, Marie-Laure Fauconnier ${ }^{3}$, Mohamed Boukharta $^{1}$, Hana Serghini-Caid' ${ }^{\text {, Ahmed Elamrani }}{ }^{1}$

1 Laboratoire de Biologie des plantes et des micro-organismes, Faculté des Sciences, Université Mohamed ler, Oujda; Morocco; ${ }^{2}$ Laboratoire Qualité et Sécurité des Produits Alimentaires, Gembloux Agro-Bio Tech, Université de Liège; Belgium; ${ }^{3}$ Laboratoire de Chimie générale et Organique, Gembloux Agro BioTech, Université de Liége; Belgium. *Presenting author: belhaj. kamal90@gmail.com.

\section{Abstract}

Sheep meat of the Beni Guil breed is one of the main Moroccan local meats, integrated into the program of agricultural development due to the savory, nutritional and sensory properties of sheep meat of Moroccan highlands (Beni Guil). However, this good reputation is still only limited to the assessments of tasting panels. Thus, the objective of this study is to assess from a scientific point of view the nutritional quality of this meat via biochemical analyses, examining major and minor muscle composition of the meat of this breed and specifically fatty acid (FA) composition of the longissumus dorsi muscle. In this first study, 10 longissumus dorsi muscle samples were selected and cut with the help of the agents of the national sheep and goat association. The results showed that $100 \mathrm{~g}$ of fresh meat material contains $25.72 \%$ of dry matter, including $5.13 \%$ of Fat, $19.42 \%$ of protein and $0.93 \%$ of mineral matter. Qualitative and quantitative analyses of fatty acids of 10 samples allowed the identification of 27 components. Palmitic, Oleic and stearic esters were the main fatty acid methyl esters (FAMEs) identified. Saturated fatty acids represented about $41.13 \%$ of FAs, with the majority being palmitic acid $(20.69 \%)$ and stearic acid (16\%). The unsaturated fatty acids were principally represented by oleic acid $(36.06 \%)$ and linolenic acid $(9.64 \%)$. The average content of total fatty acids in meat samples analyzed is 24.98 grams per 100 grams of fat. Many reports in the literature have shown that the $n-6$ and $n-3$ polyunsaturated FA are important contributors to the odor and flavor of ruminant meats and that this composition is mainly correlated with feeding systems used. Keywords: Beni Guil, Sheep, longissumus dorsi muscle, Fatty Acid.

\section{Poster \#030. General Chemical Composition of Almonds (Prunus amygdalus Miller) Grown in Eastern Morocco}

Nadia Houmy ${ }^{1,2^{*}}$, F. Mansouri' ${ }^{1}$, A. Ben-Moumen ${ }^{1}$, M. Sindic ${ }^{2}$, M-L. Fauconnier $^{3}$, H. Serghini-Caid', and A. Elamrani'

' Laboratoire de Biologie des Plantes et des Micro-Organismes, Faculté des Sciences, UMP, Oujda ; Morocco; ${ }^{2}$ Laboratoire Qualité et Sécurité des Produits Alimentaires, Gembloux AgroBio Tech, Ulg, Belgium; ${ }^{3}$ Unité de Chimie Générale et Organique, Gembloux Agro-bio Tech, ULg ; Belgium. "Presenting author: houmy.nadia@gmail.com.

\section{Abstract}

The production of almond has increased more and more in eastern Morocco, from $136000 \mathrm{~T}$ in 2012 to $183000 \mathrm{~T}$ in 2015. The chemical composition of five varieties (Marcona, Fournat, Ferragnes, Ferraduel and Bedi) were determined. Total sugar ranged between 6,2086 for Marcona and 8,5462\% for Fournat. Total protein was changed from 19,4167 for Ferragnes Ferradul to $22,261 \%$ for Beldi. Total fiber was varied from 15,4197 for Marcona to 18,150\% for Beldi. Ashes ranged between 2,9079 for Marcona and 3,5606 \% for Beldi. Oil content varieed between 51,4741 for Beldi and 56,5688\% for Ferragnes Ferraduel. This oil content requires us to determine the characteristics of this almond oil. Fatty acid profile was identified. Oleic acid, linoleic acid, palmitic acid and stearic acid ranged from 60,76 for Marcona to $69,306 \%$ for Ferragnes Ferraduel, between 20,545 for Ferragnes Ferraduel and 27,45\% for Marcona, between 7,0692 for Ferragnes Ferraduel and 8,010 for Marcona and from 2,009 for Beldi to 2,743 for Marcona, respectively. Oxidative stability was highest in Ferragnes Ferraduel. Keywords: almond oil, fatty acid, sugar, protein, fiber oil content, ashes.

\section{Poster \#031. Root Growth of Date Palm (Phoenix Dactylefera L.) Under Drought Stress}

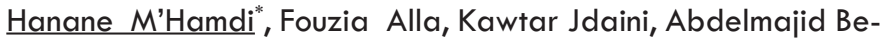
labed, and Mohammed Aziz EL Houmaizi

Laboratory of Plant Biology and Microorganisms, Department of Biology, Faculty of Sciences, BP 717 Oujda, Morocco. *Presenting author: hanane57hana@gmail.com. 


\section{Abstract}

The palm date tree is a symbolic species of Mediterranean countries and has been cultivated for its fruits for centuries. This species establishes the base of human and animal food and creates creates a microclimate allowing the development of diverse animal and plant life in desert. Numerous studies have been made on the palm tree and the production of dates. However, knowledge concerning the root system of the palm date tree are very limited. Indeed, not much information is available concerning root structure. It is probably due to the difficulty of the observation and the collection of the precise and coherent information concerning the subterranean part. The architectural analysis of the system root is essential to describe its main functions. It consists of classifying the various axes making up the plant according to their morphology, position or according to their dynamics of growth, is a way to try to understand certain effects of ecological and agronomic problems. The main objective of this project is to follow the spatiotemporal development of the root system of the palm date tree by the observation of the root parameters of the palm date tree of three cultivars, and to establish a $3 \mathrm{D}$ root model using XPLO software.

Poster \#032. The Variability of the Main Components of Dates Depending on Soil Factors and Cultural Practices

Kawtar Jdaini ${ }^{*}$, H. M'Hamdi', F. Alla', H. Rey ${ }^{2}$, C. Jourdan' ${ }^{2}$, R. Lecoustre $^{2}$, A. Belabed', and M. A. Elhoumaizi ${ }^{1}$

' Laboratory of Biology of Plants and Microorganisms, Faculty of Sciences, University Mohamed first, Oujda, Morocco; ${ }^{2}$ Agricultural Research Centre for International Development, Montpelier, France. "Presenting author: jdaini91@gmail.com.

\section{Abstract}

The date palm is one of the oldest cultivated plants, and is the backbone of the oasis ecosystem in view of its economic, social, ecological and cultural. Its fruit contains high nutrients and is a good source of energy, and has high levels of carbohydrates, proteins, minerals, vitamins and fiber. This composition varies depending on the cultivar, soil parameters, cultural practices and the maturation phases. The South East Moroccan economy heavily depends on the date palm groves. The average annual production of dates in Morocco exceeds 100,000 Tones, 25\% high quality dates, $35 \%$ average quality and $40 \%$ low quality. The composition of Moroccan dates has been widely studied but none have been conducted on the variability based on cultural and edaphic factors. The objective of our study is to evaluate all these parameters and their influence on the main components of dates and subsequently their quality. To achieve, a biometric characterization, a physicochemical and a microbiological analysis will be conducted on 5 main cultivars from palm groves situated in FIGUIG, TINJDAD, ERFOUD, RISSANI, ZAGORA TATA namely 'Aziza Bouzid', 'Assiane', 'Boufeggous', 'Jihel' and 'Majhool', respectively. We will then proceed to an assessment of physicochemical soil parameters such as texture, limestone and salinity, and an assessment of cultural practices such as irrigation modes, fertilizer types and pollination modes. This project will contribute to the development of good agricultural practices, help improve the quality and increase the quantity of Moroccan date production.

\section{Poster \#033. Estimating Sap Flux Densities in Date Palm Trees Using the Heat Dissipation Method}

Faouzi Alla", K. Jdaini, H. M'hamdi, A. Belabed, and M. A. Elhoumaizi

Laboratory of Plant Biology and Microorganisms, Department of Biology, Faculty of Sciences, BP 717 Oujda, Morocco. *Presenting author: fouzia.alla@gmail.com.

\section{Abstract}

Water is essential for life of living beings. In plants, the water requirement measurement is a crucial part of understanding the physiology of tree, and dynamics of water transfers in forest stands. Improved water management in oasis systems are one of the main challenges for the preservation of its agricultural ecosystem. The date palm is the backbone of the oasis ecosystem Saharan and pre-Saharan regions of Morocco. This tree is one of the oldest fruit species with high ecological and socioeconomic importance. Water consumption of the palm is an essential indicator of water management constraints and the overall water balance. The present study is interested in continuous measuring sap flow densities in date palm using the heat dissipation method, to ensure optimum water consumption for quality production and good profitability. Keywords: Water balance, sap flow, date palm, thermal method.

\section{Poster \#034. Saffron (Crocus sativus L.) Yield Parameter As- sessment of Stressed Corms Stored in Low Temperature}

Ibtissame Mzabri", M. Legsayer, M. Chetouani, A. Aamar, N. Kouddane, A. Boukroute, I. Bekkouch, and A. Berrichi

Laboratory of Biology of Plants and Microorganisms, Faculty of Sciences, Oujda, Morocco. *Presenting author: btissammzabri@ gmail.com.

\section{Abstract}

Saffron (Crocus sativus L.) is the most expensive spice in the world. It is cultivated in Morocco for centuries and used for culinary, medicinal and cosmetic purposes. This study aims to optimize saffron yield parameters (saffron morphology, flowering and corm yield) focusing on its performance for semi-arid region of eastern Morocco using low temperature storage, and salt and drought stresses. Corms obtained from salt and drought stresses and stored under cold storage at $4{ }^{\circ} \mathrm{C}$ for 7 and 14 days (with a control kept at room temperature) and were cultivated in open fields at the Experimental Station of the Faculty of Sciences of Oujda. The number of flowers that formed, the yield of saffron 
spice per corm and daughter corm yield depended on storage temperature and cold-storage duration. Flowers from the corm cold-stored for 14 days formed earlier than other treatments. Flower number, fresh stigma yield decreased gradually with increasing duration of cold- storage. Similarly, leaf number and plant height showed the same decrease with increasing of cold storage period. Diameter of produced daughter corms was largest in control. However, increasing cold storage time increases the number of small daughter corms per plant. Cold storage induces precocious dormancy. Overall, no benefit resulted from cold- storage of corms; also, corms from stressed plants had no effect on the studied parameters. Keywords: Saffron, cold storage, stressed corms, flower yield, corm yield.

Poster \#035. The Effect of Different Concentrations of Indole3-Butyric Acid (IBA) and the Season on the Resumption Release Date Palm (Phoenix dactylifera Variety: Aziza Bouzid)

Ayoub Aamar ${ }^{*}$, M. Chetouani, I. Mzabri, A. Berrichi, N. Kouddane, and A. Boukroute

Laboratoire de Biologie des Plantes et des Microorganismes, Faculté des Sciences, Université Mohamed Premier, Ouja, Morocco. "Presenting author: ayoubaamar@gmail.com.

\section{Abstract}

The Farmers of Figuig have great difficulties in the multiplication of date palm sucker, especially the variety of Aziza Bouzid whose regeneration rate is very low and does not exceed $10 \%$. In this work, two factors influencing this regeneration were studied: the season of transplantation and hormonal dose of indole-3-butyric acid (IBA). The results showed that the warmer spring (April) and summer (July) are the most favorable for a rooting release season of the variety studied. IBA treatments improved, in a very remarkable way, the rate of regeneration with a rate of $100 \%$ for the concentration of IBA in the spring season. Keywords: Date palm, regeneration rate, IBA, season, variety Aziza Bouzid.

Poster \#036. Antioxidant Activity of the Essentiel Oil of an Endemic Species of Morocco: Thymus marrocanus

Mohamed Ouknin ${ }^{1,2^{*}}$, Abderrahmane Romane $^{2}$, and Lhou Majidi ${ }^{1}$

1 Laboratoire des Substances Naturelles \& Synthèse et Dynamique Moléculaire, Faculté des Sciences et Techniques, Université Moulay Ismail, Errachidia, Morocco; ${ }^{2}$ Laboratoire de chimie appliquée, Faculté des Sciences-Semlalia, BP. 2390, Université Cadi Ayyad, Marrakech, Morocco. "Presenting author: medoknine@gmail.com.

\section{Abstract}

The Lamiaceae family which includes 7200 species distributed in 240 genera, is divided into 7 subfamilies. The Thymus marrocanus genus belongs to the subfamily nepetoides. This study was designed to examine the phytochemical screening and antioxidant activity of the essential oils of Thymus marrocanus stem, flower and leaf. Thymus marrocanus aerial parts were the valuable organs (flower and leaf), for the essential oil production representing a yield of $2.1 \%(\mathrm{w} / \mathrm{w})$. The phytochemical screening of Thymus marrocanus stem, leaf, and flower was characterized by high proportions of reducers compounds, flavonoids and catechin tannin compounds. Antioxidant activities of the essential oil from aerial part of Thymus marrocanus were evaluated by using three methods: free radical scavenging activity DPPH (2,2-diphenyl-1-picrylhydrazyl), the Ferric Reducing Power (FRAP), and $\beta$-Carotene. The first method showed that the essential oil of the aerial part has an ability important to reduce the iron compared to BHT. The antioxidant activity obtained by the second method showed that the essentials oil from the aerial part of Thymus marrocanus (IC $50=0.542 \pm 0.0012 \mu \mathrm{g} / \mathrm{mL}$ ) is more important than those obtained from antioxidants used in food and pharmaceutical industries namely Butylated hydroxytolvene (BHT) $(\mathrm{IC} 50=0.854 \pm 0.0041 \mu \mathrm{g} / \mathrm{mL})$. Keywords: Essentiel oil; Lamiaceae; Thymus marrocanus; DPPH; FRAP; $\beta$-Carotene.

Poster \#037. Influence of Arbuscular Mycorrhiza and Rhizobia Strain on the Growth and Physiological Parameters of Alfalfa (Medicago sativa) Under Salt Stress

Raja Ben Laouane ${ }^{1,2,3^{*}}$, A. Meddich', M. Faghire ${ }^{3}$, K. Oufdou², F. Anaya', R. Fghire', N. Bechtaoui ${ }^{2}$, F. El Amerany, M. Ait El Mokhtar ${ }^{1}$, and S. Wahbi ${ }^{1}$

' Laboratoire de Biotechnologie et Physiologie Végétale FSSM, Université Cadi Ayyad, Marrakech, Morocco; ${ }^{2}$ Laboratoire de Biologie et Biotechnologie des Microorganismes FSSM-Université Cadi Ayyad, Morocco; ${ }^{3}$ Laboratoire de Biotechnologie Végétale Faculté des Sciences Université lbn Zohr Agadir, Morocco. *Presenting author: benlaouaneraja@yahoo.fr.

\section{Abstract}

The Interactions benefits of the dual inoculation of legumes with nodule bacteria and arbuscularmycorrhizae (AM) are established. However, plant responses to this dual inoculation vary depending on the plant. The current study aimed to compare the effectiveness of autochtonous mycorhizal isolated from palm grove of tafilalet in Morocco and/or rhizobial strain RhOLl on two Medicago sativa varieties (Demnate and a variety australiene). Under $0 \mathrm{mM} \mathrm{NaCl}$ the dual symbiosis formed by $\mathrm{AM}$ fungi and Rhizobia were able to improve significantly dry matter production of variety australiene in comparison with the single inoculation and the control, although, no significant difference was detected between the single and dual symbiosis for Demnate. For both varieties, salt stress significantly reduced plant biomass and physiological parameters. However, plants water parameters didn't show any significant variation. But, these effects can be reduced by the single or dual inoculation with arbuscular-mycorrhizal autochthonous (AM) fungi and rhizobia strain. Our results suggested that Medicago sativa inoculation with rhizobia strain (RhOL1) and/ or arbuscular-mycorrhizal 
autochthonous (AM) fungi could help to alleviate salt stress effects. Keywords: Salinity, Dual inoculation, Growth parameters, Physiological parameters, Alfalfa.

Poster \#038. Effect of fluorescent Pseudomonas on the two Spotted Spider Mite Tetranychus urticae (Acari: Tetranychidae)

Redouan Qessaoui ${ }^{1}{ }^{2 *}$, R. Bouharoud ${ }^{2}$, B. Chebli ${ }^{1}$, S. Hakou ${ }^{2}$, A. Amarraque $^{2}$, A. Ajerrar ${ }^{1,2}$, and H. Mayad ${ }^{3}$

'Equipe Génie de l'Environnement et de Biotechnologie, Ecole Nationale des Sciences Appliquée, Agadir, Morocco; 2 Research Unit of Integrated Crop Production, Centre Régional de la Recherche Agronomique d'Agadir (INRA), Morocco; 3 Laboratoire des Biotechnologies végétales, Faculté des Sciences d'Agadir, Université lbn Zohr, Morocco. *Presenting author: qessaoui_bio@ hotmail.fr.

\section{Abstract}

The two spotted spider mite Tetranychus urticae (Acari: Tetranychidae) is a phytophagous pest that can cause significant yield losses in many agricultural crops, including fruits, cotton, vegetables, and ornamentals. This mite has been recorded to feed on more than 180 plants species in both greenhouse and outdoor environments. To control T. urticae, farmers spray usually chemicals (miticides) despite their harmful effects on the environment and human health. This study investigated the effects of Pseudomonas isolates (Q036B, Q110B and Q172B) as a biological control agent of T. urticae. The bacteria were isolated from tomato rhizospheric soil. Leaf dip bioassay was adopted to test the miticide effect of Pseudomonas isolates. Five concentrations of bacteria were used, 102, 104, 106, 108 and 1010 CFU/ $\mathrm{ml}$. The mortality rates were assessed 24,48 and $72 \mathrm{~h}$ after treatment. Control leaves were dipped in sterilized distillate water. Ten to 15 adults of T. urticae were introduced in Petri dish containing treated leaves and 3 replicates were used for each concentration. The statistic analysis shows that all bacteria and their concentrations significantly reduce the total numbers of $T$. urticae adults compared to control at $72 \mathrm{~h}$. The mortality rates were 49.9 and $97.8 \%$ for $Q 172 B$ and Q036B, respectively. The results of this study indicate that the fluorescent Pseudomonas isolates have an efficient activity to control $T$. urticae and can be promising tools to bild up a biological control strategy. Keywords: Tetranychus urticae, Biological control, Miticide, Pseudomonas.

Poster \#039. Biodiversity and abundance of ants (Formicidae) in the Argane (Argania spinosa) forest in the South-west of Morocco

Abdelhadi Ajerrar $^{1,2^{*}}$, R. Bouharroud ${ }^{2}$, M. Zaafrani ${ }^{1}$, B. Chebli', A. Amarraque ${ }^{2}$, R. Qessaoui ${ }^{1,2}$, and El H. Mayad ${ }^{3}$

${ }^{1}$ Ecole Nationale des Sciences Appliquée, Agadir, Morocco; ${ }^{2}$ Centre Régional de la Recherche Agronomique d'Agadir, INRA, Morocco ; ${ }^{3}$ Faculté des Sciences Ibn Zohr, Agadir, Morocco.

\section{Abstract}

Ants (formicidae) have an important role in the functioning of the terrestrial ecosystem. Ants clean and enrich the soil, contribute to spread of seeds and to prey on other organisms. This study focused on comparing the biodiversity and abundance of ants in two Argane forest areas in the Southwest Morocco. The first is located in Aoulouz (Taroudant) and the second in Sidi-Ifni. Sampling was carried out using mouth aspirator during late spring (May). Litter of two frames of $1 \mathrm{~m}^{2}$ each for every tree were collected and then kept in ethanol 75\%. In each site, seven locations were sampled and two samples were collected for each location (Total= fourteen samples per site). Preparation and slide mounting of specimens were conducted in the plant protection laboratory at National Institute for Agricultural Research (INRA), Agadir. Identification was performed using a binocular microscope and based on specific key for each family, subfamily, genus and species. A total of 10 species of ants were identified in Sidi-Ifni and only 3 in Aoulouz. The Shannon indexes ( $\left.H^{\prime}\right)$ estimated were respectively 1.37 and 0.15 . The most important genus identified was Monomorium which represented $97 \%$ in Aoulouz and $60.7 \%$ in Sidi Ifni. This work will contribute to understand different ecological relationships in the Argane forest ecosystem. Keywords: Biodiversity, Ants, Monomorium, Argane forest, Shannon index.

Poster \#040. Biennial Seed Production Tendency Evaluating Sugar Beet Genotypes Performances through Selection Cycle

Ghizlane Tobi ${ }^{1,2^{*}}$, Siham Oumouss', Ilham Rahmouni', Ouafae Benlahbib $^{2}$, and Yasmina El Bahloul ${ }^{1,2, \dagger}$

1 Unité de Recherche en Amélioration des Plantes Conservation et Valorisation des Ressources Phytogénétiques, Centre Régional de la Recherche Agronomique (CRRA), Rabat, Morocco; ${ }^{2}$ Unité de Recherche en Biotechnologies appliquées en agriculture, Agrobiodiversité et Produits de Terroir, Institut Agronomique et Vétérinaire Hassan II, Rabat, Morocco. "Presenting author: tobighizlane@gmail.com. †Corresponding author: yasmina.elbahloul@inra.org.ma.

\section{Abstract}

Seed production analysis in plant breeding has a basic role in the selection of best performing germplasm. So, conducting astudy related to this on the sugar beet (Beta vulgaris L.) in Moroccan climate conditions is an important step to determine adapted cultivars, for breeding program. Before a maternal pedigree selection method is adopted, seed production require particular conditions to initiate bolting for the reproductive stage. Low temperatures (vernalization) followed by long photoperiod are needed for flowering induction. The present study aims to evaluate the biennial seed production tendency of 40 selected sugar beet genotypes, derived from the second cycle of selection. These individuals were transplanted into the experimental field at Merchouch as a vernalizing site and were carried out by polycross design block during the 2013-2014 
and 2014-2015. Collected data showed a total response to the vernalization and resistance to early bolting, during 20132014; seed yield per plant showed a high variability ranging between $68,80 \mathrm{~g}$ and $410 \mathrm{~g}$. 1000-seed-weight was between $18 \mathrm{~g}$ and $36 \mathrm{~g}$. During the second year, seed yield varied between $56 \mathrm{~g} /$ plant and $300 \mathrm{~g} /$ plant, with 1000-seeds-wieght between $16 \mathrm{~g}$ and $28,50 \mathrm{~g}$. Germination tests showed between $80 \%$ and $100 \%$ for both years, after 3 days incubation. Results prove the genotypes capacity for biennial production of quality seeds with some variation in yield components. Keywords: Sugar beet, genotypes performances, seed production, breeding program, selection cycle.

Poster \#041. Valorization of Solid Sludge from Phosphates in Arboriculture and Forestry Using Microorganisms

Fatima Zahra Aliyat", M. Maldani, O. Zennouhi, L. Nassiri, and J. Ibijbijen

Environment \& Soil Microbiology Unit Faculty of Sciences Moulay Ismail University, Meknes, Morocco. *Presenting author: aliyatfatimazahra@gmail.com.

\section{Abstract}

Morocco is the world's leading exporter and the third largest producer of crude phosphates. It contains $75 \%$ of the known phosphate reserves on the planet. The OCP Group (The Cherifien Phosphates Office) specializes in the extraction, recovery and marketing of phosphates and their by-products. Each year, more than 23 million tones of minerals are mined. The treatment of phosphates, by wet process, generates a lot of sludge. This pulp containing $10 \%$ solids represents $90 \%$ of the rejects from the factory. The volume of this sludge is all the more important, as the production of phosphates increases. The presence of phosphorus in this sludge means loss of phosphates during treatment, from the industrial point of view, and this loss obviously leads to lower yields. However, it is mainly from the environmental point of view that this loss has serious consequences because of the large mass of sludge released into nature. They constitute a major source of environmental pollution, which can have a negative impact on the natural environment. The OCP Group is committed to promoting the use of phosphates as part of a vision of sustainable agricultural development that respects the environment. Consequently, the search for appropriate solutions to the pollution risk posed by this sludge and the recovery of some of this lost phosphorus is critical. The objectives of this work are: to use the sludge generated as a growing substrate, which can be used in nurseries in the production of fruit plants and forests; and the evaluation of the effects of substrates with microorganisms (bacteria) on the growth, development and vigor of plants.

\section{Poster \#042. The Convective Solar Drying of Cherries}

Rachida Ouaabou ${ }^{1,2^{*}}$, Hanine.Hafida ${ }^{2}$, Ali Idlimam ${ }^{3}$, Mohammed Kouhila $^{3}$, Abdelkader Lamharrar ${ }^{3}$, and Mostafa Mahrouz ${ }^{1}$
1 ERIDDECV (Research Team of Innovation and Sustainable Development \& Expertise in Green Chemistry), Department of Chemistry, Cadi Ayyad University, B.P. 2390, Marrakesh 40000, Morocco; ${ }^{2}$ Laboratory of Valorization and Safety of Food Products, Faculty of Sciences and Technics, University Sultan Moulay Slimane, Beni Mellal, Morocco; ${ }^{3}$ Laboratory of Solar Energy and Medicinal Plants, Teacher's Training College, Cadi Ayyad University BP 2400 Marrakesh, Morocco. *Presenting author: rachaovaabou@gmail.com.

\section{Abstract}

Fruits are important to human health as a food source. They are an important source of nutrients and an essential part of the human diet. Cherry is one of the most popular fruit by consumers due to its precocity and excellent quality as a food. Sweet cherry fruit has relatively low caloric content, low glycemic response, high antioxidant activity and major amounts of important phytochemicals: anthocyanins, quercetin, hydro-xycinnamates, vitamin $C$, carotenoids and melatonin, as well as nutritive compounds such as sugars and organic acids. Cherry fruit have a limited life and does not exceed 21 days in storage. This requires postharvest methods to ensure their presence throughout the year. Convective drying is one of the oldest methods of food preservation, and as often realized in natural conditions such as solar drying. The hot air drying method has several advantages that support its wide use in industry and in food industry, especially as it is relatively cheap and an easy operated drying technology. The process is based on partially solar convective drying. Therefore, this study was conducted to understand mechanisms influencing the cherry drying process. For this, we studied the behavior of the product dried in a partial solar convective dryer operating continuously. The experiments were performed under real weather conditions. We studied the effect of drying temperature using different temperatures ranging from 60 to $75^{\circ} \mathrm{C}$ with air flow drying of $300 \mathrm{~m}^{3} / \mathrm{h}$. The main aim of the studies was to find the best drying conditions, by which the drying time was shortened and the product quality degradation was minimized. Keywords: drying, solar energy, cherry, conservation process.

Poster \#043. Biological Activity of Some Aromatic and Medicinal Plants Parts Extracts Against Eutetranychus orientalis (Acari : Tetranychidae) Under Laboratory Conditions

Hassan Alahyane $^{1,2^{*}}$, H. Abousaid ${ }^{1,2}$, K. Oufdou $^{1,3}$, and S. El Messoussi ${ }^{1,2}$

1 Faculty of Science Semlalia, Cadi Ayyad University, BP 2390, 40000 Marrakech; $^{2}$ Laboratory of Molecular Modeling and Ecophysiology; 3 Laboratory of Biology and Biotechnology of Microorganisms. "Presenting author: alahyaneingeco@gmail. com.

\section{Abstract}

One of the main pests of citrus in Morocco is the phytophagous mite Eutetranychus orientalis (Acari : Tetranychidae) $[1 ; 2]$. 
To manage this pest, synthetic chemicals have traditionally been used, some of which are well known to be potentially toxic to the environment and humans [3; 4]. Therefore, alternative strategies for pest management in citrus orchards have been developed in recent years, including biological control with natural enemies such as parasitoids, predators and entomopathogenic microorganisms as well as chemical control using plant extracts. Such extracts have shown toxicity to insects which has positioned them as a common alternative in programs of integrated pest management [5]. The objective of this study was to evaluate the effect of aqueous extracts of four aromatic and medicinal plants on female of $E$. orientalis under laboratory conditions. All the extracts exhibited significant female adult mortality in comparison with the control. Zingerber officinalis L. (root), Jatropha curcas L. (seeds) extracts had significantly higher mortality rates, greater to $90 \%$, than Pelargonium graveolens L. (leaves) and Rosmariums officinalis L. (leaves), that did not exceed $67 \%$. Our results showed that several plant extracts have good potential for acaricidal activity and are worth further investigation. Keywords: Eutetranychus orientalis, aromatic and medicinal plants, aqueous extract, acaricidal activity.

\section{References}

[1] A. Mazih,. 2011. Citrus IPM in Morocco: Current status. In Proceedings of Meeting of Working Group "Integrated Control in Citrus Fruit Crops" (2010, Agadir, Morocco). IOBC/WPRS Bulletin, (62), 266 (Abstr.)

[2] M. Benziane, M. Abbassi, and A. Jahaj. 2001. Comparaison de deux méthodes de lutte intégrée contre les principaux ravageurs associés aux agrumes dans la région du Gharb. In: AMPP (ed.), Proceeding du Symposium sur "La Protection intégrée des cultures dans la région méditerranéennell, Rabat, 29-31 mai 2001: 257-269.

[3] R. Kumar, 1991, La lutte contre les insectes ravageurs. La situation de l'agriculture africaine. Editions Karthala et CTA, PaysBas, Paris, 310 p.

[4] N. Stumpf and R. Nauen. 2002. Biochemical markers linked to Abamectin resistance in Tetranychus urticae (Acari-Tetranychidae). Pestic. Biochem. Physiol. 72: $111-121$

[5] Isman M.B. 2006: The role of botanical insecticides, deterrents, and repellents in modern agriculture and an increasingly regulated world. Annual Review of Entomology, 51: 45-66.

Poster \#044. Importance of Bituminaria bituminosa to Restore Defraded Sylvopastoral Systems

Btissam Ben Messaoud", Imane Aboumerieme, Laila Nassiri, and Jamal Ibijbijen

Faculty of Sciences Moulay Ismail University, BP 11201 Zitoune, Meknes, Morocco.

\section{Abstract}

Seven million Moroccans abuse forests and place them under heavy pressure. The population increase and land require- ment for food crops and wood for domestic and industrial use also provide pressure for deforestation. Moreover, $93 \%$ of the national territory is subject to desertification and soil erosion. These natural changes cause environmental, social and economic problems. Deforestation must be slowed in order to preserve the sylvopastoral systems, and we must look for alternative strategies based on the use of biological tools such as the use of plant adapted to drought and low soil fertility mainly when it's combined with plant growth promoting rhizobacteria. The aim of present study is to select the best complex Bituminaria bituminosa-plant growth promoting rhizobacteria combination that shows the best growth (symbiotic relationship). The choice of this leguminous shrub due to its importance and use as good fodder. The experiment was conducted in the greenhouse in the Faculty of Sciences of Meknes. The experiment was setup in a completely randomized block. Each pot contains sandy soil which is nutrient-poor. For that we prepared the inoculation treatment, in the presence and absence of phosphorus fertilizer. Five repetitions are done for each treatment. The inoculum was prepared with two plant growth promoting rhizobacteria in erlenmyer. Inoculation alone showed a low beneficial effect on the height, the biomass production and the mineral nutrition. While the effect of the inoculation combined to the presence of phosphorus fertilization was most important. The use of Bituminaria bituminosa-plant growth promoting rhizobacteria will constitute good solution in semi-arid and arid regions and thus it will contribute to the preservation of the environment. Keywords: phosphorus fertilization, inoculation, Bituminaria bituminosa, plant growth promoting rhizobacteria.

\section{Poster \#045. The Fertilizing Components of Seaweeds}

Soufana Safih", K. Makroum, M. Belfaiza, A. Bakkali, A. Ezzaher, A. Alwan, L. A. Rifai, M. L. Nedjar, S. Esserti, A. Smaili, M. Faize, E. M. Kabil, and T. Koussa

Laboratory of Plant Biotechnology, Ecology and Ecosystem Valorization, Department of Biology, Faculty of Sciences, University Chouaib Doukkali, El Jadida, Morocco. "Presenting author: soufana.safih@gmail.com.

\section{Abstract}

Morocco has a high abundance and diversity of seaweeds (e.g. more than 143 algal species in El Jadida's coastline). For centuries seaweeds were applied to increase the fertility of soil, and foliar applications of algal extracts have shown many beneficial effects. Seaweed extracts have potential as fertilizers and they were not well exploited. Seaweed extracts improve rest break, bud burst and yields, upgrading the resistances to biotic and abiotic stresses and the stimulation of the vegetal defense. Now several products with seaweeds are marketed, but these uses are much limited comparatively to the richness of their composition. The biochemical characterization of seaweeds revealed answers about their beneficial effects on plants, tests conducted determined the quantity of total sugars and protein in four species of seaweeds that used preserved in various conditions (fresh 
samples, frozen samples, dries samples). The study showed differences in the contents of parameters studied according to seaweeds species and according to the state of matter. The analysis and the quantification of the components of seaweeds in particular in protein and in total sugars will help to adapt their use in agriculture.

Poster \#046. Mycorrhizal Colonization Response to Water and Salt Stresses on two Plant Species to be used in Degraded Sand Dunes' Rehabilitation Programs

Abdessamad Fakhech", Lahcen Ouahmane, and Mohamed Hafidi

Ecology and Environment Laboratory, Faculty of Sciences Semlalia, Cadi Ayyad University. *Presenting author: abdessamad. fakhech@edu.uca.ma.

\section{Abstract}

In this study, mycorrhizal colonization rates of Essaouira sand dunes arbuscular mycorrhizal fungi were observed in response to water and salt stresses on two plant species: Retama monosperma and Acacia gummifera. These species were selected due to their high plasticity and tolerance for abiotic stresses, and to be used in Essaouira sand dunes ecosystem restoration. Mycorrhizal inoculum was prepared from a mix, sampled from the rhizospheric soil of Retama monosperma and Juniperus phoenicea, which are well established species on the dunes of Essaouira. The experiment lasted 6 months. The results were then compared and tested with an ANOVA for a p-value of $50 \%$. The stresses had a little but significant impact on the colonization rates of plant roots. Overall, the mycorrhization rates showed some distinction between extreme treatments and almost no significant difference between close range treatments. Keywords: Water stress, Salt stress, mycorrhization, Nitrogen, Phosphorus, Colonisation.

Poster \#047. Correlation Between Climatic Conditions and Severity of Potato Soft Rot in Morocco

Nisrine Sbai Idrissi*, Aicha Ouarzan, Mohamed Amine Senhaji, Meryem Meftah Elkhir, Said Élantri; and Amine Abdessamad

Laboratoire de Biochimie, Environnement et Agro-alimentaire, Faculté des Sciences et Techniques de Mohammedia, University Hassan II, Morocco. *Presenting author: svtnisrine@gmail.com.

\section{Abstract}

Potato (Solanum tuberosum), the third biggest crop in Morocco, is prone to a wide range of diseases which drastically reduce yield and quality. The most common pathogens which affect potato are pectolytic enterobacteria (Pectobacterium atrosepticum, Pectobacterium carotovorum) which cause stem and tuber rot in potato (Czjakowski et al., 2011). The symptoms developed on the plant are not strain specific but are dependent on the climat- ic conditions prevailing at the infection stage. The main objective of this study is monitoring the prevalence of this disease in the different regions of Morocco known by a difference of climatic conditions. During 2015 to 2016 , different potato fields and the most important potato storages in Morocco (Moyen Atlas, Loukkos, Doukkala, Haute Moulouya, Haouz, Chaouia, Sais, Elgharb, Sous, Oriental) were surveyed and samples were collected from tubers and plants suffering from soft rot disease. Seventy five fields were visited. Different symptoms of soft rot, black leg, and wilting were found. Prevalence varies from 0 to $14 \%$. In the same region, prevalence could vary from 1 to $8 \%$ (Haute Moulouya) and from 0 to $9 \%$ (Haouz). This study shows that in Morocco, there is not always a correlation between the climatic conditions and the degree of severity of the disease (prevalence percentage). Keywords: potato, climatic conditions, prevalence, soft rot.

Poster \#048. Drought Tolerance Gene Integration in Immature Embryos of Moroccan Durum wheat by Agrobacterium fumefaciens Mediated Transformation

Ahansal Khadija ${ }^{1,2^{*}}$, Aadel hanane ${ }^{1,2}$, Abbdelwahd rabha ${ }^{2}$, Gaboun Fatima ${ }^{2}$, Udupa M. sripada ${ }^{3}$, Ibriz mohammed ${ }^{1}$, and Iraqi Driss ${ }^{2}$

1 Ibn Tofail University, Faculty of Sciences, Laboratory of Agrophysiology and in vitro culture, Kenitra, Morocco; 2 Biotechnology Unit, National Institute of Agronomic Research (INRA). Avenue de la Victoire, B.P. 415, Rabat, Morocco; ${ }^{3}$ ICARDA-INRA Cooperation Research Project, Inetrnational Center for Agriculture Research in the Dray Areas (ICARDA), B.P. 6299, Rabat, Morocco. *Presenting author: kh.ahansal@gmail.com.

\section{Abstract}

Wheat improvement by genetic engineering requires the delivery, integration and expression of defined foreign genes into suitable regenerable explants. In our experiment, we focused first on the effect of auxins 2,4-D and picloram for the plants regeneration. Further, we used Agrobacterium as mediated transformation technique with pHVA 1-FL plasmid containing drought tolerance gene HVAl, and selectable marker bar gene. In the first experiment, we used immature embryos (IE) from three durum wheat varieties (Amria, Chaoui and Marouane) for callus induction. Picloram regenerate a higher number of plants compared to 2,4-D. Therefore, picloram was selected for the genetic transformation experiment and added in induction medium. The transformation step was rbegan by using intact immature embryos, half immature embryos and small pieces of immature embryo of the same three varieties of durum wheat. The percentage of regeneration of 'Chaoui' was high when we used half embryos, a similar regeneration rate was observed for variety 'Amria' in all explants; further, variety 'Marouane' was regenerated only in half embryos. A successful integration of HVAl gene was confirmed by analyzing the plantlets using PCR amplification. 
Poster \#049. Effect of two Biostimulants on the Productivity of Mejhoul Date Palm in Tafilalet Oases

Hakim Outghouliast $^{1,2^{*}}$, Messaoudi Zerhoune', Touhami Ouzzani Amina $^{2}$, and Lhoussain Ait Haddaou'

1 Laboratory of Pomology, Arboriculture-Viticulture, National School of Agriculture, Meknes, Morocco; ${ }^{2}$ Laboratory of Botany, Biotechnology and Plant Protection, Faculty of Sciences, University Ibn Toufail, Kenitra, Morocco. *Presenting author: hakim. agro.ena@gmail.com.

\section{Abstract}

Nowadays, in the dry climate zones, such as oases, the improvement of date production as well as its physical and chemical characteristics, consider one of the fundamental research goals. An experiment was conducted out during 2016 season, in a conventional production of palm dates Mejhoul, under the climatic conditions of Tinejdad, Errachidiya region, Morocco. The aim of this study was to evaluate the effect of two biostimulants including Protifert LMW 6.3 (4 ml.L-1) and Vitazyme ${ }^{\circledR}(1.3 \mathrm{ml} . \mathrm{L}-1)$ on yield and quality of dates. Three treatments were compared (Control, Protifert, and Vitazyme). The applications of two biostimulants were repeated three times after pollination in particular late April, mid-July and mid-August. The experimental design was completely random block with 3 replicates and 3 trees per treatment (a total of 27 palm trees). Observations were made on fruit dimensions (width and length), fruit weight, flesh weight, seed weight, seed/fruit ratio, pulp/ fruit report and yield. Data shows that the treatment has affected significantly all of the parameters studied. Indeed, Protifert LMW 6.3 has enhanced yield per tree by 18 and $27 \%$, respectively compared to Vitazyme and Control. As for fruit dimensions, Protifert had longer fruits than Vitazyme and Control, whereas, both biostimulants induced fruit of the same width but larger than those from the Control trees. In addition, fruit weight ranged from a maximum of $14.51 \mathrm{~g}$ by Protifert LMW 6.3 and a minimum of $10.32 \mathrm{~g}$ observed in the Control. However, fruits of treated trees Vitazyme were richer in flesh $(92.62 \%)$ compared to those obtained by untreated palm $(90.78 \%)$, besides their environmentally safe effect as non-chemical tool. Keywords: Biostimulants, date palm, Mejhoul, production, Quantity, Quality.

Poster \#050. Optimization of growth and development of date palm seedlings by using organic and biological fertilizers

Mohamed Anli ${ }^{1 *}$, Mimoun El Kaoua ${ }^{2}$, Abdelillah Meddich', Mohamed Ait El Mokhtar ${ }^{1}$, Mounir Mansouri ${ }^{2}$, Amine FAarouk Ibrahim $^{2}$, Raja Benlaouane', Yousef Ait Rahou', Fatima El Amerany', and Abdessamad Fakhech'

1 Laboratory of Biotechnology and Plant Physiology, Faculty of Sciences Semlalia, Cadi Ayyad University, Marrakech, Morocco; 2 Laboratory of Biotechnology, Valorization and Protection of Agro-Resources, Faculty of Sciences and Technology, Cadi Ayy- ad University, Marrakech, Morocco. *Presenting author: mohamedbacoanli@gmail.com.

\section{Abstract}

The aims of our study is to evaluate the effect of compost produced locally and seaweed liquid extract on four parameters: growth, physiology, histology and mineral nutrition of seedlings of the date palm (Phoenix dactylifera). After 4 months of greenhouse cultivation, we evaluated the parameters on palm trees subjected to different treatments. The results showed the importance of the two amendments on the date palm grown in greenhouse. Indeed, the production of fresh and dry matter of the aerial part is significantly improved by different treatments applied compared to the control and $20 \%$ compost-extract combination. In addition, chlorophyll fluorescence (Fv/Fm) was enhanced in the all treatments compared to the control. However, stomatal conductance was highly affected positively for seedlings amended to $5 \%$ compost compared to the control. In addition, the number of conductive tissues (xylem and phloem) was increased by the various treatments compared to the control. In the same way, the number of sclerenchyma fibers also improved in plant treated (except to those treated with the algal extract) compared to control plants. Furthermore, the phosphorus content of the aerial part is improved in the palm trees treated with algal extract, $5 \%$ compost-extract combination and $5 \%$ compost compared to the control. The potassium content of the aerial part was also improved by $5 \%$ compost. Finally, the compost with a low dose (5\%) seems to be the best amendment for improving the growth and vigor of young palm trees. Keywords: Date palm, compost and algal extract.

Poster \#051. Genetic Identification of Adaptation and Impact of Genotype by Environment Interactions on Argan Tree Ecotypes

Ilham Rahmouni ${ }^{1,2,3^{*}}$, Mohammed El Massoudy ${ }^{1,2}$, Siham Oumouss ${ }^{1,2}$, Ghizlane Tobi', Najib Bendaou ${ }^{3}$, Mohammed Bouksaim $^{2}$, and Yasmina El Bahloul'

1 Unité de Recherche en Amélioration des Plantes Conservation et Valorisation des Ressources Phytogénétiques, Centre Régional de la Recherche Agronomique CRRA, Rabat, Morocco; ${ }^{2}$ Laboratoire Eco valorisation, Centre Régional de la Recherche Agronomique CRRA, Rabat, Morocco; ${ }^{3}$ Université Mohammed V, Faculté Des Sciences, Rabat, Morocco. "Presenting author : ilham. rahmouni@gmail.com.

\section{Abstract}

Argania spinosa, Skeels. is one of endemic species to Morocco, is currently extended in arid and semi-arid areas in southwest Morocco region. It plays a very important role for local populations. In addition, it's an essential component of forest ecosystems biodiversity. For the purpose of preserving and understanding the distribution of this tree species, a study of the variation and the influence of environmental conditions on the morphology was 
carried out on different ecotypes of Moroccan argan forest. This study is based on surveys and collections of argan genotypes as well as on the analysis of climatic and soil factors (temperature, rainfall, altitude, soil components, etc.). Individuals were selected previously to be tested on different environments. Trials are conducted in four regions of Morocco, where the soil and environmental conditions are different, to evaluate genotype $x$ environment interactions. Evaluation is based on 20 morphological traits and 12 molecular SSR species specific markers. Results of this study will contribute to identify genetic ecotype of argan forest and to determine the adaptability of different genotypes, for Argan breeding programs. Keywords: Argania spinosa, adaptability, soil factor, genotype $x$ environment interactions.

Poster \#052. Evaluation of Some Fruit Quality Traits of Eight Tomato Varieties (Solanum lycopersicum) Grown in four Different Moroccan Regions

Amraoui Rajae*, Abid Malika, Ahmed Elamrani, Hana CAID Serghini, Addi Mohamed, and Mihamou Aatika

Laboratory of Biology of Plants and Microorganisms, Faculté des Sciences Oujda - Université Mohammed Premier, BP-717 Oujda, Morocco.

\section{Abstract}

The organoleptic and nutritional quality characterization of eight tomato varieties cultivated in four different regions in Morocco (Berkane, Hoceima, Figuig and Rissani) were evaluated. Several physicochemical parameters such as $\mathrm{pH}$, titratable acidity (TA) and total phenolic compounds were analyzed on mature tomato fruits. The $\mathrm{pH}$ did not change between varieties. However, titratable acidity ranged between $2.1 \mathrm{~g} / \mathrm{I}$ for white Rissani variety to $5.6 \mathrm{~g} / \mathrm{I}$ for black Rissani. For total polyphenols content, Figuig 2 and Hoceima showed the greatest value ranged between 125 and $122 \mathrm{mg} / 100 \mathrm{~g}$, respectively. Results of this analysis showed that physicochemical parameters could be used for varietal characterization, and morphological and molecular tests indicated that Figuig and Hoceima varieties were the most interesting of those tested. Keywords: Tomato, physicochemical parameters, $\mathrm{pH}$, titratable acidity (TA), total phenolic compounds.

Poster \#053. Evaluation of Some Date Palm Males Used in Pollination in Figuig Province

Imane Zahiri" and Mohammed Aziz El Houmaizi

Laboratory of Biology of Plants and Microorganisms, Faculty of Sciences, University Mohamed I, Oujda, Morocco. "Presenting author: zahiri-imane@hotmail.fr.

\section{Abstract}

Date Palm (Phoenix dactylifera L.) is a dieocious plant with separate male and female trees. The high nutritive value of the date fruits and the substantial quantities produced justify the need for ameliorating the production by using new methods for breeding and selection of new male palm cultivars which have a high viability and compatibility with female cultivars, and positive influence on quantity or quality of fruits produced. The principal characteristics in a male palm are: fertility, blooming early in season, abundance of flowers and pollen, and production of good characters in the fruits. In the present study, several visits were carried out to the date palm farms in Figuig region, and 40 male date palm trees were selected from different local farms. Pollen viability was determined by in vitro germination, and results indicated that maximum and minimum germination varied from $18 \%$ to $90 \%$. Several morphological characteristics of the selected date palm males inflorescences were studied. These characteristics included spathe length, spathe width, pedencule length, pedencule width, flower spik length, strands length and number of strands by spathe. Keywords: Pollen, viability, morphological characteristics, invitro germination

\section{Poster \#054. Essential Oil: Adsorption Properties of Thymus willdenowii Boiss. as a Green Inhibitor for the Corrosion of Mild Steel in $1 \mathrm{M} \mathrm{HCl}$.}

Mohamed Ouknin ${ }^{1,2^{*}}$, Abderrahmane Romane ${ }^{2}$, and Lhou Majidi

1 Laboratoire des Substances Naturelles \& Synthèse et Dynamique Moléculaire, Faculté des Sciences et Techniques, Université Moulay Ismail, Errachidia, Morocco; ${ }^{2}$ Laboratoire de chimie appliquée, Faculté des Sciences-Semlalia-BP. 2390, Université Cadi Ayyad, Marrakech, Morocco. "Presenting author: medoknine@gmail.com.

\section{Abstract}

There are numerous medicinal and aromatic plants and in the process of understanding their individual benefits requires specific knowledge and expertise of each group of plants and products. According to the definition of the World Health Organization (WHO), medicinal plants include plant species of which one part or more parts contain biologically active substances that can be used for therapeutic purposes or for chemical and pharmaceutical synthesis. Therefore, medicinal and aromatic plants include plant species containing biologically active substances with practical applications in pharmaceutical, food and cosmetics industry, and industry additives such as aromatic preparations, etc. The analysis of Thymus willdenowii (TW) essential oil by Gas Chromatography (GC) and Gas Chromatography-Mass Spectrometry (GC/MS) allowed the identification of $32 \mathrm{com}$ ponents which accounted to $97.6 \%$ of the total amount. Among them, the main components were thymol, p-cymene, $\Upsilon$-terpinene, borneol and carvacrol. The inhibitive effect of this essential oil on the corrosion of mild steel in $1 \mathrm{M} \mathrm{HCl}$ solution has been investigated by weight loss measurement, as well as potentiodynamic polarization and electrochemical impedance spectroscopy (EIS) techniques. The gravimetric results indicate that TW oil exhibits good inhibition efficiency in $1 \mathrm{M} \mathrm{HCl}$ solution. Electrochemical impedance spectroscopy measurements revealed that the charge 
transfer resistance increases with increase in the concentration of essential oil. Linearity of Langmuir isotherm adsorptions indicated the monolayer formation as inhibitor on mild steel surface. Keywords: Essential Oil; Thymus willdenowii; Mild steel; Corrosion inhibitor; $\mathrm{HCl}$.

Poster \#055. Action of Physiological Factors on the In Vitro and In Vivo Development of the Argan Tree (Argania spinosa L. Skeels.)

$\underline{\text { Hassania Farhoune }}^{1,2^{*}}$, Souad Cherkaoui ${ }^{1}$, and Alaoui-Mdarhri Meriem $^{2}$

1 Mohammed V University, Faculty of Sciences Rabat, Morocco; ${ }^{2}$ National Institute of Agronomic Research (INRA-Maroc), Biotechnology Research Unit, CRRA-Rabat, BP 6570, 10101 Rabat Instituts, Morocco. *Presenting author: fhassania@gmail.com.

\section{Abstract}

The argan tree (Argania spinosa L. skeels) is an endemic tree of southwestern Morocco. It is very appreciated for the quality of its oil and wood. It plays important roles in the socio-ecological, environmental, economic, medicinal and cosmetic domains. Currently, the argan forest tree suffers from alarming degradation. Since natural regeneration cannot ensure the reconstitution of this species, several methods of classical multiplication have been tested. However, the results obtained were insufficient. To respond to the strategy of the "Green Morocco Plan", aimed at the improvement and mass production of this species, the use of biotechnology and more particularly the in vitro micropropagation technics and in vivo multiplication were studied. The work done and the results obtained seem encouraging and promising. Keywords: Argan tree, Argania spinosa, micropropagation, in vivo, in vitro.

Poster \#056. Cystic Echinococcosis: Epidemiology, Socio-Economic Impact and Consequent Control Actions Undertaken in Morocco

Ikhlass El Berbri"; Ouaffa Fassi Fihri; Anne Françoise Petavy; Wissal Maher; Franck Boué; Allal Dakkak; and Mohammed Bouslikhane

IAV Hassan II, Rabat, Morocco. *Presenting author:

\section{Abstract}

Echinoccocus granulusus, is the causal agent of cystic echinococcosis in humans, and in domestic and wild herbivores. Disease transmission occurs by ingestion of parasite's eggs living in the small intestine of canids, especially dogs. It is a matter of disease and causes major problems to human health, and economic losses. According to the latest WHO estimates, this disease is responsible of annual losses of 1-3 million DALYs (Disability Adjusted Life Expectancy Years) and of \$ 3 billion (US \$) for the treatment of patients and for livestock losses. In Morocco, an an- nual average surgical incidence of approximately 4.2 cases per 100000 inhabitants was recorded (2009-2013), involving an estimate of over 20 million MAD ( $\approx € 2$ million) for annual medical expenses. In livestock, losses associated with infected organs seizure in slaughterhouses, were estimated at 10 million MAD / year ( $\approx € 1$ million / year). To address this situation, the main undertaken actions in the field, were conducted mainly by the IAV Hassan II team. The targeted regions were the province of Khénifra (2000-2007) and, recently, the province of Sidi Kacem (2009-2014), as part of major research American and European projects, BAFI and ICONZ respectively. Field studies evaluate the disease control approaches and alternatives. The results of these actions were very promising. However, as they were located and project related, sustainability was not ensured. Thus, cystic echinococcosis is still prevailing in the country with socioeconomic and public health consequences. It was concluded that any selected control action should include health education and community based approaches.

Poster \#057. An Ethnopharmacological Survey of Plants Used in Traditional Diabetes Treatment in the Region of Beni Mellal - Khenifra, Morocco

Younesse El Ouzzani ${ }^{1,2^{*}}$, Aziz Hasib', Abdelali Boulli ${ }^{1}$, and Mustapha Bouzaid ${ }^{2}$

1 Environment Laboratory and Valorization of the Agro-Resources of the Faculty of Sciences and Techniques of Beni Mellal, Morocco; ${ }^{2}$ Laboratory of Bioprocesses and Bio-interface of the Faculty of Sciences and Techniques of Beni Mellal, Morocco. *Presenting author: y.elouazzani@yahoo.com.

\section{Abstract}

This study was carried out in the Region of Beni Mellal - Khenifra which has a sizeable botanical biodiversity as determined by herbalists and traditional healers. For about forty years ago, diabetes has been a real public health problem in the world. It is the most common metabolic pathology characterized by chronic hyperglycemia resulting from a partial or complete deficit of the pancreas cells to synthesize insulin and/or tissue resistance to insulin. Many plants are traditionally considered as antidiabetic. Some of them have led to the development of several medicines, and in front of the considerable increase in the number of diabetics and the elevation of the financial value of certain synthetic drugs, research has begun to evaluate the pharmacological actions of these medicinal plants anchored in the traditions of the population. The statistical treatment of the results obtained from the question sheets, allowed us to target the plant species suspected to have a curing power against diabetes. Keywords: Phytotherapy, Medicinal flora, Biodiversity, Ethnobotany, Antidiabetic. 
Poster \#058. Value Addition of Some Moroccan Regional Products by Liquid Fermentation: Production of Date and Apple Vinegars

\section{Maiid Mounir ${ }^{1,2^{*}}$}

${ }^{1}$ IAV Hassan II, Rabat, Morocco; ${ }^{2}$ Université de Liège, Belgium. *Presenting author: mounirmajid@gmail.com.

\section{Abstract}

Six strains of acetic acid bacteria were isolated from Moroccan local products and evaluated for their industrial vinegar production potential. Two of them, namely AFO1 and CVO1, isolated from apple (Malus domestica) and cactus (Opuntia ficus indica) fruits, respectively, were selected and investigated for their thermoresistant and thermophilic properties. A biochemical and molecular study based on a 16SrDNA gene sequence analysis confirmed that the two isolated strains belong to Acetobacter pasteurianus with $99 \%$ of homology. Their growth and acetic acid production capacity were compared with (1) the thermoresistant reference strain $A$. senegalensis isolated from mango (Senegal) and (2) other, wild acetic strains belonging to $A$. pasteurianus (LMG 1632, LMG 1607, LMG 1701, DSM 2324 and DSM 4491). The two strains showed very good growth and noticeable acetic acid production ability at high temperatures $\left(38\right.$ to $41^{\circ} \mathrm{C}$ ). A thermophilic character was noted for AFO1 strain. Indeed, this bacterium grew better at $38^{\circ} \mathrm{C}$ than at $30^{\circ} \mathrm{C}$. Subsequently, a semi-continuous fermentation was performed in a $20 \mathrm{~L}$ Bioreactor for both selected strains. A total amount of $7.64 \%$ and $10.08 \%$ acetic acid was achieved at the end of fermentation, respectively for AFO 1 and CVO1 strains. Process fermentation of CVO1 strain was marked by the ability to produce gluconic acid during acetic fermentation. Finally, an enzymatic study was carried out on the selected strains AFOI and CVOI to confirm the tolerance of their enzymes responsible for acetic fermentation process to high temperature. Results clearly showed that the two strains exhibited high ADH and ALDH enzyme activity at either 30 or 38 ${ }^{\circ} \mathrm{C}$ as compared to the mesophilic reference strain LMG 1632 which exhibited marked thermal inactivation rate. It is concluded that the two selected strains are well-suited to industrial use for vinegar production in Morocco. Keywords: Vinegar; Acetobacter; Thermoresistance; Bioreactor; Enzyme activity; Morocco.

Poster \#059. Soybean Mutations Mapping: Applications in Functional Gene Analysis and Soybean Improvement

Naoufal Lakhssassi", Shiming Liu, Zhou Zhou, and Khalid Meksem

Department of Plant Soil and Agricultural Systems, Southern IIlinois UNiversity, Carbondale, IL, USA. "Presenting author: naoufal.lakhssassi@siu.edu.

\section{Abstract}

The alteration of fatty acid profiles to improve soybean oil quality has been a long time goal of many researches through the world. Biodiesel is an up and coming trend in energy production. Breeding effort can be undertaken in order to produce higher energy profile soybean oil. Using the ethyl-methanesulfonate (EMS) mutagenesis effects on DNA, significant changes to the genes and gene network underlying oil profile can be achieved, these changes are hard to accomplish under standard breeding techniques. High content Linolenic acid is very important for fuel and Biodiesel production, but disadvantageous for food production due to the fact that the oil is oxidized easily and the foods go rancid quickly. However, soybean oil with elevated oleic acids is desirable for food. Oleic acid is a monounsaturated fatty acid that improves the nutrition and oxidative stability of soybean oil compared to other oils. The main purposes of this work were to mutation breed new soybean [Glycine max (L.) Merr.] sources containing high level of seed oleic acid good for the soy industrial and food production, on a background conferring the resistance to soybean cyst nematode ( $\mathrm{SCN}$ ), the most devastating pest in soybean production. A subset of the EMS mutagenized developed population containing about 1000 families was screened using forward genetics approach to identify mutants within the FAD2 genes. Mutations within the FAD2 genes encoding the Fatty acid desaturase were identified. Five soybean mutants with high levels of oleic acid were identified presenting 2.5 times more content than the Forrest WT. These mutants were further identified to carry one mutation each in both FAD2-1A and FAD2-1B isoforms.

Poster \#060. Influence of Drought Stress on Several Root Traits and their Correlation with Seed Protein and Oil Contents in Soybean

Ambrocio Zenis $^{1 *}$, Stella Kantartzi ${ }^{2}$, Khalid Meksem², and My Abdelmajid Kassem ${ }^{1 \dagger}$

1 Plant Genetics, Genomics, and Biotechnology Lab, Department of Biological Sciences, Fayetteville State University, Fayetteville, NC 28301, USA; ${ }^{2}$ Department of Plant, Soil, and Agricultural Systems, Southern Illinois University, Carbondale, IL 62901, USA. *Presenting author: zambrocio@uncfsu.edu. ${ }^{\dagger}$ Corresponding author: mkassem@uncfsu.edu.

\section{Abstract}

The important crop soybean [Glycine max (L.) Merr.] is cultivated worldwide and the US is its number one exporter. However, farmers face many challenges in cultivating soybeans, including drought and diseases that reduce yields drastically. The root system is very important for plants, including crops, because it receives water and minerals from the soil so that the plant/crop can photosynthesize, grow, and increase its yield. The objective of this study was to grow the 'MD 96-5722' by 'Spencer' recombinant inbred line (RIL) population $(n=86)$ in the greenhouse under normal (Group I) and drought stress (Group II) conditions, and compare the root length (RL), root surface area (RSA), average root diameter (ARD), and average root volume (ARV) in the two groups of plants. WhinRhizo software was used to measure the root traits and SPSSTM was used to evaluate population 
performance under normal and drought conditions. JMPTM was used to compare the root traits under normal and drought conditions, and to analyze the correlation between root traits, protein and oil contents. The results showed that there is a huge variation in these traits among the parents 'MD 96-5722' and 'Spencer', and among their RILs. For Group I plants, the RL of parents and RILs ranged from $20.67 \mathrm{~cm}$ to $2,327.88 \mathrm{~cm}$; the RSA ranged from $4.57 \mathrm{~cm} 2$ to $1,176.79 \mathrm{~cm} 2$; the ARD ranged from $0.38 \mathrm{~mm}$ to $4.04 \mathrm{~mm}$; and the ARV ranged from $0.08 \mathrm{~cm}^{3}$ to $47.34 \mathrm{~cm}^{3}$. For Group II plants, the RL of parents and RILs ranged from $15.70 \mathrm{~cm}$ to $3,562.42 \mathrm{~cm}$; the RSA ranged from $4.15 \mathrm{~cm}^{2}$ to $829.72 \mathrm{~cm}^{2}$; the ARD ranged from $0.24 \mathrm{~mm}$ to 5.74 $\mathrm{mm}$; and the ARV ranged from $0.03 \mathrm{~cm}^{3}$ to $23.67 \mathrm{~cm}^{3}$. It is clear from the results that Group I plants have higher means of RL [572.58 cm vs. $537.33 \mathrm{~cm}]$, RSA [201.20 cm $\mathrm{cm}^{2}$ vs. $\left.165.50 \mathrm{~cm}^{2}\right]$, ARD [3.96 mm vs. $1.45 \mathrm{~mm}$, and ARV $\left[6.31 \mathrm{~cm}^{3}\right.$ vs. $5.61 \mathrm{~cm}^{3}$ ] compared to Group II plants which demonstrates that droughtstressed plants have reduced overall plant growth and development. However, statistically, these differences were not significant; therefore, further studies with several replicates should be conducted both in the greenhouse and the field in order to determine the effects of drought stress on the 'MD 96-5722' by 'Spencer' RILs. Moreover, studies of quantitative trait loci (QTL) mapping of the root traits studied here are underway to genetically map QTL for these root traits in this soybean RIL population. Keywords: Root length (RL), Root surface area (RSA), Average root diameter (ARD), Average root volume (ARV), MD 96-5722, Spencer.

Poster \#061. Genetic Analysis of Yield Components in the PI 438489B by 'Hamilton' Recombinant Inbred Line (RIL) Population of Soybean [Glycine $\max ($ L.) Merr.]

Ragin Bobby ${ }^{1 *}$, Richard Bazzelle', Willsheana Clark', Stella K. Kantartzi ${ }^{2}$, Khalid Meksem², Masum Akond', and My Abdelmajid Kassem ${ }^{1+}$

1 Plant Genomics and Biotechnology Lab, Department of Biological Sciences, Fayetteville State University, Fayetteville, NC, USA; 2 Department of Plant, Soil, and Agricultural Systems, Southern Illinois University, Carbondale, IL, USA. "Presenting author: bragin@uncfsu.edu. ${ }^{\dagger}$ Corresponding author: mkassem@uncfsu.edu.

\section{Abstract}

Yield is a multi-factorial trait determined by several genetic traits and highly correlated with important agronomic traits in many crops including soybean. [Glycine max (L.)]. Plant height, seed and pod numbers, and seed weight are all components of yield and polygenic in nature. The objective of this study was to identify quantitative trait loci (QTL) for days to germination, days to flowering, plant height, pod number, seed number, 100-seed weight, and total seed weight in soybean using the using the PI $438489 \mathrm{~B}$ by 'Hamilton' recombinant inbred line (RIL) population (PIxH, $n=50)$. A total of 18 QTL were found on 10 different chromosomes. Three QTL for days to germination (qDG001-qDG003) have been identified on chromosomes 5b,
6, and 13b. Two QTL (qDF001 and qDF002) have been identified on chromosomes 9 and $13 \mathrm{~b}$, respectively. On QTL for plant height ( $\mathrm{qPHO01}$ ) have been identified on chromosome 6. Four QTL for pod number (qPN001-qPN004) had been identified on chromosomes 2, 6, and 8 (2 QTL), respectively. Two QTL for seed number (qSNOO1 and qSN002) have been identified on chromosomes 5b and $11 \mathrm{~b}$, respectively. Five QTL for 100-seed weight (qSW001 to qSW005) have been identified on chromosomes 5a, 6, 8, 9, and $11 \mathrm{c}$, respectively. Two QTL for total seed weight (qTSW001 and qTSW002) have been identified on chromosomes $5 b$ and $17 c$, respectively. The QTL identified here may be introduced in breeding programs to develop soybean cultivars with high yield potential. Keywords: soybean, QTL, days to germination, days to flowering, plant height, pod number, seed number, seed weight.

\section{Poster \#062. Forward and Reverse Genetic Screening of Genes Underlying Stearic Acid Content in Soybean}

Naoufal Lakhssassi", Shiming Liu, Zhou Zhou, and Khalid Meksem

Department of Plant Soil and Agricultural Systems, Southern IIlinois UNiversity, Carbondale, IL, USA. *Presenting author: naoufal.lakhssassi@siu.edu.

\section{Abstract}

Stearoyl-acyl carrier protein desaturase (SACPD), which has four isoforms in soybean: SACPD-A, $-B,-C$ and $-D$, converts stearic acid into oleic acid, influencing and controlling the accumulation of seed stearic acid. Stearic acid is a desirable constituent of oils for food use because it is less likely to be incorporated into cholesterol esters and has a neutral effect on the concentration of the blood serum LDL cholesterol. Stearic acid may be useful to eliminate the need for chemical hydrogenation of soybean oil in the production of trans-free margarines and shortenings. The available soybean lines with high level of seed stearic acid are mostly susceptible to soybean cyst nematode (SCN), one of the most devastating pests in soybean production. In order to improve the quality of soybean oil and processed foods, chemically mutagenized soybean using EMS has been developed in this work. A subset of the mutagenized population containing about 1000 families was screened using reverse (Tilling) and forward genetic screening approaches to identify mutants within the SACPD genes. Using a forward screening approach, we were able to identify four mutants: F605, F620, F714, and F813, all of which contain high level of seed stearic acid with an increased level of up to 2.4 times. Each of these four mutants was identified to carry one missense or nonsense mutation of SACPD-C: Q83* (F605), L79F (F620), D77N (F7 14), and $\mathrm{P} 102 \mathrm{~L}$ (F813), among them, Q83*, L79F, and $\mathrm{P} 102 \mathrm{~L}$ are the new SACPD-C alleles identified in soybean. However, none of the four mutants exhibited mutations in SACPD-A, SACPD-B, and SACPD-D. Furthermore, reverse genetics was used to identify mutants within the other SACPD isoforms. Thus, we identified one missense SACPD-A mutant: F1396 (D277G), three missense SACPD-D mutants: F2360 (G263E), F2374 (E37K), and F2487 
(T297M), and all the four lines were measured to contain the same level of seed stearic acid as the wild type Forrest. Thus, only the mutations of SACPD-C isoform perfectly correlate with the alteration of soybean seed stearic acid phenotype, suggesting SACPD-C is most likely responsible for the accumulation of stearic acid in soybean seed.

The International American Moroccan Agricultural Sciences Conference (AMAS Conference; www.amas-conference.org) is an international conference organized by the High Council of Moroccan American Scholars and Academics (HC-MASA; www.hc-masa.org). 